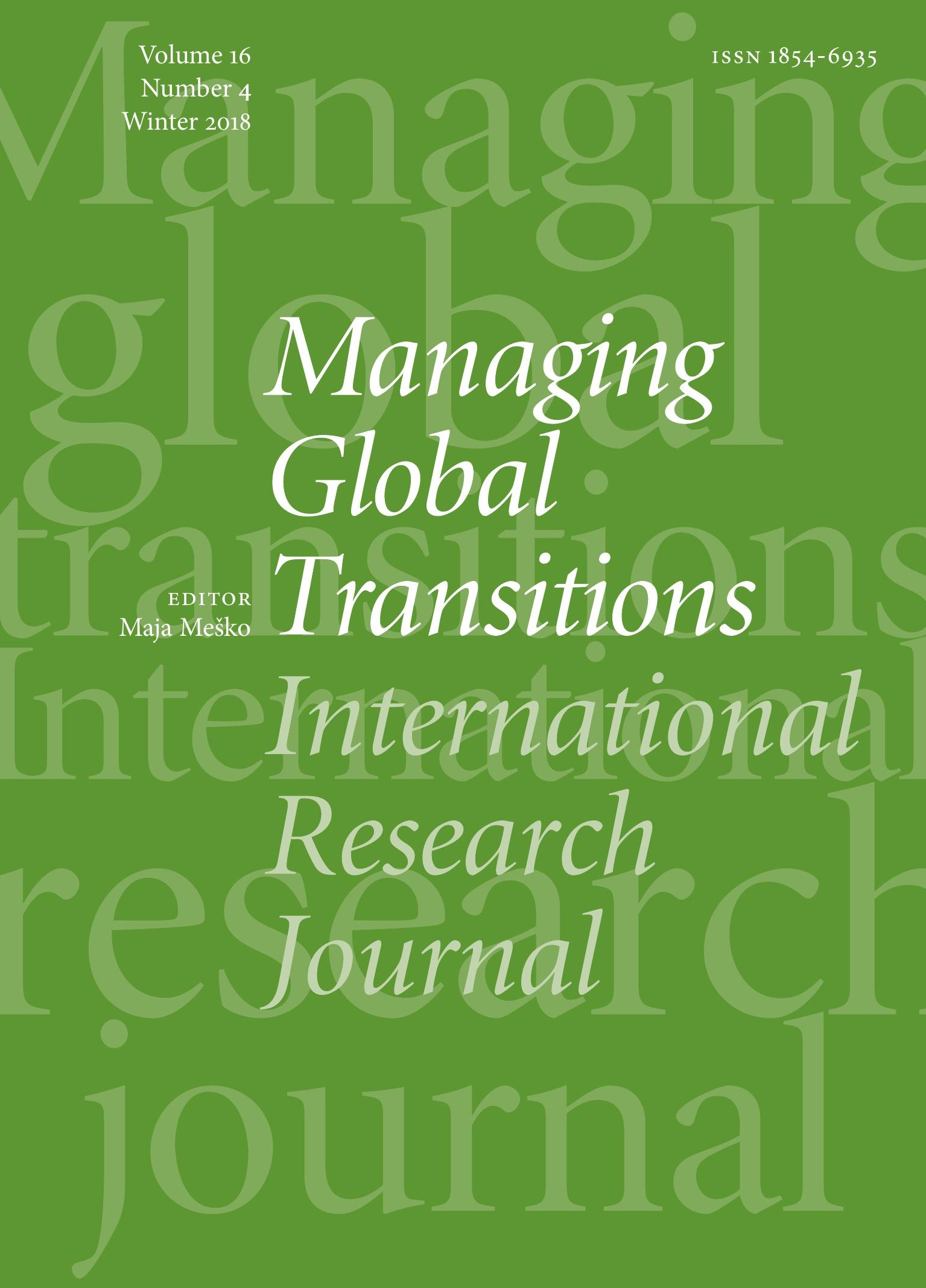




\section{Managing Global Transitions International Research Journal}

ISSN $1854-6935 \cdot$ www.mgt.fm-kp.si

EDITOR

Maja Meško, University of Primorska, Slovenia,maja.mesko@fm-kp.si

ASSOCIATE EDITORS

Andrej Bertoncelj, University of Primorska, Slovenia, andrej.bertoncelj@fm-kp.si

Gandolfo Dominici, University of Palermo, Italy,gandolfo.dominici@libero.it

Alexander Laszlo, Buenos Aires Institute of Technology, Argentina, alaszlo@itba.edu.ar

MANAGING AND PRODUCTION EDITOR

Alen Ježovnik, University of Primorska Press, Slovenia,alen.jezovnik@upr.si

EDITORIAL BOARD

Jani Bekő, Univerza v Mariboru, Slovenia, jani.beko@uni-mb.si

Heri Bezić, University of Rijeka, Croatia, bezic@efri.hr

Guido Bortoluzzi, University of Trieste, Italy, guido.bortoluzzi@deams.units.it

David L. Deeds, University of St. Thomas, usA,david.deeds@gmail.com

Evan Douglas, Griffith Universitiy, Australia, e.douglas@griffith.edu.au

Dean Fantazzini, Moscow School of Economics, Russia, fantazzini@mse-msu.ru

Henryk Gurgul, A GH University of Science and Technology, Poland, henryk.gurgul@gmail.com

András Inotai, Hungarian Academy of Sciences, Hungary, inotai.andras@krtk.mta.hu

Felicetta Iovino, University of Sannio, Italy, fiovino@unisannio.it

Hun Joon Park, Yonsei University, South Korea,hjpark@yonsei.ac.kr

Renata Karkowska, University of Warsaw, Poland,rkarkowska@wz.uw.edu.pl

Tanja Kosi Antolič, Institute of Macroeconomic Analysis and Development, Slovenia, tanja.kosi-antolic@gov.si
Leonard H. Lynn, Case Western Reserve University, UsA, leonard.lynn@case.edu Monty Lynn, Abilene Christian University, USA, monty.lynn@coba.acu.edu

Massimiliano Marzo, University of Bologna, Italy,massimiliano.marzo@unibo.it

Judita Peterlin, University of Ljubljana, Slovenia, judita.peterlin@ef.uni-lj.si

Mirjana Pejić Bach, University of Zagreb, Croatia,mpejic@efzg.hr

Sanja Peković, University of Crna Gora, Montenegro,psanja@ac.me

Sandra Penger, University of Ljubljana, Slovenia,sandra.penger@ef.uni-lj.si

Zdenko Prohaska, University of Rijeka, Croatia, zdenko.prohaska@efri.hr

José Solana Ibánez, Technical University of Cartagena, Spain, jose.solana@cud.upct.es

Marinko Škare, University of Pula, Croatia, mskare@unipu.hr

Nada Trunk Širca, International School of Social and Business Studies, Slovenia, trunk.nada@gmail.com

Šárka Velčovská, Technical University of Ostrava, Czech Republic, sarka.velcovska@vsb.cz

Manfred Weiss, Johann Wolfgang Goethe University, Germany, m.weiss@jur.uni-frankfurt.de

INDEXING AND ABSTRACTING

Managing Global Transitions is indexed/ listed in the International Bibliography of the Social Sciences, EconLit, I z Z Online, DoAJ, Erih Plus, EconPapers, Cabell's, EBsCO, and ProQuest.

SUPPORTED BY

Slovenian Research Agency.

Revija Managing Global Transitions je namenjena mednarodni znanstveni javnosti; izhaja $v$ angleščini s povzetki $v$ slovenščini. Izid revije je finančno podprla Javna agencija za raziskovalno dejavnost Republike Slovenije iz sredstev državnega proračuna iz naslova razpisa za sofinanciranje izdajanja domačih znanstvenih periodičnih publikacij. 


\section{Managing Global Transitions International Research Joumal}

VOLUME $16 \cdot$ NUMBER 4 - WINTER 2018 - ISSN 1854-6935

307 Outsourcing of Information Technology and Business Processes in Poland: Motivations and Environmental Factors

Wojciech Piotrowicz and Damian Kedziora

335 Econometric Analysis of the Effect of Economic Globalization, Energy Intensity, Urbanization, Industrialization and Growth on $\mathrm{CO}_{2}$ Emissions of Bangladesh Mowshumi Sharmin and Mohammad Tareque

355 Threshold Effect Analysis of the Relationship between Environmental Responsibility and Financial Performance Thomas Adomah Worae, Collins C. Ngwakwe, and Cosmas C. Ambe

379 Navigating New Marketing Technologies, Channels and Metrics

Petra Leonora Cvitanović

401 Future Job Profile at Smart Factories

Andrej Jerman, Tine Bertoncel, Ivan Erenda, and Anita Trnavčević

413 Abstracts in Slovene 
AIMS AND SCOPE

Managing Global Transitions (MGT) is a quarterly, scholarly journal that covers diverse aspects of transitions and welcomes research on change and innovation in increasingly digitalized and networked economic environments, from a societal, organizational, and technological perspective. MGT fosters the exchange of ideas, experience and knowledge among developed and developing countries with different cultural, organizational and technological traditions. MGT invites conceptual, theorydevelopment, empirical and review papers and case-based studies advancing the field of transitions in societies, organizations and technologies.

\section{TOPICS COVERED}

\section{Transitions in Societies}

- Geo-political transitions, transition experiments, pathways and mechanisms

- Social, demographic, cross-cultural, ethical, geo-political and security aspects of transitions

- Social change, prosperity, wellbeing, happiness

- Policy making, government regulation, social responsibility

- Knowledge-based society and world futures

- New and emerging metrics for measuring, assessing and evaluating societal transitions

\section{Transitions in Organizations}

- Organizational analysis and design, modeling, developments and changes in organizational learning and behavior

- International strategy and strategic alliances, networked businesses and operations

- Entrepreneurship and leadership, decision making

- Knowledge sourcing and innovation management, personal development, education and training, HRM

- Business systems and business models

- Connective intelligence and collective intelligence in organizational behavior
Transitions in Technologies

- Managing technological/organizational change and innovation

- Technology networks, technology transfer benefits and risks, technology acquisition and diffusion

- Smart technologies and development discontinuities, renewable sources and sustainability

- Digitalization, гот, гст, cybernetics, forecasting

- Technological traditions, strategic surprise and response systems

- Studies that promote understanding of the dynamics of socio-technical systems change

- Science and technology policy that fosters transformative advancement

- Modeling technological change in vucA (volatile, uncertain, complex, ambiguous) environments

SUBMISSIONS

The manuscripts should be submitted as e-mail attachment to the editorial office at mgt@fm-kp.si. Detailed guide for authors and publishing ethics statement are available at www.mgt.fm-kp.si.

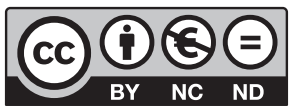

EDITORIAL OFFICE

University of Primorska

Faculty of Management

Cankarjeva 5, 6104 Koper, Slovenia

mgt@fm-kp.si · www.mgt.fm-kp.si

PUBLISHED BY

University of Primorska Press

Titov trg 4, 60oo Koper, Slovenia

zalozba@upr.si·www.hippocampus.si

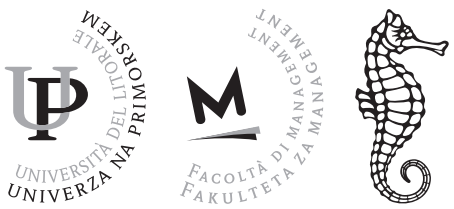




\title{
Outsourcing of Information Technology and Business Processes in Poland: Motivations and Environmental Factors
}

\author{
Wojciech Piotrowicz \\ Hanken School of Economics in Helsinki, Finland \\ wojciech.piotrowicz@hanken.fi \\ Damian Kedziora \\ Maria Curie-Sklodowska University in Lublin, Poland \\ damian.kedziora@gmail.com
}

The aim of the paper is to summarise the literature focused on Information Technology and Business Process Outsourcing in Poland and to contribute to understanding of motivations and environmental factors driving service relocations to Central and Eastern Europe. This exploratory study is based on academic literature and two data sources: government and industry reports, as well as small-scale exploratory survey. The findings confirm the cost reduction to be the main driver, followed by the willingness to improve processes and business performance. The substantial advantage of Poland is human resources - the availability of highly skilled, well-educated workforce at relatively low cost. Even though the salaries are often higher than in Asia, it is compensated by the number of graduates and knowledge of foreign languages. Membership of the European Union and political stability also plays an important role. This exploratory study, aside of relocation trends overview, enabled the views among service providers to be captured and compared with the commercial and governmental reports.

Key Words: information technology, outsourcing, offshoring, business process, transition economy, Poland, Central and Eastern Europe JEL Classification: M15

https://doi.org/10.26493/1854-6935.16.307-333

\section{Introduction}

International service transfers have been a vital part of global economic transitions and in the past decade its dynamic growth has been observed in the region of Central and Eastern Europe (CEE) (Rilla and Squicciarini 2011; Kedziora, Kraslawski, and Kärri 2016). Nevertheless, the majority of service offshoring studies have been focused on India and China (Gonzalez, Llopis, and Gasco 2013; Lacity, Khan, and Yan 2010). Focus 
on Asian countries and limited research on CEE region does not reflect current trends.

Therefore, this paper focuses on Business Process Outsourcing (в ро), together with Information Technology Outsourcing (гто) in the context of Poland and the wider Visegrad Group (v4) region. Although global Foreign Direct Investments (F D IS) in knowledge-intensive industries decreased since the late 2000 s at the global level, this trend was not observed in CEE (Micek 2015), where we had observed an increase in service investments since 2000 (Hardy, Sass, and Fifekova 2011). Between 2001 and 2012, the export of I T O/B P O had increased from $17.5 \%$ to $34 \%$ of total service export (Myszkowska 2014) and the rapid increase in services' relocations was particularly visible after the v4 countries joined the European Union in 2004 (Gál 2014; Kedziora, Karri, Kraslawski, and Halasa 2017). While initially Western companies were transferring to CEE region mainly manufacturing tasks (Collins and Grimes 2011), it had quickly started to shift onto more advanced functions (Jacoby 2010; Jürgens and Krzywdzinski 2009), transitioning the country's position from the role of materials and low technology exporter onto the modern services delivery hub (Hardy 2007; Association of Business Services Leaders 2017). Foreign investments in Poland, and the entire region, together with emerging local companies, capable of selling services abroad, influence socio-economic development and economic convergence. While there are flows of capital and investments, equally or even more important are transfers of knowledge and managerial practices, which, in turn, allow CEE-located companies to participate in international business and supply chain networks. In the mid-term, this triggers changes in the country's perception as sourcing destination, attractiveness for further investments, climbing at the global value chain by delivering more advanced services.

The paper has been structured as follows: after the introduction, the definitions and literature on offshoring and гто/в Ро are briefly overviewed; the modern services in Poland are presented and some of the factors that influence their relocation are analysed. The research is exploring perceptions of outsourcing motivations in Poland, addressing two questions:

1. What are the key motivators driving service relocations to Poland?

2. Which environmental factors are influencing Polish outsourcing of business process (В РО) and information technology (Іто)? 
TABLE 1 Academic Literature Review, Classification of Papers

Offshoring and Alsudairi and Dwivedi (2010), Bharadwaj, Saxena, and Halemane Outsourcing in (2010), Busse et al. (2017), Dibbern, Goles, and Hirschheim (2004), Business Fjermestad and Saitta (2005), Gonzalez, Gasco, and Llopis (2006), Gonzalez, Llopis, and Gasco (2013), Jayaraman et al. (2012), Kamann and Van Nieulande (2010), Kedziora, Klamut, Karri, and Kraslawski (2017), Kern and Wilcocks (2002), Lacity, Khan, and Willcocks (2009), Lacity, Khan, and Yan (2010), Lacity, Solomon, and Yan (2011), Loebbecke and Huyskens (2006), Loebbecke and Huyskens (2006), Sudan, Ayers, and Dongier (2010), Wiener, Vogel, and Amberg (2010).

B PO/ITO in Alsudairi and Dwivedi (2010), Capik and Drahokoupil (2011), Poland and Dedrick, Carmel, and Kraemer (2011), Epstein (2014), Gál (2014), other transition Guzik and Micek (2008), Hardy, Micek, and Capik (2011), Kedziora, economies Kraslawski, and Kärri (2016), Liu, Luo, and Liu (2009), Manning (2014), McNulty and Harper (2012), Micek (2015), Myszkowska (2014), Piotrowicz (2015a), Prasad and Babbar (2000), Roztocki and Weistroffer (2008), Roztocki and Weistroffer (2015), Sass and Fifekova (2011), Soja and Cunha (2015), Tambe and Hitt (2010), Vrhovec, Trkman, and Kumer (2015).

Motivations to Gál (2014), Juvonen (2009), Kedziora, Kraslawski, and Kärri (2017), outsource Lacity, Khan, and Willcocks (2009), Lacity, Khan, and Yan (2010), Schwarz (2014), Wiener, Vogel, and Amberg (2010).

Environmental Alsudairi and Dwivedi (2010), Capik and Draho-koupil (2011), Fjerfactors - $\quad$ mestad and Saitta (2005), Juvonen (2009), Lacity, Khan, and Yan selection (2010), Lacity, Solomon, and Yan (2011), Sass and Fifekova (2011), criteria Sudan, Ayers, and Dongier (2010), Wiener, Vogel, and Amberg (2010).

\section{Literature Review}

The literature review stems from information systems discipline, additionally incorporating papers from journals related to regional studies, international business and economic geography divided into four main streams (table 1).

\section{Concepts of Offshoring and Outsourcing}

Offshoring in business is to be understood as relocation of some operational task to another country (Gonzalez, Llopis, and Gasco 2013). Term nearshoring is often used when geographical and cultural distances between customer and provider are short, whereas farshoring when they are far-off (Kamann and Van Nieulande 2010; Busse et al. 2017). Captive (in-house) offshoring refers to all remote activities that are delivered within the boundaries of the same company, but in some different coun- 
try (Baier, Rammer, and Schubert 2015). Business Process Outsourcing (В РО) is a practice of sourcing operational processes with some external service providers (Lacity, Solomon, and Yan 2011, 1), across diverse service lines, such as accounting and finance, customer management, procurement, human resources and training (Jayaraman et al. 2012). Information Technology Outsourcing (гто) can be understood as a special form of process outsourcing, when operations shifted to an external provider are of Information Technology (IT) domain (e.g. assets, infrastructure, or coding activities) (Kern and Wilcocks 2002). Other associated concepts are IT services and IT-enabled services (Sudan, Ayers, and Dongier 2010) that include гт О, в Ро and manufacturing engineering. More about outsourcing-related terms can be found in the work of Alsudairi and Dwivedi (2010), who identified 42 of its variations. Within IT offshoring it is possible to separate: IT, Business Processes and Call Centres and other customer care/contact centres (Bhalla, Sodhi, and Son 2008). All such offshore operations of various types and delivery models can be broadly referred to as modern business services (Kedziora, Klamut, Karri, and Kraslawski 2017).

Iто can be 'full' when all functions are transferred or selectively focused on certain activities or processes (Loebbecke and Huyskens 2006). Unlike project-based Iто, which mainly allows for testing and adjustment, в Р о tends to be run from day one in real-time settings (Bharadwaj, Saxena, and Halemane 2010). The transaction costs of offshoring are higher compared to local outsourcing (Dibbern, Goles, and Hirschheim 2004). Nevertheless, there is an increase of I t providers from India and South-East Asia, that competes with Western companies (Gonzalez, Gasco, and Llopis 2006) taking advantage of wage differences (Fjermestad and Saitta, 2005). It is important to stress that not all outsourcing initiatives are successful and may end up in IT back-sourcing (bringing IT functions back to the incumbent organisation), or IT insourcing (keeping IT in-house) (Qu, Oh, and Pinsonneault 2010). ITo is a well-established business phenomenon, experiencing its first wave as early as the $1960 \mathrm{~s}$ (Loebbecke and Huyskens 2006), followed by the emergence of service offshoring in the 1980s (Wiener, Vogel, and Amberg 2010) and finally, в Р О as of the 1990 (Lacity, Solomon, and Yan 2011).

\section{Motivations to Outsource}

Reviews (Lacity, Khan, and Yan 2010; Lacity, Khan, and Willcocks 2009) have synthesised academic literature focused on Іто/в ро. The authors 
analysed independent variables which influenced motivations to outsource, for both гто (20 variables) and в ро (19 variables), as well as compared differences and similarities. In case of I т o, several motivating factors were identified, including: cost reduction, focus on core capabilities, access to skills/expertise, business/process improvements, technical and political reasons, concerns for security/intellectual property, and fear of losing control. For в Р о there was not much difference, as the top four motivating factors were repeated with a small change in order. A similar study, by Juvonen (2009), identified cost reduction, access to skills and technologies as top driving factors, followed by quality improvements, pressure to cut costs and debt reduction. In many cases, after the transition project transferring tasks to a new location is over, the operational effort is put on optimization and continuous improvement of the service resulting in financial benefits (Kedziora, Kraslawski, and Kärri 2017). Wiener, Vogel, and Amberg (2010) has also identified cost reduction as a top financial benefit, emphasising the quality of IT workers at low cost, and the maximisation of short-term profits. Among strategic benefits, access to skills was listed as number one, followed by quality standards and certifications, access to IT workers, focus on core competences, lack of time zones, tax breaks, global capabilities and proximity to markets. While there are differences between cited papers, there is clear agreement that the leading motivating factors are: cost reduction, access to skills and expertise, improvements in business processes (including financial performance) and focus on core capabilities. Different results were reported by Schwarz (2014) who listed the ability to access additional capabilities, skills and knowledge as the leading IT outsourcing success factors, with financial benefits listed as the third factor. Some of the criteria (such as time zone differences) are specific to offshore sourcing (Lacity, Khan, and Willcocks 2009). Local CEE advantages were also discussed by Gál (2014). Motivating factors were extracted from the above literature to be included in the questionnaire used for data collection part of the present study.

\section{Environmental Factors - Selection Criteria}

Environmental variables hardly appeared in I то studies (Lacity, Khan, and Yan 2010). Alsudairi and Dwivedi (2010) noted that social, economic, political and legal issues are not well explored in the context of гт O. A greater focus on the environment can be found in the в ро studies (Lacity, Solomon, and Yan 2011), where it was possible to distinguish countylevel characteristics such as: 
- cultural distance,

- financial attractiveness (including factors such as labour costs, taxes, regulations),

- human resources (H R) attractiveness (quality of education and availability of workforce),

- legal and political uncertainties and time zone differences.

Another literature-based analysis listed language, culture and trust as potentially problematic factors (Juvonen 2009). Cultural differences, language, legal and political uncertainty, geographical distance, workforce, infrastructure and government initiatives were also included in the analysis of IT offshoring by Wiener, Vogel, and Amberg (2010). Comprehensive work focusing on country-level competitiveness was completed by Sudan, Ayers, and Dongier (2010), who overviewed and combined several commercial frameworks used to analyse countries as outsourcing destinations, including elements such as infrastructure, labour pool, or costrelated issues. Infrastructure and technology, culture, political climate, taxes and policies were also incorporated in the framework designed by Fjermestad and Saitta (2005). Outsourcing decisions in e-banking context were also explored by Hanafizadeh and Zare Ravasan (2018).

The motivations for the service FDIS were investigated by Capik and Drahokoupil (2011) who concluded that the main drivers are: low labour costs, proximity to Western markets and availability of skilled workforce. They also listed cost effectiveness, quality of infrastructure, access to new markets, culture, previous experience in the country and investment incentives. It should be noted that these drivers were identified for the whole v4 group, not individual countries, and no ranking was calculated. Thirty interviews among V4 region managers (Sass and Fifekova 2011) indicated that market access is a leading issue in the horizontal FDIs, while for verticals: cost reduction, availability and cost of labour, followed by strategic location, infrastructure, political and business environment and cultural affinity.

\section{B PO/I To Research in Poland and Other Transition Economies}

Transitional (or transition) economies include former communist bloc countries, such as Poland, Czech Republic and Russia. Post-communist European countries are characterised by a high level of industrialisation and education, but their political and legal systems are still not at the level characterised by developed nations (Prasad and Babbar 2000). The 
emergence of market economies in CEE region was a notable event in the world economy (McNulty and Harper 2012), and they are still undergoing multidimensional and intensive transitions in the economic, legal and social environment (Liu, Luo, and Liu 2009). Research focused on Іто/в Ро in transition economies, including v4 (Czech Republic, Hungary, Poland, and Slovakia), is very limited (Roztocki and Weistroffer 2015; Piotrowicz 2015a), despite differences in IT implementation and uses between transition and developed countries (Soja and Cunha 2015). This is not surprising, as the main role of universities in many developing countries is teaching, not research (Roztocki and Weistroffer 2008).

Research focused on гто/в ро in Poland is scarce, despite the rapid growth of the sector (Gál 2014; Myszkowska 2014). Sass and Fifekova (2011), Gál (2014), Hardy, Micek, and Capik (2011), Micek (2015) and Myszkowska (2014) focused on в ро and services offshoring in the v4 and CEE region. Poland was also included in the study of software industry delocalisation (Guzik and Micek 2008; Kedziora, Kraslawski, and Kärri 2016; Kedziora, Karri, Kraslawski, and Halasa 2017). The process of services relocation to Visegrad countries was overviewed by Myszkowska (2014) using secondary data. However, as Myszkowska herself pointed out, there was a lack of statistics focused directly on offshoring activities. As a result, other indicators, such as balance of payments, were analysed in the context of size and structure of the service sector. Findings indicate the sharp growth of service exports since 2002, with Poland being the regional leader in the value of such exports (Myszkowska 2014). FDIs in business services in v4 countries were analysed by Capik and Drahokoupil (2011) who overviewed policies and practices towards a knowledgebased economy, including FDIs in the service sector in each country. Capik concludes that investments in services are mainly utilising existing resources, which allows for the development of individual workers rather than increasing and transforming local knowledge creation. Moreover, Capik and Drahokoupil (2011) offered an overview of services offered by v4 countries: back office, customer contact, common corporate functions, knowledge services and decision analysis, and Research and Development (R\&D). The presence of FDIS in в PO was also investigated by Micek (2015). The studies on the Kraków region as a location for software development (Micek 2008), and offshoring destination (Micek, Działek, and Górecki 2011) were also conducted. The research utilises multiple data sources, including interviews, and is focused on the links between offshoring and impact on local markets, such as job creation and 


\begin{tabular}{c|cc|c}
2013 & 454 & 2013 & 99000 \\
2014 & 542 & 2014 & 118000 \\
2015 & 580 & 2015 & 139000 \\
2016 & 697 & 2016 & 174000 \\
2017 & 748 & 2017 & 198000 \\
$* 2018$ & 800 & ${ }^{*} 2018$ & 220000 \\
FIG U RE 1 & Growth of the Polish Service Offshoring Sector in 2013-2017 \\
& (left - number of centres, right - headcount of employees, ${ }^{*}$ estimate; \\
& adapted from Association of Business Services Leaders 2017)
\end{tabular}

various taxes paid by individuals and organisations (Micek, Działek, and Górecki 2011). There is also an interview with а в ро expert focused on the nature of Polish в Р О/І т о sector (Piotrowicz 2015b), as well as a study of personal development and leadership perception among employees of this industry (Kedziora et al. 2018).

As pointed out by Micek (2008), initially the development of companies was not balanced spatially, with majority of them being located in major agglomerations (Micek 2008), but later secondary locations were chosen and spatial deconcentration was observed. In such comparison, Poland holds a position of a regional leader in CEE region, in the same time being the second largest remote services delivery hub in Europe. Despite the rapid growth of the offshoring sector, it is important to remember that the share of knowledge intensive services and $\mathrm{R} \& \mathrm{D}$ expenditure is rather low in relation to other, developed $\mathrm{EU}$ countries (Capik and Drahokoupil 2011). Moreover, low R \& D expenditure results in underutilisation of available, well-qualified labour (Hardy 2007). Initially, manufacturers which moved to Poland relocated merely basic, simple operations, keeping R\&D in the West (Jürgens and Krzywdzinski 2009). As a result, multinational corporations are largely controlling $\mathrm{R} \& \mathrm{D}$ and innovation (Epstein 2014). The Visegrad group, including Poland, still have low FDIS in the service sector compared to Asian countries (Myszkowska 2014).

\section{State of the ITO and BPO in Poland}

The sector of modern business services in Poland has been rapidly growing for the past few years (Kedziora, Kraslawski, and Kärri 2016), and currently employs nearly 200 ooo workers in over 700 delivery centres (Association of Business Services Leaders 2017), as presented in figure 1.

The offshored delivery centres are owned by global brands, from variety of sectors. They key types processes executed in those centres are: IT: 
User Support/Service Desk, Finance \& Accounting (F\&A), B FSI: Banking, Financial and Insurance specific services, Customer Operations, Research \& Development, HR (incl. Payroll), Supply Chain Management \& Logistics and Procurement (Association of Business Services Leaders 2017). In general, the years 2000-2016 were associated with the sustained economic growth in Poland, with increasing income and quality of life (OECD 2016b), which has changed the overall position of the country. In 2016, Poland moved up the list of the AT Kearney Global Service Location Index, achieving 1oth place in the world; being the highest rank of any European country (AT Kearney 2016). The latest Tholons ranking listed Kraków as number 8 for 'top outsourcing destinations' and two other Polish cities appear among the top 100; Warsaw at 23 and Wrocław at 78 (see http://www.tholons.com).

This trend is likely to continue as Deloitte (2016) anticipates that the market will continue to merge services from the perspective of technology, process and capability-based models. A global increase in гто/в Ро migrations is not surprising as already in 2010, Poland was expected to become one of the emerging Knowledge Process Outsourcing (К Ро) economies due to low entry barriers and the availability of a highly skilled workforce (Jones Lang LeSalle 2010). Documents which target investors have been used, listing the advantages of Poland such as a large labour pool, a highly educated workforce, language skills, availability of office space and close proximity to West European markets (JP Weber/Pariz, 2014). Documents prepared by the Polish Investment and Trade Agency stress issues such as: scale of economic growth, stability, large number of graduates, highly qualified staff at relatively low cost and existing R\&D units, as well as improvement in institutional and legal environment (PAIiIZ 2014).

\section{Research Design}

The research had three main stages: (1) review of academic research, (2) analysis of the reports, (3) pilot study, and small scale. The issues identified in the previous гто/в Ро research were incorporated into the questionnaire, secondary data sources, such as reports and statistics, were also analysed. The survey was developed in electronic format and its distribution has been supported by the Outsourcing Portal, the leading webportal dedicated to the growing гто/в ро industry in Poland. A link to the survey was emailed in a newsletter to the subscribers of the Outsourcing Portal and advertised on its website. From the 70 collected responses, 
after removal of incomplete questionnaires or those with suspicious data, as well as those completed by nоn-гто/в Ро organisations and individuals, 15 completed questionnaires remained. This represents $3.2 \%$ of organisations operating at the data collection time (2015). The survey was conducted in English. The questionnaire included Likert-scale answers and a section requesting information about respondents and their companies (single, multiple answers and open text). The limitations of this exploratory study are reflected in a non-random and non-representative sample, but it presents the main structure of гто/в Pо. As for the size of companies examined, the majority (9) of 15 organisations surveyed employed up to 250 people, two employed between 251 and 1,000 and four over 2,501. Seven of 15 respondents held managerial positions, while the rest were employees/specialists. Among them, seven were from Finances and Accounting Departments, three from Operations, three from IT, two from Marketing and a single respondent from H R and from Manufacturing. In terms of the location of company headquarters, there were four from the UK, four from the USA, three from Germany, two from France and one each from Ireland and Poland. Most of the companies offered services related to transaction processing (13 of 15), query management, invoice (12), accounts, data and customer administration processing (11). Most of the surveyed companies operate for the $\mathrm{EU}$ market. This is in line with service exports statistics, which indicate that $70 \%$ of exports is to the EU market (Myszkowska 2014), The majority of respondents were from the financial sector.

\section{Findings of the Pilot Survey}

This section presents the findings. Firstly, motivations to outsource are listed; then the role of environmental factors in the selection of г то/в Ро destination is presented.

\section{MOTIVATIONS TO OUTSOURCE}

The first set of questions addressed the motivation; why, according to respondents, organisations made the decision to use companies located in Poland. Respondents were asked to rank 'motivating factors for the outsourcing of Іто/в Ро in Poland' on a five-point Likert scale, from 'not important,' via 'neutral/not applicable' to 'very important.' Results (table 2) indicate that the top four reasons are related to efficiency related drivers: cost reduction, followed by performance improvement, better cost con- 
TABLE 2 Motivation for outsourcing in Poland

\begin{tabular}{lr}
\hline Motivating factor & Rank \\
\hline Cost reduction & 1 \\
Improve business/process performance & 2 \\
Increase cost control and predictability & 2 \\
Ability to focus on core capabilities & 3 \\
Access to suppliers' expertise/skills & 4 \\
Eliminate a burdensome function or process from organisation & 5 \\
Drive innovation & 6 \\
Increase ability to adapt to change & 7 \\
Previous positive experience on the Polish market & 8 \\
Access new technology offered by suppliers & 10 \\
Reduce the number of own employees & 11 \\
Access to the European market & 12 \\
Answer to the It skills shortage & 13 \\
Demonstrate success required for promotion & 14 \\
Access to the Polish market & 15 \\
Change organisational structure of a company & 9 \\
\hline
\end{tabular}

trol and focus on core capabilities. The fifth element was 'access to suppliers' expertise/skills.'

\section{OUTSOURCING IN POLAND - SELECTION CRITERIA}

The second set of questions is related to the selection criteria - why organisations decided to use Poland as an outsourcing destination. Respondents were asked to 'rank the importance of the following factors in selecting Poland as an гто/в Ро location,' and again the five-point Likert scale was used (from 'not important,' via 'neutral/not applicable' to 'very important'). Among the top five aspects, four are related to workforce: foreign languages, number of graduates, system of education, and, in second place, the 'labour cost' was listed. The fifth criterion was the level of Iто/в Ро maturity (table 3 ).

\section{Discussion}

This section analyses and discusses key motivations for moving to Poland, comparing them against relevant І то/в Ро literature, public sector reports, statistics, as well as commercial publications. 
ta b LE 3 Main Criteria Considered during the Selection Process

\begin{tabular}{lr}
\hline Criteria for selection & Rank \\
\hline Foreign languages spoken in a country & 1 \\
Labour costs & 2 \\
Number of graduates available per year & 2 \\
System of education & 3 \\
Level of maturity in I T/B P outsourcing & 4 \\
Number of I and engineering graduates available per year & 5 \\
Work ethics and motivation among employees & 6 \\
Eu membership & 7 \\
Political stability & 8 \\
Location & 9 \\
Property prices & 10 \\
Quality of IT and telecommunication infrastructure & 11 \\
Language barrier & 12 \\
Easy travel (by land or air) & 13 \\
Lack of time-zone differences & 14 \\
Cultural similarity & 15 \\
Transport infrastructure & 16 \\
Local work regulations & 17 \\
Government support (tax breaks) & 18 \\
Special economic zones & 20 \\
Crime and security & 21 \\
Availability of information about the country & 22 \\
Level of taxation & 23 \\
Level of corruption & 24 \\
Existing commercial relationships (trade, investments) & 5 \\
\hline & 20 \\
\hline
\end{tabular}

MOTIVATION FOR OFFSHORE OUTSOURCING IN POLAND

Firstly, the collation of ranks and weights given to key motivators identified in the empirical part of this study, compared to the two broad reviews of outsourcing literature on Iто (Lacity, Khan, and Willcocks 2009) and в р о (Lacity, Solomon, and Yan 2011) shall be presented in table 4.

Across nearly 30 years of academic research, as of the early 1990s, the offshoring decision-making process had mainly been based on costsaving (Mihalache and Mihalache 2016). The top motivator for outsourc- 
TABLE 4 Top Five Motivating Factors Driving Iт and в Р Outsourcing, Findings vs. Literature

\begin{tabular}{lrrrrr}
\hline Motivating factor & $(1)$ & $(2)$ & $(3)$ & $(4)$ & $(3)$ \\
\hline Cost reduction & 1 & 1 & 0 & 1 & 0 \\
Improve business/process performance & 2 & 4 & +2 & 4 & +2 \\
Increase cost control and predictability & 3 & 13 & +10 & $* *$ & - \\
Ability to focus on core capabilities & 4 & 2 & +2 & 2 & 0 \\
Access to suppliers' expertise/skills & 5 & 3 & -2 & 3 & -2 \\
\hline
\end{tabular}

NOTES Column headings are as follows: (1) ranked by respondents, (2) Iтo literature (Lacity, Khan, and Willcocks 2009), (3) difference - factor ranked by respondents, (4) в Ро literature (Lacity, Solomon, and Yan 2011). ${ }^{\star *}$ Not listed.

ing in Poland was listed as 'cost reduction.' Previous papers (Lacity, Khan, and Yan 2010; Lacity, Khan, and Willcocks 2009) concluded that cost reduction is a number one motivator in both Іто and в РО, and its importance was also confirmed in other studies (Juvonen 2009; Wiener, Vogel, and Amberg 2010). There have been instances of global sourcing activities transferring some operations to more developed and expensive countries, e.g. internet traffic exchange, but only in case of services with a high amount of automation or complexity (Alpar 2016). Most frequently though, the researchers tend to use the outsourcing concept to reflect the low-cost dimension of (re)location activities (Maskell et al. 2007).

The other two top motivating factors were also identified in the work by Lacity, Khan, and Willcocks (2009) although there was a difference in the order. 'Increase cost control and predictability' listed as 13th, here was listed much higher (3rd). 'Access to suppliers' expertise/skills' was ranked lower (5th) than in other researchers' reviews (Juvonen 2009; Lacity, Khan, and Willcocks 2009). Many times, companies decide to move processes offshore to access specialized skillset unavailable at homelocation (Nachum and Zaheer 2005), because partners based in foreign locations can be particularly knowledgeable in certain activities (Jensen 2009). When the incumbent country environment becomes a pushing element, for instance when talents in science and engineering ( $\mathrm{S} \& \mathrm{E})$ are in short or expensive supply, the host country can act as a pull force, providing innovative solutions to challenges that firms face in home countries (UNCTAD 2005). In the context of this study, we can argue that although the Digital Economy and Society Index (DESI) of Poland is relatively low, as it currently holds the 23 rd place, out of the $28 \mathrm{EU}$ countries 
(see https://ec.europa.eu/digital-single-market/en/desi), it assumes high scores for STем graduates (Science, Technology, Engineering, Mathematics) and number of enrolled students (OECD 2015). Therefore, size and quality of Polish tech graduate's market is still attractive for investors.

Motivation to drive innovation was ranked surprisingly high ( 7 th), considering the low position of Poland as a place for innovation. Even though there was constant growth in R\&D (a 122.5\% increase between 2002 and 2010), this level is below the $\mathrm{EU}$ average (2\% for $\mathrm{EU}, 0.74 \%$ for Poland (paIiIz 2014). Likely, the real driver could be the availability of a highly skilled workforce, which can then create innovation, driven by foreign companies. It could be related to the fact that outsourcing in Poland is in the relatively early stages, so there is a limited number of established organisations which work in this area. This confirms the observations of Capik and Drahokoupil (2011) who pointed out that in overall, investors tend to utilise human resources rather than change innovation systems. At this point of the industry's development, this is probably not a key motivator for some firms, as they may be afraid of losing innovation capability through unprepared offshoring of high level, knowledge-intensive activities, acting under pressure of managerial attention (Mihalache et al. 2012). Moreover, $R \& D$ offshoring contracts are often more strategic in their aims and longer in duration, which applies more to the partner with whom a company has been cooperating already for many years (Stauss and Jedrassczyk 2008). Therefore, the offshore investments in CEE region may be shifting onto some more knowledge-intensive and innovation driven in the closer destinations.

\section{Selection Criteria and Environmental Factors of Polish В P O/I TO Industry}

This section discusses the importance of the role played by selection criteria and environmental factors in the relocation of І то/в Ро services. The following aspects are critically discussed workforce and its quality, labour costs, political and business environment, location, IT infrastructure, tax incentives and special economic zones (table 5), compared to the two significant reviews of outsourcing literature on в Ро (Lacity, Solomon, and Yan 2011) and I то (Lacity, Khan, and Willcocks 2009).

Top selection criteria and environmental factors influencing IT and в р Outsourcing, findings vs. literature (Lacity, Khan, and Willcocks 2009; Lacity, Solomon, and Yan 2011)

Workforce - the quality of workforce available in Poland was listed as 
тав LE 5 Top Five Motivating Factors Driving гт and в р Outsourcing, Findings vs. Literature

\begin{tabular}{lrrrrr}
\hline Selection criteria & $(1)$ & $(2)$ & $(3)$ & $(4)$ & $(3)$ \\
\hline Workforce quality & $*$ & 3 & - & 2 & - \\
Labour costs & 2 & 1 & -1 & 1 & -1 \\
Political and business environment & 9 & 7 & -2 & 9 & 0 \\
Location & 10 & $* *$ & - & 31 & +21 \\
IT infrastructure & 12 & $* *$ & - & 29 & +17 \\
Tax and other government incentives & 19 & $* *$ & - & $* *$ & - \\
\hline
\end{tabular}

NOtes Column headings are as follows: (1) ranked by respondents, (2) Iт literature (Lacity, Khan, and Willcocks 2009), (3) difference - factor ranked by respondents, (4) в Р О literature (Lacity, Solomon, and Yan 2011). ${ }^{\star} 1,3,4,6,7$ (related aspects), ${ }^{* *}$ not listed.

a driving factor for the majority of respondents. Those included issues in six of the top ten criterions, namely:

- Foreign languages spoken in a country (1st)

- Number of graduates available per year (3rd)

- System of education (4th)

- Number of It and engineering graduates available per year (6th)

- Work ethics and motivation among employees ( 7 th)

The quality of workforce has also been highly valued in the literature review of Іто: 3 rd position, and в Ро: 2nd position (Lacity, Khan, and Willcocks 2009; Lacity, Solomon, and Yan 2011). This also partly confirms the work of Micek (2015) who listed the availability of a welleducated workforce as a leading factor, as well as Capik and Drahokoupil (2011), who listed them as the third leading motivator. The importance of education and its role in attracting investments is also in line with other works, pointing out that human capital is a strong advantage of the entire CEE region (Association of Business Services Leaders 2017). As pointed out by Sass and Fifekova (2011), the region has knowledge advantage when compared to other, lower cost, destinations. The role of education goes beyond practical skills; it also allows transfer of knowledge, habits and shared values (Assar, Amrani, and Watson 2010). However, it should also be noted that IT and codification of knowledge enables the transfer of knowledge between organisations and regions (Maskell and Malmberg 1999), providing Poland with the knowledge which was not present in local companies. Moreover, there are already cases where 
knowledge is created locally (Filippov 2014). However, to attract higher value and more advanced services, there is a constant need for a highly skilled workforce (Hardy, Micek, and Capik 2011). This indicates an important role of IT-related and language education as the driver of country level and regional development. The availability of graduates from the engineering sciences, such as mathematics and IT was listed as an advantage (6th) together with language skills (1st). As we can see from the responses, languages, numbers of graduates, including graduates in engineering, were all ranked high in the Polish context. Such drivers are confirmed as leading factors by reports such as those prepared by the Association of Business Service Leaders (2017). However, Manning (2014) indicated that there were communication problems between Us and Polish companies. As Gál (2014) pointed out, the CEE region attracts organisations offering talented and skilled labour, so the low wages are not the main driver. Competition based on a skilled workforce was made possible due to changes in the education system. OECD (2016a) report indicated, the strong growth in the number of adults who attained a tertiary degree, from $17 \%$ in 2005 to $28 \%$ in 2015 (OECD 2016). Polish university sector is also growing, with around 1665300 students in 2015, which had direct impact of the development of the гт о/в ро industry (see http://ec.europa.eu/eurostat). Another factor which likely influences the quality of labour is obligatory exams in mathematics for all secondary school leavers (PAIiIz 2010). It is likely that a good quality educated workforce will be available in the near future, since the PISA report (OECD 2012), which measured skills among 15-year old children, listed Poland at 14th place in the world in mathematics, statistically significantly above the OECD average, with similar results achieved in reading and science. Countering this, however, Poland has an ageing population (see http://ec.europa.eu/eurostat).

Labour costs - respondents listed labour costs as the second most important factor, which is also reflected in the analysed гто and в Ро literature review, being the top important factor (Lacity, Khan, and Willcocks 2009; Lacity, Solomon, and Yan 2011). The same in the work of Capik and Drahokoupil (2011), who pointed out that labour costs are the leading issue, and elaborated on the linkages between quality, availability and costs. Based on the responses we can observe that labour costs, together with the highly valued workforce quality, point on an actual value of workforce as a composite notion: the balance between quality of workforce, labour costs and work ethics. The investors are aiming to get good value 
for money and rank it as a leading factor. This was in line with Sass and Fifekova (2011), as well as Guzik and Micek (2008), who mentioned the mix of cost and quality as one of most influential aspects for the $\mathrm{V} 4 / \mathrm{CEE}$ region. Micek (2008) listed two leading issues for foreign software development in Poland that are cost of service and availability of skilled graduates, which was also observed by Wiener, Vogel, and Amberg (2010) in an international context. Guzik and Micek (2008) also found that for the Polish IT subcontracting sector, the skillset and expertise was a leading factor, not the low cost (without specifying what costs are included). They have also pointed out that in the CEE region, it is possible to achieve similar productivity as in Western Europe, but at lower cost (due to differences in salaries). Nevertheless there are already cases where costs in Poland are getting close to those in the West, so the quality of workforce needs to compensate for this cost factor (Guzik and Micek 2008). Monthly Salary levels in Warsaw (per FTE) is estimated at the level of 950-4940 EUR gross/month in ITO and 900-4730 EUR gross/month in в PO (Association of Business Services Leaders 2017). However, there are differences in salary levels between cities and regions (Micek 2008). For instance, the values in Lodz are at the level of 760-4690 E U R gross/month in ITO and $760-4260$ EUR gross/month in B PO (Association of Business Services Leaders 2017). According to the 2013 salary report (Hays 2013), the monthly salary for .NET/C\# Developer was between 9000 and 12000 PLN gross, and financial analysts between 7000 and 9000 PLN gross (Hays 2017).

Political and business environment - in this work, respondents ranked political stability and EU membership highly (8th and 9th place respectively), just behind the factors related to workforce. It is similar to the referenced literature review of гто and в Ро, where it has assumed 9th position (Lacity, Khan, and Willcocks 2009; Lacity, Solomon, and Yan 2011). Importance of political stability and regulatory frameworks was confirmed by Hansen, Mena, and Aktas (2018). In the paper of Sass and Fifekova (2011), this factor was mentioned by $50 \%$ of respondents from v4 countries. The importance of political (and fiscal) stability, together with EU membership was also listed as important by Guzik and Micek (2008), importance of the EU accession for FDI flows was also stressed by Medve-Bálint (2014), as in fact in many cases decisions to enter the market are based on cultural linkages, not no cost-benefit calculations. Additionally, Poland can be considered, due to its social structure, close to the 'terrorism-free zone' (Mareš 2011), unlike some of other regions. For 
Poland, both NATO and EU membership increased stability, however the situation in Ukraine remains unresolved (although from the other hand, such situation reduces the risk that companies will relocate from Poland to Russia or Ukraine). However, the time of data collection came prior to, and thus could not account for, the increasing migration problems in the EU, so as the Brexit decision in the United Kingdom.

Location - in contrast to Capik and Drahokoupil (2011) who concluded that access and proximity to Western markets was one of the leading factors, location was ranked by respondents at 1oth place, which was also of lower importance for the $\mathrm{v} 4$ countries. In the analysed в ро literature review, it has been listed on 31th place that is much lower (Lacity, Solomon, and Yan 2011). Sass and Fifekova (2011) and Guzik and Micek (2008) found that it was in the last of five analysed factors. Similarly, Micek (2008) listed proximity to customers as the fifth leading issue. In contrast, Gál (2014) pointed out that geographical proximity was among the highest ranked aspects. While location was important, surprisingly it was not among top factors, contrary to some earlier findings. This can be related to the fact that most services are offered online, which reduces transportation time and costs. Also, since most customers were located in the $\mathrm{EU}$, the lack of time-zone differences was not highly ranked (15th).

IT infrastructure - similar to location, IT and telecommunication infrastructure was not listed as a top issue in research by Sass and Fifekova (2011), but over $50 \%$ of respondents mentioned this factor (12th place) in the present study, as well as the в ро literature (Lacity, Solomon, and Yan 2011), where it has assumed 29th position. This could be due to recent improvements and large investments in infrastructure, often supported from EU funds, which allowed the reduction of the gap between Western EU countries and Poland in this area. Poland demonstrated a balanced digital development path (Cruz-Jesus, Oliveira, and Bacao 2012), however it is not classified as a 'digital leader' in ICT.

Tax incentives and special economic zones - the findings confirmed those reported by Sass and Fifekova (2011), who suggested that among companies, government incentives were not listed as key issues (ranked 19th and 2oth). This is in line with Medve-Bálint (2014) who pointed out that the necessity of such incentives was based on the perception of local government; as a result some of the reductions are not in line with the EU recommendations for free competition. Despite this finding there are various mechanisms and incentives available for investors, for example, 
special economic zones, with corporate tax reductions or exceptions (Association of Business Services Leaders 2017).

\section{Conclusions and Recommendations}

The paper addressed the dynamic growth of service offshoring sector in Poland and the entire CEE region, which has been observed in the past decade. The results showed that the strongest advantage of Poland as offshore destination is the value of its workforce, which combines: low costs (but still higher than in some Asian locations), language spoken, high number of graduates, good level of education (including engineering sciences), and work ethics. What was surprising, considering the scale of such initiatives, was that government incentives, such as tax reductions, were not highly ranked. To maintain its competitive attractiveness, the region needs to remain focus on issues such as quality of labour and level of accumulated knowledge (Collins and Grimes 2011). Further developments should allow not only for transferring knowledge into the region, but also for its creation and dissemination, especially since the CEE region has a history of earlier technological advances (Filippov 2014). The findings show that motivations for service outsourcing are not much different to those already reported in the literature, such as cost reduction and increased cost control, drive to improve processes and focus on core capabilities, with the exception of 'Increase cost control and predictability, which was listed much higher than in the work of Lacity, Khan, and Willcocks (2009).

From the literature point of view, Poland and other v4 countries, are almost unexplored in the research on modern offshored services of І то/в Ро type, therefore academic debate is unable to follow the changes in business practices, nor drive such changes. There are broad opportunities for both quantitative and qualitative work for comparative studies (within and across the regions and sectors), and this can be done with the cooperation of Polish academics. Another stream could be the work focused on education in Poland, as it drives regional advantage. Topics which need further investigation include the impact of гто/в ро on employment and foreign exchange reserves (Walsham and Sahay 2006), analysis of emerging regional specialisation among urban centres and regions (Maskell and Malmberg 1999) and development of secondary regions and cities as гто/в ро hubs. Moreover, the limitation of this study was that the data was gathered from a selected number of actors. For achieving broader point of view, further research on the more represen- 
tative sample of managers is recommended to compare and carefully support the conclusions based on it. In the past decade, the research on sustainable entrepreneurship has become one of the most vibrant subdomains that reflects the surge of solutions to social and environmental problems (Stubbs 2017). Therefore, the authors would like to recommend further study on how assumed microeconomic actions applied on the companies' level in the service offshoring industry may support the global pillars of sustainable development.

As for the recommendations for practice and policy, the authors would first like to address the role of г то/в Р о-driven education. The current system needs to be investigated, and compared with foreign-based solutions, to capture positive and negative lessons. The country level policy needs to understand and respond to the гт о/в ро industry's demand, by investing in the life-long education in foreign languages and the areas of 'hard' subjects such as math, coding and engineering. The success of a knowledge-intensive R\&D offshoring, depends very much of national culture enhancing innovation (Hahn and Bunyaratavej 2010). Therefore, the authorities of Poland and the entire CEE region should respond to this demand by offering more investor-friendly incentives, supporting and facilitating the innovative, knowledge-intensive operations. Such initiatives need to go beyond the largest urban/academic centres and could be co-funded by the state, such as putting extra resources toward education in smaller urban centres - attracting investors by lower infrastructure and average salary costs, at the same time providing quality of workforce comparable to large agglomerations. It is necessary to avoid unsustainable regional development and polarisation between largest agglomerations and rest of the country. As large agglomerations, due to its fast development pace attract talent at expense of smaller urban centres. Increasing R \& D capabilities also appears to be a necessity, to avoid being locked into a dependence upon foreign knowledge and technologies, which will suppress further development, especially capital and knowledge accumulation among local companies. In addition, Poland, which has already partially done this, should market itself as a high value, skilled location, which is not competing merely in costs, but offers high value for reasonable price in a stable political environment, climbing up the global value chain, and ready to deliver more complex services. This would allow reducing risk of reshoring Іто/в Ро centres after increase in costs (mainly labour costs). However, at present, the structure of services exports, comparing to other markets, suggests that Poland is still ready for 
further Іто/в ро investments. Even though this might put pressure on salaries, especially in prime locations, as was already observed by Micek (2008), it could be reduced by the development of secondary locations, compensated for by further investments in the level of workforce education, as well as close cooperation between companies and educational establishments. Another important factor strengthening the competitiveness of the region shall be the centralization, sorting and robotics automation of processes (Kedziora and Kiviranta 2018). Such initiatives are lately growing on popularity among substantial offshore players, aiming for additional facilitation of operations, creating best practices at the source and cultural work-environment platform. Such initiatives should be considered by more and more offshore delivery centres in the region.

\section{References}

Association of Business Services Leaders. 2017. Business Services Sector in Poland 2017. Warsaw: Association of Business Services Leaders.

Alpar, P. 2016. 'Offshoring in the Wrong Direction?' In Services and Outsourcing: A Contemporary Outlook, edited by J. Kotlarsky, I. Oshri, and L. Willcocks, 166-77. Lecture Notes in Business Information Processing 266. Cham: Springer.

Alsudairi, M., and Y. K Dwivedi 2010 'A Multi-Disciplinary Profile of Is/IT Outsourcing Research.' Journal of Enterprise Information Management 23 (2): 215-58.

Assar, S., R. El Amrani, and R. T. Watson 2010 'IC T and Education: A Critical Role in Human and Social Development.' Information Technology for Development 16 (2): 151-8.

Aт Kearney. 2016. 'On the Eve of Disruption: A New Business Model Threatens Established Concepts of Offshoring and Expands the Market.' https://www.atkearney.com/documents/10192/7094247/On+the +Eve+of+Disruption.pdf/49fa89fa-7677-4ab8-8854-5003af $40 \mathrm{ofc} 8 \mathrm{e}$

Baier, E., C. Rammer, and T. Schubert 2015 'The Impact of Captive Innovation Offshoring on the Effectiveness of Organizational Adaptation.' Journal of International Management 21 (2): 150-65.

Bhalla, A., M. S. Sodhi, and B. G. Son 2008 'Is More it Offshoring Better? An Exploratory Study of Western Companies Offshoring to South East Asia.' Journal of Operations Management 26(2): 322-35.

Bharadwaj, S. S., K. B. C. Saxena, and M. D. Halemane. 2010 'Building a Successful Relationship in Business Process Outsourcing: An Exploratory Study'. European Journal of Information Systems 19 (2): 16880.

Busse, C., M. Schleper, J. Weilenmann, and S. Wagner. 2017. 'Extending the 
Supply Chain Visibility Boundary: Utilizing Stakeholders for Identifying Supply Chain Sustainability Risks.' International Journal of Physical Distribution \& Logistics Management 47 (1): 18-40.

Capik, P., and J. Drahokoupil. 2011. 'Foreign Direct Investments in Business Services: Transforming the Visegrád Four Region into a Knowledgebased Economy?' European Planning Studies 19 (9): 1611-31.

Colliers International. 2014. 'Outsourcing and Offshoring in CEE: A Rapidly Changing Landscape.' http://www.colliers.com/-/media/files/emea/ easterneuropeaninformation/2014eeresearchpage/office/ee-2014 -oursourcing-and-offshoring-incee.pdf?la=en-gb

Collins, P., and S. Grimes. 2011. 'Cost-Competitive Places: Shifting Fortunes and the Closure of Dell's Manufacturing Facility in Ireland.' European Urban and Regional Studies 18 (4): 406-26.

Cruz-Jesus, F., T. Oliveira, and F. Bacao. 2012. 'Digital Divide Across the European Union.' Information \& Management 49 (6): 278-91.

Dedrick, J., E. Carmel, and K. L. Kraemer. 2011. 'A Dynamic Model of Offshore Software Development.' Journal of Information Technology 26 (1): 1-15.

Deloitte. 2016. '2016 Global Outsourcing Survey: Outsourcing Accelerates Forward.' https://www2.deloitte.com/content/dam/Deloitte/fi/ Documents/technology/2016\%20GOS\%2oExec\%2oSummary _Nordic.pdf

Dibbern, J., T. Goles, and R. Hirschheim. 2004. 'Information Systems Outsourcing: A Survey and Analysis of the Literature.' ACM SIGMIS Database 35 (4): 6-102.

Epstein, R. A. 2014. 'Overcoming "Economic Backwardness" in the European Union'. JCMs: Journal of Common Market Studies 52 (1): 17-34.

Filippov, S. 2014. 'Knowledge-Sharing Subsidiaries in Central and Eastern Europe.' Europe-Asia Studies 66 (9): 1553-71.

Fjermestad, J., and J. A. Saitta. 2005. 'A Strategic Management Framework for Iт Outsourcing: A Review of the Literature and the Development of a Success Factors Model.' Journal of Information Technology Case and Application Research 7(3): 42-60.

Gál, Z. 2014. 'Relocation of Business Services into Central and Eastern Europe.' Romanian Review of Regional Studies 10 (1): 67-78.

Gonzalez, R., J. Gasco, and J. Llopis. 2006. 'Information Systems Outsourcing: A Literature Analysis.' Information \& Management 43 (7): 821-34.

Gonzalez, R., J. Llopis, and J. Gasco. 2013. 'Information Systems Offshore Outsourcing: Managerial Conclusions from Academic Research.' International Entrepreneurship and Management Journal 9 (2): 229-59.

Guzik, R., and G. Micek. 2008. 'Impact of Delocalisation on the European Software Industry'. In The Moving Frontier: The Changing Geography 
of Production in Labour-Intensive Industries, edited by L. Labrianidis, 229-54. Aldershot: Ashgate.

Hanafizadeh, P., and A. Zare Ravasan 2018. 'An Empirical Analysis on Outsourcing Decision: The Case of E-Banking Services.' Journal of Enterprise Information Management 31 (1): 146-72.

Hansen, C., C. Mena, and E. Aktas. 2018. 'The Role of Political Risk in Service Offshoring Entry Mode Decisions.' International Journal of Production Research 55 (7): 1-17.

Hahn, E., and K. Bunyaratavej. 2010. 'Services Cultural Alignment in Offshoring: The Impact of Cultural Dimensions on Offshoring Location Choices.' Journal of Operations Management 28 (3): 186-93.

Hardy, J. 2007. 'The New Competition and the New Economy: Poland in the International Division of Labour. Europe-Asia Studies 59 (5): 76177.

Hardy, J., G. Micek, and P. Capik. 2011. 'Upgrading Local Economies in Central and Eastern Europe? The Role of Business Service Foreign Direct Investment in the Knowledge Economy.' European Planning Studies 19 (9): 1581-91.

Hardy, J., M. Sass, and M. P. Fifekova. 2011. 'Impacts of Horizontal and Vertical Foreign Investment in Business Services: The Experience of Hungary, Slovakia and the Czech Republic.' European Urban and Regional Studies 18 (4): 427-43.

Hays. 2013. Raport placowy 2013: Trendy na rynku pracy. Warsaw: Hays. - 2017. Raport placowy 2017: Trendy na rynku pracy. Warsaw: Hays. Jayaraman, V., M. Mandar, and A. Anandnarayan. 2012. 'From a Caged Tiger to a Sauntering Elephant: Sustainability as a Driver for Profit and Innovation in Indian IT Companies.' In Sustainable Supply Chains: Models, Methods, and Public Policy Implications, edited by T. Boone, V. Jayaraman, and R. Ganeshan, 73-96. New York: Springer.

Jacoby, W. 2010. 'Managing Globalization by Managing Central and Eastern Europe: The EU's Backyard As Threat and Opportunity.' Journal of European Public Policy 17 (3): 416-32.

Jensen, P. D. 2009. 'A Learning Perspective on the Offshoring of Advanced Services.' Journal of International Management 15 (2): 181-93.

Jones Lang LeSalle. 2010. 'Onshore, Nearshore, Offshore: Unsure? A 2010 Polish Perspective.' https://www.paih.gov.pl/files/?id_plik=12179

JP Weber/PAin. 2014. Investor's Guide - Poland: How to do Business. Warsaw: PAIiz.

Jürgens, U., and M. Krzywdzinski. 2009. 'Changing East-West Division of Labour in the European Automotive Industry.' European Urban and Regional Studies 16 (1): 27-42.

Juvonen, P. 2009. 'Evaluating the Driving Factors and the Suppressing 
Factors Related to Is Outsourcing in Four Finnish Information Systems Organizations.' In Information Systems Development, edited by C. Barry, M. Lang, W. Wojtkowski, K. Conboy, and G. Wojtkowski, 687-98. New York: Springer.

Kamann, D. J., and V. Van Nieulande. 2010. 'A Four-Filter Method for Outsourcing to Low-Cost Countries.' Journal of Supply Chain Management 46 (2): 64-79.

Kedziora, D., T. Karri, A. Kraslawski, and M. Halasa. 2017. 'Nearshore Service Transfers in the EU: Legal and Economic Issues.' Economics and Sociology 10 (1): 290-309.

Kedziora, D., E. Klamut, T. Karri, and A. Kraslawski. 2017. 'Higher Education Offshoring as an Innovative Response to Global Learning Challenges.' International Journal of Management, Knowledge and Learning 6 (2): 239-6o.

Kedziora, D., H. M. Kiviranta. 2018. 'Digital Sales Value Co-Creation with Robotic Process Automation (RPA) of the Finance and Accounting Industry in Northern and Central Europe.' Management 13 (2): 161-74. Kedziora, D., A. Kraslawski, and T. Kärri. 2016. 'Offshored Service Cost Model as a Key Post-Transition Challenge.' Journal of International Studies 3 (9): 229-40.

- 2017. 'Reengineering of Offshored I T Helpdesk Operational Model for Transitional Optimisation.' International Journal of Management and Decision Making 16 (1): 375-406.

Kedziora, D., W. Piotrowicz, K. Kolasinska-Morawska. 2018. 'Employee Development and Leadership Perception in the Polish Service Delivery Centres.' Foundations of Management 10 (1): 225-36.

Kern, T., and L. P. Willcocks. 2002. 'Exploring Relationship in Information Technology Outsourcing: The Interaction Approach.' European Journal of Information Systems 11 (1): 3-19.

Lacity, M. C., S. Khan, and A. Yan. 2010. 'A Review of the iт Outsourcing Empirical Literature and Future Research Directions.' Journal of Information Technology 25 (4): 395-433.

Lacity, M. C., S. A. Khan, and L. P. Willcocks. 2009. 'A Review of the IT Outsourcing Literature: Insights for Practice.' The Journal of Strategic Information Systems 18 (3): 130-46.

Lacity, M. C., S. Solomon, and A. Yan. 2011. 'Business Process Outsourcing Studies: A Critical Review and Research Directions.' Journal of Information Technology 26 (4): 221-58.

Liu, Y., Y. Luo, and T. Liu. 2009. 'Governing Buyer-Supplier Relationships through Transactional and Relational Mechanisms: Evidence from China.' Journal of Operations Management 27 (4): 294-309.

Loebbecke, C., and C. Huyskens. 2006. 'What Drives Netsourcing Deci- 
sions? An Empirical Analysis.' European Journal of Information Systems 15 (4): 415-23.

Manning, S. 2014. 'Mitigate, Tolerate or Relocate? Offshoring Challenges, Strategic Imperatives and Resource Constraints.' Journal of World Business 49 (4): 522-35.

Mareš, M. 2011. 'Terrorism-Free Zone in East Central Europe? Strategic Environment, Risk Tendencies, and Causes of Limited Terrorist Activities in the Visegrad Group Countries.' Terrorism and Political Violence 23 (2): 233-53.

Maskell, P., and A. Malmberg. 1999. 'The Competitiveness of Firms and Regions: "Ubiquitification" and the Importance of Localized Learning.' European Urban and Regional Studies 6 (1): 9-25.

Maskell, P., T. Pedersen, B. Preuss, and J. Dick-Nielsen. 2007. 'Learning Paths to Offshore Outsourcing: From Cost Reduction to Knowledge Seeking.' Industry and Innovation 14 (3): 239-57.

Medve-Bálint, G. 2014. 'The Role of the EU in Shaping FDI Flows to East Central Europe.' Journal of Common Market Studies 52 (1): 35-51.

McNulty, J. E., and J. T. Harper. 2012. 'Obstacles to Financial Development in Transition Economies: A Literature Survey.' Financial Markets, Institutions \& Instruments 21 (4): 203-40.

Micek, G. 2008. 'Exploring the Role of Sticky Places in Attracting the Software Industry to Poland.' Geographia Polonica 81 (2): 43-6o.

- 2015. 'FDI Trends in the Business Services Sector: The Case of Poland.' In Foreign Investment in Eastern and Southern Europe after 2008: Still a Lever of Growth? Edited by B. Galgóczi, J. Drahokoupil, and M. Bernaciak, 297-318. Brussels: European Trade Union Institute.

Micek, G., J. Działek, and J. Górecki. 2011. 'The Discourse and Realities of Offshore Business Services to Kraków.' European Planning Studies 19 (9): 1651-68.

Mihalache, M., and O. R. Mihalache. 2016. 'A Decisional Framework of Offshoring: Integrating Insights from 25 Years of Research to Provide Direction for Future.' Decision Sciences 47 (6): 1103-49.

Mihalache, O. R., J. J. J. P. Jansen, F. A. J. Van den Bosch, and H. W. Volberda. 2012. 'Offshoring and Firm Innovation: The Moderating Role of Top Management Team Attributes.' Strategic Management Journal 33 (1): 1480-98.

Myszkowska, M. 2014. 'The Scale and Characteristics of Services Offshoring in the Visegrád Countries.' Entrepreneurial Business and Economics Review 2 (3): 33-46.

Nachum, L., and S. Zaheer. 2005. 'The Persistence of Distance? The Impact of Technology on MNE Motivations for Foreign Investment.' Strategic Management Journal 26 (8): 747-67. 
OECD. 2012. PISA 2012 Results: What Students Know and Can Do. Paris: OECD.

- 2015. OECD Economic Surveys: Poland. Paris: OECD.

- 2016a. Education at a Glance: Country Note; Poland. Paris: oECD.

- 2016b. OECD Economic Surveys: Poland. Paris: OECD.

PAIiI Z. 2010. 'Largest Foreign Direct Investments in 2010.' https://www

.paih.gov.pl/20101220/largest_foreign_direct_investments_in_poland _2010

- 2014. RङD Sector in Poland. Warsaw: PAIiIz.

Piotrowicz, W. 2015a. 'Information Technology and Systems in the Visegrad Group of Countries.' Journal of Global Information Technology Management 18 (2): 77-93.

- 2015b. 'An Interview With Wiktor Doktór: Business Process Outsourcing in the Visegrád Group of Countries: Czech Republic, Hungary, Poland, and Slovakia.' Journal of Global Information Technology Management 18 (2): 146-52.

Prasad, S., and S. Babbar. 200o. 'International Operations Management Research: Discipline Note.' Journal of Operations Management 18 (3): 209-47.

Qu, W. G., W. Oh, and A. Pinsonneault. 2010. 'The Strategic Value of IT Insourcing: An IT-Enabled Business Process Perspective.' The Journal of Strategic Information Systems 19 (2): 96-108.

Rilla, N., and M. Squicciarini. 2011. 'R\&D (Re)location and Offshore Outsourcing: A Management Perspective.' International Journal of Management Reviews 13 (4): 393-413.

Roztocki, N., and H. R. Weistroffer. 20o8. 'Information Technology Investments in Emerging Economies.' Information Technology for Development 14 (1): 1-10.

—. 2015 'Information and Communication Technology in Transition Economies: An Assessment of Research Trends.' Information Technology for Development 21 (3): 330-64.

Sass, M., and M. Fifekova. 2011. 'Offshoring and Outsourcing Business Services to Central and Eastern Europe: Some Empirical and Conceptual Considerations.' European Planning Studies 19 (9): 1593-609.

Schwarz, C. 2014. 'Toward an Understanding of the Nature and Conceptualization of Outsourcing Success.' Information \& Management 51 (1): 152-64.

Soja, P., and P. Cunha. 2015. 'IC T in Transition Economies: Narrowing the Research Gap to Developed Countries.' Information Technology for Development 21 (3): 323-9.

Sudan, R., S. Ayers, and P. Dongier. 2010. The Global Opportunity in ITBased Services. Washington, DC: The World Bank. 
Stauss, B., and M. Jedrassczyk. 2008. 'Business Process Outsourcing (в Р о): Value Creation through External Service Providers.' Journal of Applied Management and Entrepreneurship 13 (3): 20-34.

Stubbs, W. 2017. 'Sustainable Entrepreneurship and B Corps.' Business Strategy and the Environment 26 (3): 331-44.

Tambe, P. B., and L. M. Hitt. 2010. 'How Offshoring Affects Iт Workers.' Communications of the ACM 53 (10): 62-70.

UNCTA D. 2005. World Investment Report: Transnational Corporations and the Internationalization of $R \& D$. New York: United Nations.

Vrhovec, S. L., M. Trkman, and A. Kumer. 2015. 'Outsourcing as an Economic Development Tool in Transition Economies: Scattered Global Software Development.' Information Technology for Development 21 (3): 445-59.

Walsham, G., and S. Sahay. 2006. 'Research on Information Systems in Developing Countries: Current Landscape and Future Prospects.' Information Technology for Development 12 (1): 7-24.

Wiener, M., B. Vogel, and M. Amberg. 2010. 'Information Systems Offshoring: A Literature Review and Analysis.' Information Systems 27 (25): 455-92.

Williamson, O. E. 1985. The Economic Institutions of Capitalism: Firms, Markets, Relational Contracting. New York, NY: Free Press. 



\section{Econometric Analysis of the Effect of Economic}

Globalization, Energy Intensity, Urbanization, Industrialization and Growth on $\mathrm{CO}_{2}$ Emissions of Bangladesh

Mowshumi Sharmin

Bangladesh Institute of Governance and Management, Bangladesh mowshumi.sharmin@bigm.edu.bd

Mohammad Tareque

Bangladesh Institute of Governance and Management, Bangladesh mohammad.tareque@bigm.edu.bd

This paper examines the effect of economic globalization, energy intensity, urbanization, industrialization and growth on per capita $\mathrm{CO}_{2}$ emissions of Bangladesh employing techniques of Johansen co-integration, Vector Error-Correction Models (vecm) and vec Granger Causality Tests. To analyse the impacts of innovations in all variables on $\mathrm{CO}_{2}$ emissions, this study additionally employs variance decomposition (VDC) for robust findings. The result of long run and causality test postulates that growth stimulates energy consumption and consequently causes $\mathrm{CO}_{2}$ emissions. VDC result posits that in the long run, energy intensity, urbanization, industrialization and growth contribute more than $60 \%$ of the $\mathrm{CO}_{2}$ emission in Bangladesh. On the other hand, effect of economic globalization becomes stronger in the long run but in explaining fluctuations in $\mathrm{CO}_{2}$ emissions it contributes only $9 \%$. To avoid adverse effect of growth implementations of energy conservation policies are needed.

Key Words: Johansen co-integration, globalization, $\mathrm{CO}_{2}$ emissions, urbanization, industrialization

JEL Classification: 044, Q20, Q43

https://doi.org/10.26493/1854-6935.16.335-354

\section{Introduction}

Since the last few decades of the preceding century there has been rising concern on the impact of economic growth spurring from energy consumption and its effect on environment. The synergy between the $\mathrm{CO}_{2}$ emissions, economic development and globalization is wide-ranging. United Nations Convention on Climate Change postulates that by 2030 seventy five percent population of this planet will live in urban areas. 
The Intergovernmental Panel on Climate Change (IP CC Report 2013) divulged that carbon dioxide absorption had increased by 40 percent since pre-industrial times, primarily from fossil fuel emissions and secondarily from net land use change emissions. The report included the global trends toward greater urbanization as one of the several important types of land use and land cover change. Besides, it brought to the fore that land use change had also contributed almost 30 percent of total anthropogenic $\mathrm{CO}_{2}$ emissions since 1850. The Paris Climate Conference agreement also declared limiting emissions following national level environment policies which augmented an increase in the study regarding carbon emission, energy consumption and environmental pollution. In this backdrop, the prime objective behind exploring this study in the context of Bangladesh is that this kind of nexus has got immense potential to play on contemporary disputes on environmental conservation and sustainable development.

Bangladesh is one of the fastest growing emerging economies in Asia; averaging around 7.1\% annual GDP growth and industrial sector is making the most impact on this projected growth (see https://www.bb.org.bd). According to Bangladesh Bureau of Statistics (see http://bbs.gov.bd) the contribution of industrial sector to the GDP is 33.71 percent that grew robustly by 11.1 percent in FY16, buoy by power, gas and water supply, and mining and quarrying subsectors. Available statistics further demonstrates that urban population of the country is $35.8 \%$ of total population (2017) and rate of urbanization is $3.19 \%$ (2015-2020 estimated). The rapid speed of urbanization and industrialization has led to serious environmental consequences for the developing economy like Bangladesh. Natural resource depletion due to urbanization, industrialization, energy consumption and growth and their subsequent pollution produce has elevated the spectre of environmental dilapidation threatening sustainable economic growth. A strong interactive connection between economic growth and energy supply and demand can be observed since Bangladesh's entrance to the global market. In any economy, sustainable economic growth could be achieved by sustainable environment development.

Climate change could spring from many environmental issues (i.e. anthropogenic pollutants emission from sulphur dioxide, oxides of nitrogen etc.), but this study focuses on $\mathrm{CO}_{2}$ emission related problems that spur global warming. The general assumption is that intense energy consumption by city residents causes more fossil fuel burn and therefore causes 
large-scale of $\mathrm{CO}_{2}$ emission. But the theories of ecological modernization and urban environmental transition clearly indicates that urbanization can have both positive and negative impacts on the environment despite the difficulties encountered in determining the net effect a priori. The compact city theory, on the other hand, emphasizes that urbanization improves the environmental quality. Be that as it may, since Bangladesh is still in the first stage of economic development, so it is highly likely that urbanization would lead more $\mathrm{CO}_{2}$ emission, like other countries at this stage (Sadorsky 2014, 147).

The government of Bangladesh initiated an environmental policy in 1992 to control environmental degradation with sustained level of economic growth. The main objective of the National Environmental Policy was to protect, conserve and restore environment. As stated earlier that grasping the relationship between energy consumption and $\mathrm{CO}_{2}$ emission is significant not only for resolving the energy sector crises, but also for long term sustainable development of the country. This paper intends to provide some policy options based on the study findings which relates to the country's national energy policy for sustainable development (Ministry of Power, Energy and Mineral Resources 2004). The policy postulates that energy should be for sustainable economic growth ensuring environmentally sound sustainable energy development program causing minimum damage to environment. This study has taken into account most of the sustainable development issues for instance, climate change, energy, urbanization (captures social development), environment with global concerns.

In this era of globalization, economies augment their interdependence through international cooperation. In order to reap the benefits of globalization, each economy needs to accelerate its growth to keep pace with global economy through trade, industrialization and social collaboration. Existing economic theories proclaim that trade between economies with different levels of environmental safeguard could lead pollution-intensive industry. Developing countries as they aspire for speedy growth have flexible environmental regulations compared to developed countries. Against this backdrop, the moot question is whether Bangladesh will be able to sustain economic growth using resources efficiently without ruining the environment?

In order to answer the question posed above this research have tied various issues like growth, energy intensity, urbanization, industrialization and economic globalization in a common thread and tries to find 
out the short and long-run relationships of energy intensity, urbanization, industrialization, per capita GDP growth (hereafter, growth) and economic globalization on $\mathrm{CO}_{2}$ emissions. Thus the study has attempted to examine the causal relationships among energy intensity, urbanization, industrialization, growth and economic globalization on $\mathrm{CO}_{2}$ emissions of Bangladesh as well.

One avenue of empirical research which remains unscathed for Bangladesh economy relates to the fact of possible asymmetries existing in the context of globalization, industrialization, energy and growth relationship. This study, probably for the first time contributes to the existing literature as it tries to see the effect of industrialization and economic globalization along with other variables on $\mathrm{CO}_{2}$ emissions. Most importantly no prior study has been conducted on this issue specifically in the context of Bangladesh. The results may vary from country to country as the nature and comparative significance of energy sources of each economy is unique. Besides, the technological advancement may permit economies to enhance the use of environment friendly energy options over the time.

In order to keep the tenor of the above mentioned discourses this study is organized as follows: Introduction is presented in the first section. The next section briefly reviews the empirical evidence from the literature. The third section describes objectives of the study, the fourth section examines data sources and time series properties, the fifth section represents econometric methodology. Empirical results are analysed in the sixth section. The final section draws conclusion and policy recommendations.

\section{Existing Empirical Evidence}

The literature on carbon emissions and economic growth is abundant and ample numbers of studies have attempted to analyse the link between energy consumption, growth and $\mathrm{CO}_{2}$ emissions that examine the causal relationship among these variables. The recent stream of research has emerged, which examines the long-run co-integrating relationship and short-run dynamics among $\mathrm{CO}_{2}$ emission, growth and energy consumption.

Stern (2000) investigated the relationship among income, energy use, labour, and capital stock in the Us for the period 1948-1994 applying co-integration and vector error correction modelling. Findings suggest that there is mutual causality between energy consumption and GDP in 
the Us. The study of Hossain (2011) included urbanization, $\mathrm{CO}_{2}$ emissions, GDP (economic growth), energy consumption and trade of nine newly industrialized countries (Brazil, China, India, Malaysia, Mexico, Philippines, South Africa, Thailand and Turkey). The result specifies that higher energy consumption is causing more $\mathrm{CO}_{2}$ emissions. But in respect of GDP, trade openness and urbanization the environmental quality are stable in the long-run. In their study of B RIC countries, Pao and Tsai (2010) found bidirectional causal relationship between pollutant emissions and energy consumption, and GDP and energy consumption in the long run but unidirectional causal relationship between energy consumption and GDP in the short run.

The study of Sharma (2011) found that urbanization has negative and significant impact on carbon emissions for a panel of 69 countries but this impact was considered insignificant in view of the size of the income-level group. Employing a STIRPAT model, Sadorsky (2014) examined the effect of urbanization on $\mathrm{CO}_{2}$ emissions in 7 emerging economies. Using ARDL model he illustrates that augment in affluence, population, or energy intensity raise $\mathrm{CO}_{2}$ emissions in the long-run. A study by Azam et al. (2015) on three ASEAN countries i.e. Indonesia, Malaysia, and Thailand spanning from 1980 to 2012 found that urbanization growth has significant positive effect on energy use for Thailand and Indonesia, while, population growth rate has significant positive impact on energy consumption in the case of Malaysia. The foregoing analysis reveals that urbanization growth may contribute to higher emissions, energy use through urbanization's links with industrialization process, where inhabitants move from agriculture sector to industry and services sectors. This transformation of people from rural to urban areas causes extensive energy use in many ways.

Further, the econometric estimation of Halicioglu (2009) and Zhang and Cheng (2009) includes trade, urbanization, and human development in order to avoid omitted variable bias. In the study of Zhang and Cheng (2009) the results show that neither carbon emissions nor energy consumption leads economic growth for China. York (2007) and Cole and Neumayer (2004) found a positive relationship between urbanization and $\mathrm{CO}_{2}$ Emissions for a panel of 86 countries but Chen, Jia, and Lau (2008) and Liddle (2004) found that urbanization and urban density helps to increase the efficiency of public infrastructure use lowering energy consumption and emissions. Soytaş, Sari, and Ewing (2007) examine the effect of energy consumption and output on carbon emissions in the United 
States. The findings suggest income does not Granger cause carbon emissions in the us in the long run, but energy use does. Hence, income growth by itself may not become a solution to environmental problems.

Employing the co-integration technique, Pao and $\mathrm{Fu}$ (2013) found unidirectional causal relationship between economic growth and energy consumption for Brazil from 1980 to 2010. Soheilakhoshnevis and Bahram (2014) examine the long and short run relation among carbon emissions, energy consumption, economic growth, urbanization, financial development and trade openness in Iran employing ARDL technique. Furthermore, Shahbaz and Lean (2012) incorporate the Vector Error Correction model and the findings holds the feedback hypothesis for Pakistan. Additionally, Shahbaz, Khanb, and Tahir (2013) examined the causal relationship between energy consumption and economic growth of China and finds energy consumption causes economic growth. The study of Shahbaz et al. (2013) supports the feedback hypothesis for Indonesia as well. Yang and Zhao (2014) used Granger causality tests and found that energy consumption causes carbon emissions and economic growth, but there is bidirectional causal link between $\mathrm{CO}_{2}$ emissions and economic growth.

Few studies investigated the relationship among energy or electricity consumption and economic growth in the context of Bangladesh. Using time series data of South Asia including Bangladesh from 1972 to 2004 and applying ARDL technique, Khan and Qayyum (2007) found, both in the long and short-run the causality running from energy consumption to GDP in all concerned economies. Similarly, Asaduzzaman and Billah (2008) found positive relationship between energy consumption and economic growth for Bangladesh using data spanning from 1994 to 2004 and reported that higher level of energy use led to higher level of growth. Taking time series data from 1971 to 2008, Ahamad and Islam (2011) examines the energy consumption-growth nexus of Bangladesh applying the Vector Error Correction Model and found a bidirectional relationship running from electricity consumption to economic growth in the long-run. Recently Azam and Khan (2015) using st IR PAT model for 4 South Asian countries i.e. Bangladesh, India, Pakistan, and Sri Lanka from 1982 to 2013 found that urbanization has negative impact on $\mathrm{CO}_{2}$ emission which leads to environmental improvement.

Above mentioned findings of different studies is a clear testimony that there exists relationship among economic growth, energy consumption and the other drivers of economic growth. Some observations deem eco- 
nomic growth as the prime mover of energy consumption. Others put emphasis on the significance of energy as an indispensable factor of production and consequently recommend that energy is necessary for economic growth. Some other analyses put forward that both energy consumption and economic growth affects each other. Finally, some postulates that there is no causal relationship between energy consumption and economic development.

To sum up from the above it can be concluded that available findings are not undisputed comparing their outcomes which direct to a conventional conclusion keeping it open to diverse rationalization. This study endeavours to examine the relationships among energy intensity, urbanization, industrialization, economic growth, economic globalization and $\mathrm{CO}_{2}$ emission in the context of Bangladesh. We expect findings will carry a significant reference for the government of Bangladesh as well as to other developing economies to formulate their long-term energy policies for environmental sustainability without endangering their economic development.

\section{Objectives}

The prime objective of this study is to empirically examine the impact of energy intensity, urbanization, industrialization, economic globalization and per capita GDP growth on per capita $\mathrm{CO}_{2}$ emissions of Bangladesh. The specific objectives are:

- To investigate the long-run and short-run relationships among energy intensity, urbanization, industrialization, economic globalization and per capita GDP growth on per capita $\mathrm{CO}_{2}$ emissions; and

- To look into the causal relationships among the variables.

\section{Data Sources and Time Series Properties}

\section{DATA DESCRIPTION}

This paper uses time series dataset of Bangladesh from 1980 to 2014 as the existing data period of World Development Indicator related to $\mathrm{CO}_{2}$ emission and energy intensity is from 1980 to 2014. Compared to other available sources, it is the more reliable and easily accessible data source; in addition our key variables are $\mathrm{CO}_{2}$ emission and Energy intensity. Annual data of all the variables except for economic globalization have been obtained from the World Development Indicators (see 
www.worldbank.org). Economic Globalization (EG) data have been collected from коғ. The коғ Index of Globalization (http://globalization .kof.ethz.ch) is a ranking of the most global countries based on three dimensions of globalization: economic globalization, social globalization and political globalization. The descriptions of variables with measurement are presented in the following paragraphs (all data are in the form of natural logarithm of the numbers hence their first differences approximate their growth rates):

- $\mathrm{CO}_{2}$ is per capita carbon emissions (metric tons per capita)

- Y indicates GDP per capita (constant 2010 US\$),

- EI signifies energy intensity (measured as energy consumption kg of oil equivalent per capita divided by GDP per capita),

- $\mathrm{U}$ denotes urbanization (urban population \% of total),

- I is industrialization (industry, value added as \% of GDP) and

- EG represents economic globalization.

Correlation matrix between variables of this study (table is not given to save space) show the highest $\mathrm{CO}_{2}$ emissions correlation (99\%) with urbanization followed by (97\%) with per capita GDP and followed by Economic globalization (94\%) and industrialization (93\%) respectively. $\mathrm{CO}_{2}$ emission correlates negatively with energy intensity but has positive correlation with per capita GDP growth, industrialization, urbanization and economic globalization.

\section{STATIONARY FEATURE OF THE DATA}

To observe some salient features of the data i.e. trend, structural breaks, seasonality and stationary quality, the graphical manifestation of the data taking natural log of both level and first difference data are used. A stationary time series of the graph always demonstrates a process of fluctuating around its mean whereas non-stationary series exhibits different mean in different periods (figures are not given to save space). From the graphs, it is evident that the variables are not stationary at level but after first differencing they become stationary and regarding the data point given the size of the observation there is no structural break. Later unit root test also confirm the same.

\section{Research Methodology}

The model specification to investigate the effect of economic globalization, energy intensity, growth, industrialization and urbanization on $\mathrm{CO}_{2}$ emissions of Bangladesh in the log-linear form is given below: 


$$
\operatorname{lncO}_{2}=\alpha+\beta_{1}(\operatorname{lnEI})+\beta_{2}(\ln E G)+\beta_{3}(\ln \mathrm{I})+\beta_{4}(\ln \mathrm{U})+\beta_{5}(\ln \mathrm{Y})+\mu_{t},
$$

where $\mathrm{CO}_{2}$ is the dependent variable and Energy Intensity (EI), Economic Globalization (EG), Industrialization (I), Urbanization (U) and Per Capita GDP Growth $(\mathrm{Y})$ are explanatory variables. Theoretical expectation of the model is $\beta_{1}>0, \beta_{2}>0, \beta_{3}>0, \beta_{4}>0$ and $\beta_{5}>0$.

Several steps are followed to estimate the link among the variables of this study. Firstly, Augmented Dickey-Fuller (ADF) (Dickey and Fuller 1979) unit root tests are carried out to test the stationarity of the series to get rid of spurious results. The ADF test has been carried out based on:

$$
\Delta y_{t}=\mu+\beta_{t}+\sigma y_{t-1}+\sum_{j=1}^{k} \alpha_{j} \Delta y_{t-j}+\varepsilon_{t},
$$

where $\Delta$ is the difference operator, $t$ is the time trend, $\varepsilon$ is the error term considered as a white noise error, $y_{t}$ is the series and $k$ is the number of lags. Secondly, after doing the ADF test, VAR lag order selection criteria are carried out to find out the number of lags selected by the criterion.

Thirdly, co-integration tests are performed based on ADF test results using Johansen multivariate co-integration techniques proposed by (Johansen 1988) and (Johansen and Juselius 1990) to investigate the existence of long-run relationships among the variables. Fourthly, as cointegration is confirmed among the variables, Vector Error Correction Model (VECM) is used to see both the short run and long-run effects. The VECM specifications are as under:

$$
\begin{aligned}
& \Delta \operatorname{lnco}_{2 t}=\alpha_{1}+\sum_{i=1}^{p} \beta_{11 i} \operatorname{lnco}_{2 t-1}+\sum_{i=1}^{p} \beta_{12 i} \Delta \operatorname{lnEI}_{t-1}+\sum_{i=1}^{p} \beta_{13 i} \Delta \operatorname{lnEG}_{t-1} \\
& +\sum_{i=1}^{p} \beta_{14 i} \Delta \ln _{t-1}+\sum_{i=1}^{p} \beta_{15 i} \Delta \ln _{t-1}+\sum_{i=1}^{p} \beta_{16 i} \Delta \ln _{t-1} \\
& +\sum_{i=1}^{p} \beta_{17 i} \operatorname{lnY}_{t-1}+\gamma \mathrm{ECT}_{t-1}+\varepsilon_{1 t} \\
& \Delta \operatorname{lnEI}_{t}=\alpha_{2}+\sum_{i=1}^{p} \beta_{21 i} \operatorname{lnco}_{2 t-1}+\sum_{i=1}^{p} \beta_{22 i} \Delta \operatorname{lnEI}_{t-1}+\sum_{i=1}^{p} \beta_{23 i} \Delta \operatorname{lnEG}_{t-1} \\
& +\sum_{i=1}^{p} \beta_{24 i} \Delta \operatorname{lnI}_{t-1}+\sum_{i=1}^{p} \beta_{25 i} \Delta \ln _{t-1}+\sum_{i=1}^{p} \beta_{26 i} \Delta \ln _{t-1} \\
& +\sum_{i=1}^{p} \beta_{27 i} \ln _{t-1}+\gamma \mathrm{ECT}_{t-1}+\varepsilon_{1 t}
\end{aligned}
$$




$$
\begin{aligned}
& \Delta \ln \mathrm{EG}_{t}=\alpha_{3}+\sum_{i=1}^{p} \beta_{31 i} \operatorname{lnCo}_{2} t-1+\sum_{i=1}^{p} \beta_{32 i} \Delta \ln \mathrm{II}_{t-1}+\sum_{i=1}^{p} \beta_{33 i} \Delta \ln \mathrm{EG}_{t-1} \\
& +\sum_{i=1}^{p} \beta_{34 i} \Delta \ln _{t-1}+\sum_{i=1}^{p} \beta_{35 i} \Delta \ln \mathrm{I}_{t-1}+\sum_{i=1}^{p} \beta_{36 i} \Delta \ln \mathrm{U}_{t-1} \\
& +\sum_{i=1}^{p} \beta_{37 i} \operatorname{lnY}_{t-1}+\gamma \mathrm{ECT}_{t-1}+\varepsilon_{1 t} \\
& \Delta \operatorname{lnI}_{t}=\alpha_{4}+\sum_{i=1}^{p} \beta_{41 i} \operatorname{lnco}_{2 t-1}+\sum_{i=1}^{p} \beta_{42 i} \Delta \operatorname{lnEI}_{t-1}+\sum_{i=1}^{p} \beta_{43 i} \Delta \ln G_{t-1} \\
& +\sum_{i=1}^{p} \beta_{44 i} \Delta \operatorname{lnI}_{t-1}+\sum_{i=1}^{p} \beta_{4{ }_{i}} \Delta \operatorname{lng}_{t-1}+\sum_{i=1}^{p} \beta_{46 i} \Delta \ln \mathrm{U}_{t-1} \\
& +\sum_{i=1}^{p} \beta_{47 i} \operatorname{lnY}_{t-1}+\gamma \mathrm{ECT}_{t-1}+\varepsilon_{1 t} \\
& \Delta \ln _{t}=\alpha_{5}+\sum_{i=1}^{p} \beta_{51 i} \operatorname{lnco}_{2 t-1}+\sum_{i=1}^{p} \beta_{52 i} \Delta \operatorname{lnEI}_{t-1}+\sum_{i=1}^{p} \beta_{53 i} \Delta \operatorname{lnEG}_{t-1} \\
& +\sum_{i=1}^{p} \beta_{54 i} \Delta \ln _{t-1}+\sum_{i=1}^{p} \beta_{55 i} \Delta \ln _{t-1}+\sum_{i=1}^{p} \beta_{56 i} \Delta \ln \mathrm{U}_{t-1} \\
& +\sum_{i=1}^{p} \beta_{57 i} \ln \mathrm{Y}_{t-1}+\gamma \mathrm{ECT}_{t-1}+\varepsilon_{1 t} \\
& \Delta \operatorname{lng}_{t}=\alpha_{6}+\sum_{i=1}^{p} \beta_{61 i} \operatorname{lnco}_{2 t-1}+\sum_{i=1}^{p} \beta_{62 i} \Delta \operatorname{lnEI}_{t-1}+\sum_{i=1}^{p} \beta_{63 i} \Delta \operatorname{lnEG}_{t-1} \\
& +\sum_{i=1}^{p} \beta_{64 i} \Delta \operatorname{lnI}_{t-1}+\sum_{i=1}^{p} \beta_{65 i} \Delta \operatorname{lng}_{t-1}+\sum_{i=1}^{p} \beta_{66 i} \Delta \ln \mathrm{U}_{t-1} \\
& +\sum_{i=1}^{p} \beta_{67 i} \operatorname{lnY}_{t-1}+\gamma \mathrm{ECT}_{t-1}+\varepsilon_{1 t}
\end{aligned}
$$

Here, $\mathrm{CO}_{2}, \mathrm{EI}, \mathrm{EG}, \mathrm{I}, \mathrm{U}$ and $\mathrm{Y}$ represents $\mathrm{CO}_{2}$ emissions, energy intensity, economic globalization, industrialization, urbanization and per capita GDP respectively. The symbol $\Delta$ signifies first differences and ECT indicates error correction terms and the coefficients of ECT determine the speeds of adjustment. The sign $\alpha_{1}$ to $\alpha_{6}$ are intercepts and $p$ refers to lag lengths. 
TABLE 1 ADF Unit Root Test

\begin{tabular}{|c|c|c|c|c|c|}
\hline \multirow[t]{2}{*}{ Variables } & \multicolumn{2}{|c|}{ Level } & \multicolumn{3}{|c|}{ 1st Difference } \\
\hline & (1) & (2) & (1) & (2) & (3) \\
\hline $\operatorname{lncO} \mathrm{O}_{2}$ & $\begin{array}{r}0.431838 \\
(0.9812)\end{array}$ & $\begin{array}{r}-1.893040 \\
(0.6340)\end{array}$ & $\begin{array}{r}-5.067460 \\
0.0003)\end{array}$ & $\begin{array}{r}-5.031633 \\
(0.0017)\end{array}$ & $\mathrm{I}(1)$ \\
\hline $\ln Y$ & $\begin{array}{r}7.138111 \\
(1.0000)\end{array}$ & $\begin{array}{r}0.747788 \\
(0.9995)\end{array}$ & $\begin{array}{r}-2.398586 \\
(0.1498)\end{array}$ & $\begin{array}{r}-7.422360 \\
(0.0000)\end{array}$ & $\mathrm{I}(1)$ \\
\hline $\ln E I$ & $\begin{array}{r}-0.587421 \\
(0.8605)\end{array}$ & $\begin{array}{r}-2.001101 \\
(0.5799)\end{array}$ & $\begin{array}{r}-7.325253 \\
(0.0000)\end{array}$ & $\begin{array}{r}-7.722324 \\
(0.0000)\end{array}$ & $\mathrm{I}(1)$ \\
\hline $\ln U$ & $\begin{array}{r}1.499809 \\
(0.9990)\end{array}$ & $\begin{array}{r}-0.379022 \\
(0.9843)\end{array}$ & $\begin{array}{r}-9.975108 \\
(0.0000)\end{array}$ & $\begin{array}{r}-9.633819 \\
(0.0000)\end{array}$ & $\mathrm{I}(1)$ \\
\hline $\ln I$ & $\begin{array}{r}-0.322522 \\
(0.9112)\end{array}$ & $\begin{array}{r}-2.459462 \\
(0.3448)\end{array}$ & $\begin{array}{r}-5.087616 \\
(0.0002)\end{array}$ & $\begin{array}{r}-5.000243 \\
(0.0016)\end{array}$ & $\mathrm{I}(1)$ \\
\hline $\ln E G$ & $\begin{array}{r}-1.340764 \\
(0.5991)\end{array}$ & $\begin{array}{r}-2.883777 \\
(0.1800)\end{array}$ & $\begin{array}{r}-5.522193 \\
(0.0001)\end{array}$ & $\begin{array}{r}-5.507705 \\
(0.0004)\end{array}$ & $\mathrm{I}(1)$ \\
\hline
\end{tabular}

Notes Column headings are as follows: (1) intercept, (2) intercept and trend, (3) order of integration. $p$-values in parenthesis.

In the fifth step, vec Granger Causality/Block Exogeneity Wald Tests are employed to see the causal relationship among the variables. Granger (1988) implies that if two time-series variables are co-integrated, then at least one-directional Granger causation exists. Granger causality test between the variables is examined using the equations (3) to (8).

Finally, innovation accounting methods for instance, forecast error variance decomposition (VDC) is carried out. Furthermore, to determine rigorousness and stability of the estimation Breusch-Godfrey Serial Correlation LM test, Heteroskedasticity test, Jarque-Bera Normality test, Stability Diagnostic tests and Inverse Roots of A R are carried out.

\section{Empirical Results and Discussion}

Augmented Dickey-Fuller (ADF) (Dickey and Fuller 1979) technique is used to validate the unit root property of the series since usually the time series data provide spurious results. The ADF test is carried out both at level and at first difference. Table 1 exhibits the results:

The results presented in the table above show that all the variables are found to be non-stationary at level but after first difference all the variables become stationary and found to be integrated in the same order. At 5 percent level of significance the order of integration is I(1) implying that all series has to be differenced once in order to be stationary. 
TABLE 2 VAR Lag Order Selection Criteria

\begin{tabular}{lrrrrrr}
\hline Lag & $\log \mathrm{L}$ & $\mathrm{LR}$ & $\mathrm{FPE}$ & $\mathrm{AIC}$ & $\mathrm{SC}$ & $\mathrm{HQ}$ \\
\hline $\mathrm{O}$ & 19.43317 & $\mathrm{NA}$ & 0.023817 & -0.902073 & -0.673052 & -0.826159 \\
1 & 51.26215 & $51.72210^{*}$ & 0.003475 & -2.828884 & $-2.554059^{*}$ & -2.737788 \\
2 & 52.66904 & 2.198268 & $0.003397^{*}$ & $-2.854315^{*}$ & -2.533685 & $-2.748036^{*}$ \\
3 & 53.03951 & 0.555693 & 0.003546 & -2.814969 & -2.448535 & -2.693507 \\
\hline
\end{tabular}

NOTES Endogenous variables: $\ln \mathrm{CO}_{2}, \ln \mathrm{I}$, $\ln \mathrm{U}, \ln \mathrm{l}, \ln \mathrm{Y}, \ln$ EG. LR: sequential modified LR test statistic (each test at 5\% level), FPE: final prediction error, AIC: Akaike information criterion, sc: Schwarz information criterion, HQ: Hannan-Quinn information criterion. ${ }^{\star}$ Indicates lag order selected by the criterion.

TABLE 3 Unrestricted Co-Integration Rank Test (Trace and Maximum Eigenvalue)

\begin{tabular}{|c|c|c|c|c|c|}
\hline \multicolumn{3}{|c|}{ Trace } & \multicolumn{3}{|c|}{ Maximum Eigenvalue } \\
\hline (1) & (2) & (3) & (1) & (2) & (3) \\
\hline None $^{*}$ & 199.0195 & 0.0000 & None $^{*}$ & 96.20702 & 0.0000 \\
\hline At most $1^{*}$ & 102.8124 & 0.0000 & At most $1^{\star}$ & 38.60867 & 0.0126 \\
\hline At most $2^{*}$ & 64.20378 & 0.0007 & At most $2^{*}$ & 28.07790 & 0.0432 \\
\hline At most $3^{*}$ & 36.12588 & 0.0082 & At most 3 & 19.94793 & 0.0725 \\
\hline At most $4^{*}$ & 16.17795 & 0.0394 & At most $4^{*}$ & 16.10970 & 0.0253 \\
\hline At most 5 & 0.068252 & 0.7939 & At most 5 & 0.068252 & 0.7939 \\
\hline
\end{tabular}

NOTES Column headings are as follows: (1) hypothesized number of $\mathrm{CE}(\mathrm{s}),(2)$ statistic, (3) probability. ${ }^{\star}$ Denotes rejection of the hypothesis at the 0.05 level.

The first step in the construction of a VAR model is to determine the appropriate lag length using multivariate information criterion. Table 2 summarizes the results of VAR lag order selection.

Table 2 shows that most of the criteria chooses lag 2 , hence it was incorporated throughout this study as selected by FPE, AIC and HQ.

The results of co-integration test of the pertinent variables are displayed in table 3 .

Johansen Co-integration Trace statistics test results identifies five cointegrating equations and maximum Eigen value results show three cointegrating equations at $5 \%$ levels of significance. As a result, the null hypothesis of no co-integration is rejected. This indicates that there have indeed long-run co-integrations in the model. The co-integration results also indicate the existence of error correction term in the model. For good measure, the long-run co-integration should be checked. Sign is reversed in the long-run in the normalization process. The significant pos- 
itive relationship also implies there is truly long-run relationship among the variables and VECM long-run equation also gives the same result.

As there is co-integration VECM needs to be tested to see the short as well as long-run dynamics of the co-integrated series. The error correction model shows the speed of adjustments to reach equilibrium. The term error-correction, relates to the fact that last period deviation from long-run equilibrium influences the short-run dynamics of the dependent variable.

Conventional VЕСм for co-integrated series is given below:

$$
\Delta y_{t}=\beta_{\circ}+\sum_{i=1}^{n} \beta_{i} \Delta y_{t-1}+\sum_{i=\mathrm{o}}^{n} \delta \Delta x_{t-1}+\varphi z_{t-1}+\mu_{t} .
$$

Results of VЕСм long-run and short-run are demonstrated in table 4. Estimated VECM with $\mathrm{CO}_{2}$ as target variable:

$$
\begin{aligned}
\Delta \operatorname{lnco}_{2 t}= & -1.69 e c t_{t-1}+0.65 \operatorname{lnco}_{2 t-1}+0.44 \operatorname{lnco}_{2} t-2-1.93 \operatorname{lnEI}_{t-1} \\
& -0.87 \operatorname{lnEI}_{t-2}+3.21 \ln _{t-1}-2.09 \ln _{t-2}-0.89 \operatorname{lnI}_{t-1} \\
& -0.04 \operatorname{lnI}_{t-2}-2.61 \operatorname{lnY}_{t-1}+0.17 \operatorname{lng}_{t-1}+0.15 \operatorname{lnEG}_{t-1} \\
& +0.08 \operatorname{lnEG} t_{t-2}+0.029
\end{aligned}
$$

where ect $t_{t-1}=\varphi=1.69$ and $\beta_{\circ}=0.029 . \varphi$ is the speed of adjustment towards long-run equilibrium which is significant and negative. The economic interpretation is that as being negative it implies that if there is a departure in one direction the corrections will have to pull back to the other direction to ensure the equilibrium. $\mathrm{VECM}$ with $\mathrm{CO}_{2}$ as target variable shows about $169 \%$ of the departure in the long run is corrected each period. As the coefficient is negative and significant it indicates the process will converge in the long run. It can also be said that depending on the speed of adjustment the explanatory variables granger causes the dependent variables.

Long-run model is given below:

$$
\begin{aligned}
& e c t_{t-1}=1.0000 \operatorname{lnCO}_{2 t-1}-1.51 \operatorname{lnEI} I_{t-1}-1.56 \operatorname{lnU}_{t-1}-0.10 \operatorname{lnI}_{t-1} \\
& -0.69 \operatorname{lny}_{t-1}-0.09 \operatorname{lnEG}_{t-1}+9.517 \text {. }
\end{aligned}
$$

The outcome of the normalized co-integration coefficients of the VECM long-run model indicates energy intensity, urbanization, industrialization, economic globalization and per capita GDP growth have significant positive relationship with per capita $\mathrm{CO}_{2}$ emissions. In the short-run urbanization, growth and economic globalization is positively 
TABLE 4 VECM Long-Run and Short-Run Output

\begin{tabular}{|c|c|c|c|c|}
\hline & Variables & Coefficient & Std. error & $t$-statistics \\
\hline \multirow[t]{7}{*}{ Long-run } & $\operatorname{lnCO}(-1)$ & 1.000000 & & \\
\hline & $\ln E I(-1)$ & -1.515083 & 0.08452 & -17.9262 \\
\hline & $\ln U(-1)$ & -1.566547 & 0.06361 & -24.6291 \\
\hline & $\ln I(-1)$ & -0.105926 & 0.06682 & -1.58534 \\
\hline & $\ln Y(-1)$ & -0.697303 & 0.05307 & -13.1403 \\
\hline & $\ln E G(-1)$ & -0.091785 & 0.03117 & -2.94477 \\
\hline & $\mathrm{C}$ & 9.517586 & & \\
\hline \multirow[t]{14}{*}{ Short-run } & CointEq1 & -1.694896 & 0.48025 & -3.52916 \\
\hline & $\mathrm{D}\left(\operatorname{lnc} \mathrm{O}_{2}(-1)\right)$ & 0.659612 & 0.27361 & 2.41074 \\
\hline & $\mathrm{D}\left(\operatorname{lnCO}_{2}(-2)\right)$ & 0.445900 & 0.24387 & 1.82843 \\
\hline & $\mathrm{D}(\ln \mathrm{I}(-1))$ & -1.932464 & 0.55170 & -3.50272 \\
\hline & $\mathrm{D}(\ln \mathrm{I}(-2))$ & -0.872762 & 0.50944 & -1.71318 \\
\hline & $\mathrm{D}(\ln \mathrm{U}(-1))$ & 3.219596 & 2.39173 & 1.34614 \\
\hline & $\mathrm{D}(\ln \mathrm{U}(-2))$ & -2.098407 & 1.40470 & -1.49384 \\
\hline & $\mathrm{D}(\ln \mathrm{I}(-1))$ & -0.894141 & 0.34951 & -2.55827 \\
\hline & $\mathrm{D}(\ln \mathrm{I}(-2))$ & -0.048883 & 0.38139 & -0.12817 \\
\hline & $\mathrm{D}(\ln \mathrm{Y}(-1))$ & -2.616522 & 0.86134 & -3.03772 \\
\hline & $\mathrm{D}(\ln \mathrm{Y}(-2))$ & 0.179221 & 0.80085 & 0.22379 \\
\hline & $\mathrm{D}(\ln \mathrm{G}(-1))$ & 0.150063 & 0.11367 & 1.32017 \\
\hline & $\mathrm{D}(\ln \mathrm{G}(-2))$ & 0.084669 & 0.11494 & 0.73662 \\
\hline & $\mathrm{C}$ & 0.029967 & 0.04132 & 0.72522 \\
\hline
\end{tabular}

related whereas, energy intensity and industrialization is negatively related with per capita $\mathrm{CO}_{2}$ emissions.

To analyse the short-run and long-run causal relationship, Granger Causality in the VЕCM framework is estimated and table 5 illustrates the outcomes of causality test based on VECM framework. Significance at $10 \%$ level is also considered for causality test.

The existence of co-integration among the series implies that causality must be present at least in one direction. The result of the shortrun causality shows energy intensity, industrialization, has unidirectional causal relationship; whereas per capita GDP has bidirectional causal relationship with $\mathrm{CO}_{2}$ emission. The unidirectional causal flow from energy intensity to $\mathrm{CO}_{2}$ emission, industrialization to $\mathrm{CO}_{2}$ emission suggests en- 


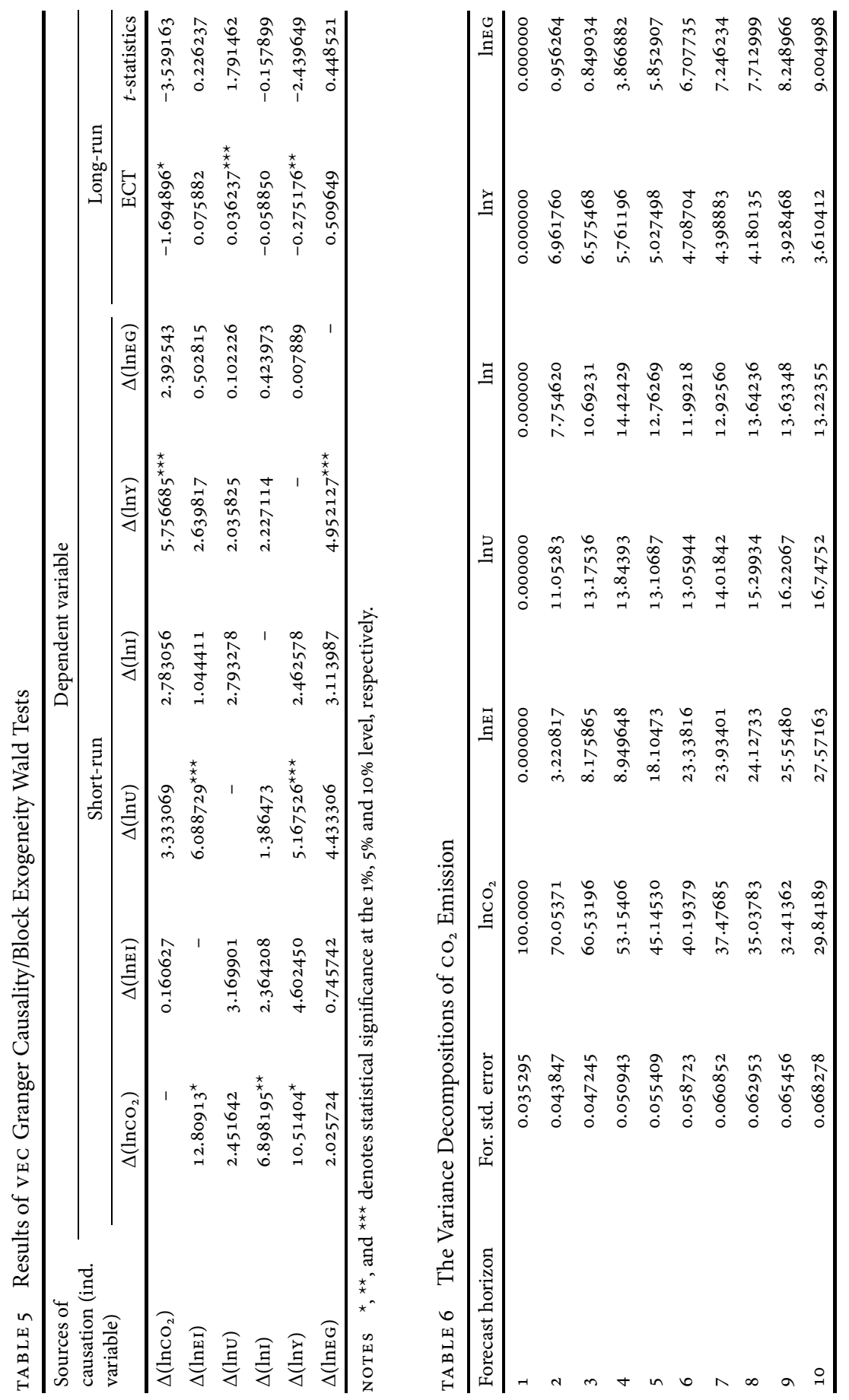


ergy intensity and industrialization lead to $\mathrm{CO}_{2}$ emission. The long-run causality on the other hand is supported by the lagged error correction term which is negative and statistically significant in per capita $\mathrm{CO}_{2}$ emission $\left[\Delta\left(\operatorname{ln\mathrm {CO}_{2})}\right)\right.$, and per capita GDP $[\Delta(\ln \mathrm{Y})]$ equation. This result implies that economic growth stimulate energy consumption and consequently causes $\mathrm{CO}_{2}$ emissions for Bangladesh.

To analyse the impacts of innovations in all variables on $\mathrm{CO}_{2}$ emissions, this study employs variance decomposition (VDC) to get some useful insights about the short run. Variance decompositions trace out the proportion of the movements in the dependent variables that are due to their own shocks versus shocks to the other variables (Brooks 2014, 342343 ). The variance decomposition is useful in evaluating how shocks reverberate through a system due to external shocks to each economic variable showing relative importance. Forecast from error variance decompositions helps to determine the proportion of variation of the dependent variable explained by each of the independent variables in the same VAR system. The variance decompositions are summarized in table 6 .

The forecast horizon is yearly in the table 6 . The influence on past $\mathrm{CO}_{2}$ emission shocks dominates in the short-run but eventually becomes less dominant in the long-run. In the long-run energy intensity, urbanization, industrialization and growth contribute more than $60 \%$ of the $\mathrm{CO}_{2}$ emission in Bangladesh. Economic globalization becomes stronger in the long-run but in explaining fluctuations in $\mathrm{CO}_{2}$ emissions it contributes only $9 \%$.

Finally, in order to verify rigorousness of the models, Breusch-Godfrey Serial Correlation LM test, Heteroskedasticity test, Jarque-Bera Normality test, Stability Diagnostic tests (CUSUm and Cusum of Squares) and Inverse Roots of A R are carried out (table 7). From the diagnostic tests no anomalies are found. Residuals are normally distributed; there is no evidence of serial correlation and the model is dynamically stable.

\section{Conclusion and Policy Recommendations}

This paper empirically examines the relationships among $\mathrm{CO}_{2}$ emissions, energy intensity, urbanization, industrialization, economic globalization and growth in a multivariate setting. Findings postulates economic globalization, industrialization, urbanization, growth and energy intensity causes $\mathrm{CO}_{2}$ emissions resulting in global warming and consequently climate change. Furthermore, it is also a widely accepted fact that energy intensity, urbanization, industrialization, economic globalization and 
TABLE 7 Diagnostic Tests

\begin{tabular}{lll}
\hline Breusch-Godfrey Serial Correlation LM Test & F-statistic & 0.3339 \\
& Prob. $F(2,16)$ & 0.7210 \\
& Prob. Chi-Square(2) & 0.5267 \\
\hline Heteroskedasticity Test: Breusch-Pagan-Godfrey & Prob. F(18,13) & 0.8360 \\
& Prob. Chi-Square(18) & 0.6851 \\
& Prob. Chi-Square(18) & 0.9998 \\
\hline Jarque-Bera Normality Test & Jarque-Berra & 3.0077 \\
\hline Cusum and CUSUM of Squares Test & Prob. & 0.2222 \\
\hline Inverse Roots of A R & Stable & \\
\hline
\end{tabular}

growth are the principal forces driving the increase in energy demand; this increase in energy demand has profound effect on growth of $\mathrm{CO}_{2}$ emission leading to global warming. Findings of the study also confirm the same result therefore it is assumed that in the long run, energy intensity, urbanization, industrialization and growth contribute more than $60 \%$ of the $\mathrm{CO}_{2}$ emission in Bangladesh. Besides, causality test result postulates energy intensity, urbanization, globalization and growth are raison dêtre for $\mathrm{CO}_{2}$ emission. Therefore, this study opens up new insights for policy makers to formulate a comprehensive economic, financial and trade policy for continuation of growth, industrialization and urbanization by improving the environment quality. As a result, there is relatively more scope for energy conservation measures as a feasible policy for Bangladesh.

To rise above unpleasant situation of the contemporary debate of global warming and climate change, the government of Bangladesh needs to be cautious in formulating its national energy development policies, emphasizing the environment and the sustainability of energy resources. For optimal utilization of energy and to lessen $\mathrm{CO}_{2}$ emissions the country could do the following. The country has many options for energy policy reform for a sustainable energy use. It is imperative to comprehend the vast human and economic potential of this country with a more balanced concern of political and economic criteria as most of the eye-catching energy options are the cause of higher carbon emissions. Hence, the composition of energy use and technological innovation should be carefully chosen for preservation of environment. 
Moreover, in recent past there was a global tendency of depending more on the use of fossil fuels and non-renewable energy sources causing $\mathrm{CO}_{2}$ emissions. In this backdrop, to ensure the accessibility of green and affordable energy sources has been deeply acknowledged globally keeping energy as the seventh Sustainable Development Goal (SDG) of the United Nations. Thus, use of cleaner energy sources i.e. solar, water, biogas, tidal and wave power and nuclear energy instead of fossil fuels could help decreasing $\mathrm{CO}_{2}$ emissions but further research on viable composition of energy sources in the country context is needed for efficient energy use. In particular, the country could extend bio-energy usage practice for as a cleaner energy option, which can augment energy supply and reduce the trouble of waste disposal and solid waste management.

Sustainable, clean and affordable energy as a part of the SDGS, the country might preferably consider viable energy options that will contribute not only to its macroeconomic indicators but also establish harmony with the ecosystem reducing $\mathrm{CO}_{2}$ emissions consequently global warming. Emerging economies like Bangladesh are on the trajectory of increasing growth. Hence, for energy efficiency, pricing on polluters could help maintaining equilibrium both in growth and environmental preservation. Finally, to facilitate the transition towards cleaner options, government's firm intervention is needed to finance the projects and the development of the country's energy infrastructures. Encouragement of urbanization with decentralization of urban population with low-carbon urban infrastructure and transportation system is desirable to reduce $\mathrm{CO}_{2}$ emissions. Economic growth of the country could be accelerated through globalization and proper utilization of global technological advancement and innovation in energy sector for preserving the environment.

\section{References}

Ahamad, M. G., and A. K. M. N. Islam. 2011. 'Electricity Consumption and Economic Growth Nexus in Bangladesh: Revisited Evidences.' Energy Policy 39:6145-50.

Asaduzzaman, M., and A. H. M. Billah. 2008. 'Energy for Future Bangladesh.' In Emerging Issues in Bangladesh Economy: A Review of Bangladesh's Development 2005-06, 361-92. Dhaka: Centre for Policy Dialogue.

Azam, M., and A. Q. Khan. 2015. 'Urbanization and Environmental Degradation: Evidence from Four SA A RC Countries-Bangladesh, India, Pakistan, and Sri Lanka.' Environmental Progress \& Sustainable Energy $35: 823-832$. 
Azam, M., A. Q. Khan, B. Bakhtyar and C. Emirullah. 2015. 'The Causal Relationship between Energy-Consumption and Economic Growth in the ASEAN-5 Countries.' Renewable and Sustainable Energy Reviews 47:732-45.

Brooks, C. 2014. Introductory Econometrics for Finance. Cambridge: Cambridge University Press.

Chen, H., B. Jia, and S. S. Y. Lau. 2008. 'Sustainable Urban Form for Chinese Compact Cities: Challenges of a Rapid Urbanized Economy'. Habitat International 32:28-40.

Cole, M. A., and E. Neumayer. 2004. 'Examining the Impact of Demographic Factors on Air Pollution.' Population and Environment 26 (1): 5-21.

Dickey, D., and W. Fuller. 1979. 'Distribution of Estimation for Autoregressive Time Series with a Unit Root.' Journal of American Statistical Association 74 (366): 427-31.

Granger, C. W. J. 1988. 'Some Recent Developments in a Concept of Causality.' Journal of Econometrics 39:199-211.

Halicioglu, F. 2009. 'An Econometric Study of $\mathrm{CO}_{2}$ Emissions, Energy Consumption, Income and Foreign Trade in Turkey.' Energy Policy 37:115664.

Hossain, M. S. 2011. 'Panel Estimation for $\mathrm{CO}_{2}$ Emissions, Energy Consumption, Economic Growth, Trade Openness and Urbanization of Newly Industrialized Countries.' Energy Policy 39:6991-9.

IP CC. 2013. Climate Change 2013: The Physical Science Basis. Cambridge: Cambridge University Press.

Johansen, S. 1988. 'Statistical Analysis of Cointegrating Vectors.' Journal of Economic Dynamics and Control 12:231-54.

Johansen, S., and K. Juselius. 1990. 'Maximum Likelihood Estimation and Inference on Cointegration with Applications to the Demand for Money. Oxford Bulletin of Economics and Statistics 52: 169-210.

Khan, A. M., and A. Qayyum. 2007. 'Dynamic Modelling of Energy and Growth in South Asia.' The Pakistan Development Review 46:481-98.

Liddle, B. 2004. 'Demographic Dynamics and Per Capita Environmental Impact: Using Panel Regressions and Household Decompositions to Examine Population and Transport.' Population and Environment 26:23-39.

Ministry of Power, Energy and Mineral Resources. 2004. 'National Energy Policy.' http://www.asialeds.org/sites/default/files/resource/file/NEP _2004_fulldoc.pdf

Pao, H. T., and H. C. Fu. 2013. 'Renewable Energy, Non-Renewable Energy and Economic Growth in Brazil.' Renewable and Sustainable Energy Reviews 25:381-92. 
Pao, H.-T., and C.-M. Tsai. 2010. ' $\mathrm{CO}_{2}$ Emissions, Energy Consumption and Economic Growth in B RIC Countries.' Energy Policy 38:7850-60.

Sadorsky, P. 2014. 'The Effect of Urbanization on $\mathrm{CO}_{2}$ Emissions in Emerging Economies.' Energy Economics 41:147-53.

Shahbaz, M., and H. H. Lean. 2012. 'The Dynamics of Electricity Consumption and Economic Growth: A Revisit Study of Their Causality in Pakistan.' Energy 39:146-53.

Shahbaz, M., S. Khanb, and M. I. Tahir. 2013. 'The Dynamic Links between Energy Consumption, Economic Growth, Financial Development and Trade in China: Fresh Evidence from Multivariate Framework Analysis.' Energy Economics 40:8-21.

Shahbaz, M., I. Ozturk, T. Afza, and A. Ali. 2013. 'Revisiting the Environmental Kuznets Curve in a Global Economy'. Renewable and Sustainable Energy Reviews 25:494-502.

Sharma, S. S. 2011. 'Determinants of Carbon Dioxide Emissions: Empirical Evidence from 69 Countries.' Applied Energy 88:376-82.

Soheilakhoshnevis, Y., and S. Bahram. 2014. 'The Econometric Model for $\mathrm{CO}_{2}$ Emissions, Energy Consumption, Economic Growth, Foreign Trade, Financial Development and Urbanization of Iran.' Journal of Environmental Research and Development 8 (3A): 828-40.

Soytas, U., R. Sari, and B. T. Ewing. 2007. 'Energy Consumption, Income, and Carbon Emissions in the United States.' Ecological Economics 62:482-9.

Stern, D. I. 2000. 'A Multivariate Cointegration Analysis of the Role of Energy in the us Macroeconomy'. Energy Economics 22:267-83.

Yang, Z., and Y. Zhao. 2014. 'Energy Consumption, Carbon Emissions, and Economic Growth in India: Evidence from Directed Acyclic Graphs' Economic Modelling 38:533-40.

York, R. 2007. 'Demographic Trends and Energy Consumption in European Union Nations, 1960-2025'. Social Science Research 36(3): 855-72.

Zhang, X. P., and X. M. Cheng. 2009. 'Energy Consumption, Carbon Emissions, and Economic Growth in China.' Ecological Economics 68:270612. 


\title{
Threshold Effect Analysis of the Relationship between Environmental Responsibility and Financial Performance
}

\author{
Thomas Adomah Worae \\ University of Limpopo, South Africa \\ broyaw65@gmail.com \\ Collins C. Ngwakwe \\ University of Limpopo, South Africa \\ ccngwakwe@ul.ac.za \\ Cosmas C. Ambe \\ University of Limpopo, South Africa \\ ccambe@hotmail.com
}

The paper examines environmental responsibility threshold effect on the financial performance of JSE SRI's firms for the period 2008-2014. Employing bootstrap dynamic panel threshold estimations, the paper confirms the existence of triple threshold in all the regression relationship. Furthermore, the study established a nonlinear (inverted U-shape) association between environmental initiative, measured by energy usage intensity and return on sale, and a linear (inverse U-shape) relationship between carbon input intensity and market value of equity deflated by sale. We also found that return on sale decreases by -0.08868 when environmental responsibility, measured by energy usage intensity ratio exceeds 0.00093 . The results however showed that an increase in energy usage intensity ratio at any point increases equity returns.

Key Words: emissions intensity, energy usage intensity, financial performance, threshold effect, South Africa JEL Classification: Q5, Q56 https://doi.org/10.26493/1854-6935.16.355-377

\section{Introduction}

Since their seminal presentations on capital structure effect on firms' financial value (Miller and Modigliani 1958; 1963) a great deal of time has been devoted to studying factors influencing financial value of firms from shareholder perspective (Margaritis and Psillaki 2010; Ebaid 2009). More recently researchers in the subject area have examined financial implica- 
tion of environmental responsibility amidst global warming and fossilenergy depletion.

Capital markets and rating agencies have therefore recognised that carbon emission possesses current and future risks to corporate valuation and competitive advantage (Barley 2009).

The claims suggest that corporate environmental performance is critical in the determination of risks profile, potential liabilities and long-term valuation. Notwithstanding, as to whether there exist a linkage between corporate 'environmental pro-activeness' and its 'bottom line' becomes an important question. This is because there is a belief among some researchers that ethics has no place in business, and that businesses only need to appear ethical in the quest to achieving corporate objectives and preserving their legitimacy (Wagner et al. 2002; Friedman 1970).

A research question worth asking is that, is there not a 'tipping point' of firms' 'environmental responsibility' beyond which corporate financial performance retards or improves significantly? This study focused on providing answers to the question of environmental responsibility 'tipping point' beyond which financial performance retards. The paper is meant to promote internal corporate carbon policy, through the provision of an integrated guide to improve managerial decisions in creating a balance between fossil energy usage, emissions reduction and financial performance in a more sustainable manner. We extended sustainability accounting research by applying bootstrap methodology and dynamic panel threshold techniques, using data from JSE's SRI manufacturing and mining firms for a period 2008-2014.

We confirmed the existence of triple threshold in the regression relationship, and lack of linear relationship between the intensity of energy usage and return on sale, but a linear (inverse u-shape) relationship between the intensity of energy usage and equity market value deflated by sale. It was again found that return on sale decreases by -0.08868 when environmental responsibility, measured by energy usage intensity ratio exceeds 0.00093 . On the contrary, increase in energy usage intensity ratio at all levels increase equity returns.

\section{Literature}

Sustainability accounting research in the past few decades has examined environmental responsibility effect on firm financial performance, and has thus far provided mixed and conflicting findings. For example, Orlitzky (2001) asserted that firm's that have exhibited higher social respon- 
sibility experience lower financial risks and concluded that 'social responsibility' and 'financial risk' appears to be one of 'reciprocal causality'.

Makni, Francoeur, and Bellavance (2009) argued that there exist no significant relationships between corporate social responsibility and financial performance except for market returns. Clarkson, Overell, and Chapple (2011) studied the impact of environmental approaches on financial performance, and found a causal relationship between environmental performance and financial resources and management capability.

Salama (2005) examined effects of 'sustainability performance' on financial performance of British companies, applying median regression, and found stronger relationship between factors when outliers and unobserved omitted variable are accounted for.

Qi et al. (2014) examined 'direct effect' of industrial sustainability pro-activeness on financial performance and 'indirect effects' of 'industrial munificence and resource slack' on environmental and financial performance link, and demonstrated that improvement in corporate 'industrial-level environmental performance' significantly influences corporate economic performance, with 'resource slack' significantly reflecting environmental and financial performance link. Nakao et al. (2007) cited that corporate sustainability performance positively affect financial performance and vice versa. In another related research by Gallego-Alvarez, Segura, and Martínez-Ferrero (2014; the effect of carbon emission variations on firm performance was evaluated after considering extraneous variables such as size, legal, growth; results indicated that improved financial performance is related to firm's carbon reduction.

Horvathova (2012) found a negative effect of environmental performance on financial performance if environmental performance is lagged by 1 year, but a positive effect if environmental performance is 2 years lag. Ki-Hoon, Byung, and Keun-Hyo (2015) demonstrated that carbon emissions decreases 'firm value.' Examining the effect of chemical emissions measured by 'aggregated toxic risk' on 'sale' and 'return on asset,' Fujii et al. (2012) found a significant relationship between firm's sustainability improvement and return on asset.

Nishitani et al. (2011) assessed 'emissions reduction' effect on corporate financial performance in Japan, and found that companies that reduced 'pollution emissions' increased their financial performance through increase in demand for the firms' products. Lioui and Sharma (2012) examined effect of social responsibility, measured by 'strengths and concerns' on financial performance, measured by return on asset and Tobin's q, and 
found that there exist a negative effect of 'strengths and concerns' on return on asset and Tobin's q. After accounting for the 'interaction' between 'environmental effort and research' the paper demonstrated that the result was no different.

On how 'environmental responsibility engagement' affects corporate financial performance, Wahba (2008), Wingard and Vorster (2001), Sen, Roy, and Pal (2015), and Sambasivan, Bah, and Jo-Ann (2012) showed that there exist a positive association between 'environmental engagements' with financial performance. After controlling for 'omitted variable bias', Muhammad et al. (2015) also found a positive association between environmental initiative and financial performance.

On the contrary, Gonzalez-Benito and Gonzalez-Benito (2005) demonstrated that certain 'environmental engagement types' produce negative effects on corporate financial performance. Chien and Peng (2011) showed that firms that invest more in 'pollution prevention' financially perform better compared with counterparts who are more engaged with corrective measures after pollution has occurred.

Exploring how 'eco-innovation' impacts 'accounting-based' measures, Przychodzen and Przychodzen (2014) showed that 'eco-innovators' generally enhance 'return on asset,' equity returns, but lowers 'earnings retention.' On how 'sustainability pro-activeness' improves firms' return on sale, Telle (2006) showed that there exist a positive relationship between 'sustainability performance' and return on sale. When the paper controls for firms' 'specific effect', the results showed an insignificant relationship between the factors prompting a conclusion that an 'estimated positive effect' could have been due to 'omitted variable bias.'

On how 'operations strategy' affect return on asset, return on equity and earnings per share, Klingenberg et al. (2013) cited that there exists no consistent relationship between return on asset, return on equity and earnings per share and 'operations strategy.'

An important research question worth asking is, is there not a 'tipping point' in firms' environmental responsibility beyond which financial performance retards or improves significantly? We therefore hypotheses as:

Ho There is no environmental responsibility threshold effect on financial performance of JSE'S SRI manufacturing and mining firms.

\section{Methods and Materials}

This paper examined environmental responsibility threshold effect on the financial performance of JSE'S SRI manufacturing and mining firms for 
the period 2008-2014. Hansen (1999) argued that in order to confirm the existence of threshold effect, it is vital to analyse the threshold significance. Hansen (1999) therefore applied fixed effect for analysing short time dimension and larger cross sectional data.

On the contrary, Chudik et al. (2015) applied panel with large 'cross sectional dimension' and 'time dimension.' Dang, Kim, and Shin (2012) argued that Generalised Method of Moments in short dynamic panel analysis. Seo and Shin (2014) however applied dynamic threshold estimation and presumed 'slope homogeneity' using 'instruments' to cater for 'endogeneity' by first-differencing.

We applied bootstrap methodology and dynamic panel threshold approach in the attempt to determining statistical significance of 'environmental responsibility threshold effect' on the financial performance of JSE'S SRI firms. And we specified our dynamic threshold models following Seo and Shin (2014) as:

$$
\begin{aligned}
y_{i t} & =\left(1, x_{i t}^{\prime}\right) \Phi_{1} 1\left(q_{i t} \leq \gamma\right)+\left(1, x_{i t}^{\prime}\right) \Phi_{2} 1\left(q_{i t}>\gamma\right)+\varepsilon_{i t}, i,=1, \ldots, n ; \\
t & =1, \ldots, T,
\end{aligned}
$$

where $\varepsilon_{i t}$ is the regression error, consisting of the error components:

$$
\varepsilon_{i t}=a_{i}+v_{i t},
$$

where $a_{i}$ is the 'individual and unbiased fixed effect' and $v_{i t}$ is a 'random disturbance.' $v_{i t}$ is the 'martingale difference.'

Nickell (1981) cited 'downward biasness' of the linear dynamic panels' fixed effect estimation of autoregressive parameters. Hence, we estimate the 'correlation of independent variables' as in the dynamic panel threshold regression equation (1), applying Arellano-Bond (1991) D PD estimation, and considered the first-difference transformation of equation (1) as:

$$
\Delta y_{i t}=\beta^{\prime} \Delta \chi_{i t}+^{\prime} \chi_{i t}^{\prime}{ }^{1 i t}(\gamma)+\Delta \varepsilon_{i t},
$$

where $\Delta$ is the first difference operator,

$$
\underset{k_{1} x_{1}}{\beta}=\left(\Phi_{12}, \ldots, \Phi_{1, k_{1}}+1\right),_{k_{1}+x_{1}}^{\prime} \ddot{\ddot{o}}=\Phi_{2}-\Phi_{1}
$$

Extending equations (2) and (3), we re-specified our threshold regression as:

$$
\begin{aligned}
y_{i t}= & \left(1, x_{i t}^{\prime}\right) \Phi_{1} 1\left(q_{i t} \leq \gamma\right)+\left(1, x_{i t}^{\prime}\right) \Phi_{2} 1\left(q_{i t}>\gamma\right) \\
& +\left(1, x_{i t}^{\prime}\right) \Phi_{3} 1\left(q_{i t}>\gamma\right)+a_{i}+v_{i t} .
\end{aligned}
$$


In model (4), when environmental responsibility, measured by emissions intensity is used as a transition variable, we used environmental responsibility, measured by energy usage intensity and the financial measure, GROWTH as regressors. Alternatively, when environmental responsibility, measured by if energy usage intensity is used as the transition variable, we utilised both the environmental responsibility, measured by emissions intensity and GROWTH as regressors. Thus, we introduced GROWTH into the model to allow for effect of changes in growth opportunities. We employed 4 indicators to proxy financial performance: (i) ROA - return on assets, (ii) ROS - return on sale, (iii) EQRTNS - return on equity, and (iv) $\mathrm{MVE} / \mathrm{s}$ - market value of equity deflated by sales. While environmental responsibility is proxy by (i) EMSINT - emissions intensity and (ii) ENGINT - energy usage intensity.

We compiled environmental responsibility data from the Carbon Disclosure Project, uk based company database. While the market and accounting-based performance measures data were compiled from Tickdatamarket, a French-based company, and from respective companies' database. The panel consists of 14 JSE'S SRI firms who have consistently reported annual performances (i.e. financial and sustainability) for at least 7 years, (i.e. Anglo American Plc, Anglogold Ashanti, Arcelor Mittal South Africa, B H P Billiton, Exxaro Resources, Gold Fields Ltd, Harmony Gold Mining Ltd, Lonmin Plc, Merafe Resources, Murray and Roberts, Pretoria Portland Cement Ltd, Sabmiller Plc, Sappi Ltd, Sassol) covering an annual data for the period 2008-2014.

\section{Empirical Results}

The paper examined 'environmental responsibility' threshold effect on the financial performance of JSE'S SRI firms for the period 2008-2014. Financial performance is measured by return on assets (ROA), return on sale (ROS), equity returns (EQRTNS) and market value of equity deflated by sales $(\mathrm{MVE} / \mathrm{s})$. Alternatively, 'environmental responsibility' is measured by energy usage intensity (ENGINT) and carbon emissions intensity (EMSINT).

Employing dynamic panel threshold regressions the study allowed sequentially for zero, single, double, and triple thresholds. Statistics results for F1, F2 and F3, critical values and $p$-values appear in Table 1 .

From F1, F2 and associated critical values, we could not reject the null (но) for the single threshold F1, and double threshold F2. The test for the third threshold F3 rejects the null (Ho) at 0.05 significant level with a 
TABLE 1 ENGINT Threshold Effect on ROA

\begin{tabular}{ll}
\hline F1 & 16.75533 \\
$P$-value & 0.20 \\
Critical values & $20.08167,24.52529,27.9868$ \\
\hline F2 & 16.97452 \\
$P$-value & 0.17 \\
Critical values & $22.98719,28.90956,42.13225$ \\
\hline F3 & 36.2881 \\
$P$-value & 0.023 \\
Critical values & $19.49541,22.95595,43.6704$ \\
\hline
\end{tabular}

NOTES CVS at $10 \%, 5 \%$ and $1 \%$.

TABLE 2 ENGINT-ROA Threshold Estimate

\begin{tabular}{ll}
\hline Estimate & $95 \%$ Confidence Interval \\
\hline 0.0009 & {$[0.0001,0.0010]$} \\
0.0001 & {$[0.0001,0.0001]$} \\
0.0001 & {$[0.0001,0.0001]$} \\
\hline
\end{tabular}

TABLE 3 Estimated Coefficients of ROA

\begin{tabular}{lrrrr}
\hline Coeff. & Value & Std. error & White & t-stat. \\
\hline$\Phi_{1}$ & 0.14421 & 0.08778 & 0.05994 & 2.40601 \\
$\Phi_{2}$ & 0.17430 & 0.22442 & 0.21126 & 0.82505 \\
$\Phi_{3}$ & 0.29772 & 0.07663 & 0.06966 & 4.25542 \\
$\Phi_{4}$ & -0.08868 & 0.12110 & 0.08944 & -0.99156 \\
\hline
\end{tabular}

bootstrap $p$-value of 0.023 . We therefore confirmed the existence of triple threshold in the regression relationship.

Table 2 shows the thresholds and confidence intervals, which are $0.0009,0.0001$ and 0.0001 . Thus, four classes of companies are 'low energy usage firms,' 'medium energy usage firms,' 'high energy usage firms' and 'very high energy usage firms.' Table 3 reports the regression slope coefficients, standard errors, the standard errors, $t$-stats and four regimes. We expressed our estimated model from our findings as:

$$
\begin{aligned}
& \text { if } q_{i t-1} \leq 0.00013 \\
& \text { if } 0.00013<q_{i t-1} \leq 0.00017 \\
& \text { if } 0.00017<q_{i t-1} \leq 0.00093
\end{aligned}
$$


TABLE 4 EMSINT Threshold Effect on ROA

\begin{tabular}{ll}
\hline F 1 & 19.31735 \\
$P$-value & 0.22 \\
Critical values & $26.17635,30.89724,34.16181$ \\
\hline F 2 & 10.76762 \\
$P$-value & 0.41 \\
Critical values & $24.51725,29.84084,37.34802$ \\
\hline F3 & 35.52142 \\
$P$-value & 0.03 \\
Critical values & $21.92242,29.38851,44.77624$ \\
\hline
\end{tabular}

NOTES CVS at $10 \%, 5 \%$ and $1 \%$.

if $q_{i t-1}>0.00093$.

In the first regime (low energy usage firms) where the ENGINT ratio is less than 0.00013 , the estimated coefficient $\Phi_{1}$ is 0.14421 . This indicates that ROA increases by 0.14421 with $1 \%$ increase in the ENGINT ratio. In the second regime, i.e. medium energy usage firms, where the $\mathrm{EN}$ GINT ratio is between 0.00013 and 0.00017 , the estimated coefficient $\Phi_{2}$ is 0.17430 . This similarly shows that ROA increases by 0.17430 with $1 \%$ increase in the ENGINT ratio. In the third regime, i.e. high energy usage firms) where the ENGINT ratio is between 0.00017 and 0.00093 , the coefficient $\Phi_{3}$ is 0.29772 . This also shows that ROA increase by 0.29772 in with $1 \%$ increase in the ENGINT ratio. The last regime, i.e. very high energy usage) where the ENGINT ratio exceeds 0.00093 , the estimated coefficients $\Phi_{4}$ is -0.08868 . This indicate that ROA decreases by -0.08868 with $1 \%$ increase in the ENGINT ratio. The results indicate that any time the ENGINT ratio improves beyond $0.00093 \mathrm{ROA}$ tends to decline by 0.08868 .

The study also estimated the number of thresholds in the carbon output intensity (EMSINT)-ROA relationship estimating equation (4), employing dynamic panel. Based on the test statistics (F1, F2) and critical values the study could not reject the null ( $\mathrm{Ho}$ ) of no threshold for the single threshold F1, and double threshold F2. The test for the third threshold F3 rejects the null ( $\mathrm{HO}$ ) at 0.05 significant level with a bootstrap $p$-value of 0.03 . The statistics indicate the presence of triple threshold in the regression relationship (table 4). Hence, the rest of the study uses triple threshold estimation. 
TABLE 5 EMSINT-ROA Threshold Estimate

\begin{tabular}{ll}
\hline Estimate & $95 \%$ Confidence Interval \\
\hline 0.0005 & {$[0.0004,0.0005]$} \\
0.0001 & {$[0.0001,0.0002]$} \\
0.0001 & {$[0.0001,0.0001]$} \\
\hline
\end{tabular}

TABLE 6 Estimated Coefficients of ROA

\begin{tabular}{lrrrr}
\hline Coeff. & Value & Std. error & White & $t$-stat. \\
\hline$\Phi_{1}$ & 0.19622 & 0.08492 & 0.07707 & 2.54592 \\
$\Phi_{2}$ & -0.32231 & 0.15698 & 0.24278 & -132755 \\
$\Phi_{3}$ & 0.15745 & 0.08714 & 0.06052 & 2.60166 \\
$\Phi_{4}$ & 0.51799 & 0.10768 & 0.07604 & 6.81168 \\
\hline
\end{tabular}

Our estimations appear in table 5. The point estimates are 0.00015 , 0.00016 and 0.00053 . These point estimations represents the 'low emitting firms,' 'medium emitting firms,' 'high emitting firms' and 'very high emitting' firms. Table 6 reports the regression slope coefficients, standard errors, standard errors, $t$-stat and for four regimes. We expressed our estimated model from the findings as:

$$
\begin{aligned}
& \text { if } q_{i t-1} \leq 0.00015, \\
& \text { if } 0.00015<q_{i t-1} \leq 0.00016, \\
& \text { if } 0.00016<q_{i t-1} \leq 0.00053, \\
& \text { if } q_{i t-1}>0.00053 .
\end{aligned}
$$

In the first regime (low emitting firms) where EMSINT ratio is less than 0.00015 , the estimated coefficient $\Phi_{1}$ is 0.19622 , indicating that ROA increases by 0.19622 with $1 \%$ increase of in EMSINT ratio. In the second regime (i.e. medium emitting firms) where EMSINT ratio lies between 0.00015 and 0.00016 , the estimated coefficient $\Phi_{2}$ is -0.32231 . This indicates that ROA decreases by -0.32231 with $1 \%$ increase in EMSINT ratio. In the third regime (i.e. high emitting firms) where EMSINT ratio is between 0.00016 and 0.00053 , the coefficient $\Phi_{3}$ is 0.15745 , indicating that ROA increases by 0.15745 with $1 \%$ increase in EMSINT ratio. In the last regime (i.e. very high emitting firms) where EMsINT ratio exceeds 0.00053 , the estimated coefficients $\Phi_{4}$ is 0.51799 . This indicates that ROA increases by 0.51799 with $1 \%$ increase in EMSINT ratio. The results further showed that ROA decreases when the EMSINT ratio is between 0.00015 and 0.00016 . 
TABLE 7 ENGINT Threshold Effect on ROS

\begin{tabular}{ll}
\hline F1 & 104.2437 \\
$P$-value & 0.00 \\
Critical values & $23.18085,43.68785,65.43865$ \\
\hline F2 & 45.51412 \\
$P$-value & 0.00 \\
Critical values & $20.17043,23.37171,30.69071$ \\
\hline F3 & 286.9418 \\
$P$-value & 0.00 \\
Critical values & $33.63791,55.60378,106.6214$ \\
\hline
\end{tabular}

NOTES CVS at $10 \%, 5 \%$ and $1 \%$.

TABLE 8 ENGINT-ROS Threshold Estimate

\begin{tabular}{ll}
\hline Estimate & $95 \%$ Confidence Interval \\
\hline 0.0009 & {$[0.0009,0.0010]$} \\
0.0011 & {$[0.0006,0.0012]$} \\
0.0001 & {$[0.0001,0.0001]$} \\
\hline
\end{tabular}

TABLE 9 Estimated Coefficients of ROS

\begin{tabular}{lrrrr}
\hline Coeff. & Value & Std. error & White & $t$-stat. \\
\hline$\Phi_{1}$ & 0.1170 & 0.1948 & 0.1231 & 0.9504 \\
$\Phi_{2}$ & 0.2413 & 0.1964 & 0.2051 & 1.1764 \\
$\Phi_{3}$ & -3.0147 & 0.3767 & 0.2854 & -10.5644 \\
$\Phi_{4}$ & -0.3467 & 0.4047 & 0.1594 & -2.1756 \\
\hline
\end{tabular}

To determine the number of threshold in the carbon input intensity (ENGINT)-return on sales (ROS) relationship, equation (4) is estimated by a dynamic panel estimation. The Null (Ho) is rejected at 0.01 in the case of F1, F2, and F3, with associated $p$-values showing significant $p$ values of 0.00 in each case. The authors concluded that the relationship contains three thresholds.

Table 8 presents the triple threshold approach with resulting estimations as $0.00017,0.00093$, and 0.00119 , representing the 'low energy usage firms,' 'medium energy usage firms,' 'high energy usage firms' and 'very high energy usage firms.'

Table 9 reports the regression slope coefficients, standard errors, the 
TABLE 10 EMSINT Threshold Effect on ROS

\begin{tabular}{ll}
\hline F1 & 119.3488 \\
$P$-value & 0.00 \\
Critical values & $38.17907,47.77101,73.24798$ \\
\hline F2 & 31.97693 \\
$P$-value & 0.035 \\
Critical values & $24.9378,28.02969,47.28648$ \\
\hline F3 & 200.1955 \\
$P$-value & 0.00 \\
Critical values & $33.61706,47.32239,77.18123$ \\
\hline
\end{tabular}

NOTES CVS at $10 \%, 5 \%$ and $1 \%$.

standard errors, and $t$-stat and for four regimes. Our estimated model from the findings is written as:

$$
\begin{aligned}
& \text { if } q_{i t-1} \leq 0.00017, \\
& \text { if } 0.00017<q_{i t-1} \leq 0.00093, \\
& \text { if } 0.00093<q_{i t-1} \leq 0.00119, \\
& \text { if } q_{i t-1}>0.00119 .
\end{aligned}
$$

In the first regime where ENGINT ratio is less than 0.00017 , the estimated coefficient $\Phi_{1}$ is 0.1170 . This indicates that Ros increases by 0.1170 with an increase of $1 \%$ in ENGINT ratio. In the second regime where ENGINT ratio lies between 0.00017 and 0.00093 the estimated coefficient $\Phi_{2}$ is 0.2413 . This means that Ros increases by 0.2413 with an increase of $1 \%$ in ENGINT ratio. In the third regime where ENGINT ratio is between 0.00093 and 0.00119 , the coefficient $\Phi_{3}$ is -3.0147 . This indicates that ROs decreases by -3.0147 with $1 \%$ increase in ENGINT ratio. In the last regime where ENGINT ratio exceeds 0.00119, the estimated coefficients $\Phi_{4}$ is -0.3467 . This showed that Ros decreases by -0.3467 with $1 \%$ increase in ENGINT ratio. The results suggest that the relationship between ENGINT and ROS varies in accordance with different changes in ENGINT, exhibiting a nonlinear relationship (inverted u-shape).

The study similarly determined the number of thresholds in the carbon output intensity (EMSINT)-Return on sales (ROS) relationship estimating equation (4) by dynamic panel estimation allowing for zero, one, two and three thresholds. Test statistics F1, F2 and F3, critical values, and bootstrap $p$-values are reported in table 10. The null hypothesis (но) is rejected at 0.01 in the case of the single threshold F1, 0.05 in the case of 
TABLE 11 EMSINT-ROS Threshold Estimate

\begin{tabular}{ll}
\hline Estimate & $95 \%$ Confidence Interval \\
\hline 0.0005 & {$[0.0005,0.0005]$} \\
0.0006 & {$[0.0006,0.0021]$} \\
0.0002 & {$[0.0001,0.0002]$} \\
\hline
\end{tabular}

TABLE 12 Estimated Coefficients of ROS

\begin{tabular}{lrrrr}
\hline Coeff. & Value & Std. error & White & $t$-stat. \\
\hline$\Phi_{1}$ & 0.1944643 & 0.1552055 & 0.1213879 & 1.6020072 \\
$\Phi_{2}$ & -1.3523797 & 0.3796068 & 0.2801250 & -4.8277716 \\
$\Phi_{3}$ & 1.0841738 & 0.3559689 & 0.2678195 & 4.0481507 \\
$\Phi_{4}$ & 0.0002893 & 0.6081785 & 0.2675641 & 0.0010812 \\
\hline
\end{tabular}

double threshold F2, and 0.01 in the case of triple threshold F3, with bootstrap $p$-values of 0.00 for F1, 0.035 for F2, and 0.00 for F3. We conclude that the relationship contains three thresholds.

Table 11 shows the threshold estimations, which are 0.00026, 0.00044, and 0.00061 and these constitute low values in the EMSINT-Ros distribution. The point estimates reflect four categories of firms, which are 'low emitting firms,' 'medium emitting firms,' 'high emitting firms' and 'very high emitting firms.'

Table 12 reports the regression slope coefficients, standard errors, the standard errors and $t$-stat. Our estimated model from the findings is written as:

$$
\begin{aligned}
& \text { if } q_{i t-1} \leq 0.00026, \\
& \text { if } 0.0002<q_{i t-1} \leq 0.00044, \\
& \text { if } 0.00044<q_{i t-1} \leq 0.00061, \\
& \text { if } q_{i t-1}>0.00061 .
\end{aligned}
$$

In the first regime where EMSINT ratio is less than 0.00026 the estimated coefficient $\Phi_{1}$ is 0.1944643 , indicating that Ros increases by 0.1944643 with an increase of $1 \%$ in EMSINT ratio. In the second regime where EMSINT ratio is between 0.00026 and 0.00044 , the estimated coefficient $\Phi_{2}$ is -1.3523797 . This shows that Ros decreases by -1.3523797 , with $1 \%$ increase in EMSINT ratio. In the third regime, when EMSINT ratio is between 0.00044 and 0.00061 , the coefficient $\Phi_{3}$ is 1.0841738 . This tends to show that ROS increases by 1.0841738 with $1 \%$ increase in $\mathrm{EM}$ SINT ratio. In the last regime where EMSINT ratio exceeds 0.00061 , the 
TABLE 13 ENGINT Threshold Effect on EQRTNS

\begin{tabular}{ll}
\hline F1 & 9.39125 \\
$P$-value & 0.49 \\
Critical values & $15.145,17.79878,21.07797$ \\
\hline F2 & 14.21751 \\
$P$-value & 0.16 \\
Critical values & $15.54133,16.93608,23.53217$ \\
\hline F3 & 23.86557 \\
$P$-value & 0.003 \\
Critical values & $12.47649,14.83339,18.10099$ \\
\hline
\end{tabular}

NOTES CVS at $10 \%, 5 \%$ and $1 \%$.

TABLE 14 ENGINT-EQRTNS Threshold Estimate

\begin{tabular}{ll}
\hline Estimate & $95 \%$ Confidence Interval \\
\hline-9.5011 & {$[-9.7630,-5.1195]$} \\
-6.555347 & {$[-9.0956,-6.5373]$} \\
-10.34246 & {$[-10.4143,-6.7987]$} \\
\hline
\end{tabular}

estimated coefficients $\Phi_{4}$ is 0.0002893 . This indicates that Ros increases by 0.0002893 with $1 \%$ increase in EMSINT ratio. The results seem to indicate that EMSINT negatively affect ROS when the EMSINT ratio lies between $0.00026-0.00044$.

The study also determined the number of thresholds in the carbon input intensity (ENGINT)-Equity returns (EQRTNS) relationship, estimating equation (4), and allowing for zero, single, double, and triple thresholds. Our test statistics F1, F 2 and F3, critical values, and bootstrap $p$ values are reported in table 12. Based on the test statistics (F1, F2) and the critical values the study could not reject the Null (Ho) of no threshold for the single threshold F1, and double threshold F2. Test for the third threshold F3 rejects the null hypothesis ( $\mathrm{Ho}$ ) of no threshold at 0.01 significant level with a $p$-value of 0.003 . The study concludes that the relationship contains a triple threshold.

Table 14 presents the estimations, which are $-10.34246,-9.672444$ and -6.555347. These constitute small values in the ENGINT-EQRTNS distribution. The estimations were for the following clusters of companies, 'high energy usage firms' and 'very high energy usage firms.' Regression slope coefficients, standard errors, the standard errors and $t$-stat for four 
TABLE 15 Estimated Coefficients of EQRTNS

\begin{tabular}{lrrrr}
\hline Coeff. & Value & Std. error & White & $t$-stat. \\
\hline$\Phi_{1}$ & 0.04136 & 0.05654 & 0.02412 & 1.71483 \\
$\Phi_{2}$ & 0.08056 & 0.04948 & 0.02630 & 3.06249 \\
$\Phi_{3}$ & 0.14173 & 0.05775 & 0.03151 & 4.49782 \\
$\Phi_{4}$ & 0.16847 & 0.07131 & 0.03388 & 4.97300 \\
\hline
\end{tabular}

regimes are reported in table 15 . We expressed our estimated model from the findings as:

$$
\begin{aligned}
& \text { if } q_{i t-1} \leq-10.34246, \\
& \text { if }-10.34246<q_{i t-1} \leq-9.672444, \\
& \text { if }-9.672444<q_{i t-1} \leq-6.555347, \\
& \text { if } q_{i t-1}>-6.555347 .
\end{aligned}
$$

In the first regime (low energy usage firms) where ENGINT ratio is less than -10.34246 , the estimated coefficient $\Phi_{1}$ is 0.04136 . This indicates that EQRTNS increases by 0.14421 with $1 \%$ increase in ENGINT ratio. In the second regime (medium energy usage firms) where ENGINT ratio lies between -10.34246 and -9.672444 the estimated coefficient $\Phi_{2}$ is 0.08056 . This shows that EQRTNS increases by 0.08056 with $1 \%$ increase in ENGINT ratio. In the third regime (high energy usage firms) where ENGINT ratio is between -9.672444 and -6.555347 and the coefficient $\Phi_{3}$ is 0.14173 indicates that EQRT N increase by 0.14173 with $1 \%$ increase in ENGINT ratio. In the last regime (very high energy usage firms) where ENGINT ratio exceeds -6.555347 , the estimated coefficients $\Phi_{4}$ is 0.16847 and shows that EQRTNS increases by 0.16847 with $1 \%$ increase in ENGINT ratio. The results generally indicate that increase in ENGINT ratio generally increases EQRTNS.

The study again estimated the number of thresholds in the carbon output intensity (EMSINT)-Equity returns (EQRTNS) relationship estimating equation (4) and sequentially allowed for a zero to triple thresholds. Table 16 presents the statistical tests showing the critical values for F1, F2, and F3.

Based on the test statistics (F1, F2), and the critical values the study accepts the Null (Ho) of no threshold for the single threshold F1, and double threshold F2. Test for third threshold F3 rejects the Null (Ho) of no threshold at 0.01 level with a bootstrap $p$-value of 0.00 . We therefore conclude that there exists a triple threshold in the regression relationship.

Our point estimates of the triple threshold together with confidence in- 
TABLE 16 EMSINT Threshold Effect on EQRTNS

\begin{tabular}{ll}
\hline F 1 & 7.181246 \\
$P$-value & 0.74 \\
Critical values & $15.60819,18.62255,21.69831$ \\
\hline F2 & 8.942155 \\
$P$-value & 0.51 \\
Critical values & $13.98637,16.7379,20.41019$ \\
\hline F3 & 30.33787 \\
$P$-value & 0.00 \\
Critical values & $12.00513,13.27987,17.9077$ \\
\hline
\end{tabular}

NOTES CVS at $10 \%, 5 \%$ and $1 \%$.

TABLE 17 EMSINT-EQRTNS Threshold Estimate

\begin{tabular}{ll}
\hline Estimate & $95 \%$ Confidence Interval \\
\hline-10.0995 & {$[-11.2147,-6.1184]$} \\
-8.0528 & {$[-11.2147,-7.3666]$} \\
-10.0995 & {$[-10.6471,10.0995]$} \\
\hline
\end{tabular}

TABLE 18 Estimated Coefficients of EQRTNS

\begin{tabular}{lrrrr}
\hline Coeff. & Value & Std. error & White & $t$-stat. \\
\hline$\Phi_{1}$ & -0.16415 & 0.07467 & 0.05620 & -2.92049 \\
$\Phi_{2}$ & -0.13837 & 0.08764 & 0.06800 & -2.03484 \\
$\Phi_{3}$ & -0.16484 & 0.10162 & 0.07764 & -2.12321 \\
$\Phi_{4}$ & -0.35923 & 0.14963 & 0.10898 & -3.29611 \\
\hline
\end{tabular}

tervals are also shown in table 17. Our estimates $-10.0995,-8.052812$ and -10.0995 , which constitute small values in the EMSINT-EQRTNS threshold distribution. The estimations were for the following firm categories: 'low emitting firms,' 'medium emitting firms', 'high emitting firms' and 'very high emitting firms.' Regression slope coefficients, standard errors, the standard errors and $t$-stat for four regimes are reported in table 18 . And our estimated model from the findings is written as:

$$
\begin{aligned}
& \text { if } q_{i t-1} \leq-10.0995, \\
& \text { if }-10.0995<q_{i t-1} \leq-8.0528, \\
& \text { if }-8.0528<q_{i t-1} \leq-10.0995, \\
& \text { if } q_{i t-1}>-10.0995 .
\end{aligned}
$$


TABLE 19 ENGINT Threshold Effect on MVE/s

\begin{tabular}{ll}
\hline F1 & 220.0344 \\
$P$-value & 0.01 \\
Critical values & $30.13489,48.46399,164.3896$ \\
\hline F2 & 269.3122 \\
$P$-value & 0.00 \\
Critical values & $25.12891,33.27547,45.46908$ \\
\hline F3 & 315.7607 \\
$P$-value & 0.00 \\
Critical values & $19.46946,23.50075,34.30394$ \\
\hline
\end{tabular}

NOTES CVS at $10 \%, 5 \%$ and $1 \%$.

TABLE 20 ENGINT-MVE/s Threshold Estimate

\begin{tabular}{ll}
\hline Estimate & $95 \%$ Confidence Interval \\
\hline 0.0009 & {$[0.0009,0.0010]$} \\
0.0006 & {$[0.0006,0.0006]$} \\
0.0011 & {$[0.0001,0.0017]$} \\
\hline
\end{tabular}

In the first regime (low emitting firms) where EMsint ratio is less than -10.0995 , the estimated coefficient $\Phi_{1}$ is -0.16415 , indicating that EQRTNS decreases by -0.16415 with $1 \%$ increase in EMSINT ratio. In the second regime (medium emitting firms) where EMSINT ratio is between -10.0995 and -8.052812 the estimated coefficient $\Phi_{2}$ is -0.13837 , indicating that EQRTNS decreases by -0.13837 with $1 \%$ increase in EMSINT ratio. In the third regime (high emitting firms) where EMSINT is between -8.052812 and -10.0995 and coefficient $\Phi_{3}$ is -0.16484 . This similarly shows that EQRTNS decreases by -0.16484 with $1 \%$ increase in EMSINT ratio. In the last regime (very high emitting firms) where EMSINT ratio exceeds -10.0995 and estimated coefficient $\Phi_{4}$ is -0.35923 . This equally shows that EQRTNS decreases by -0.35923 with $1 \%$ increase in EMSINT ratio. The results generally indicate that improvement in EMSINT is inimical EQRTNS growth.

The study similarly determined the number of thresholds in the carbon input intensity (ENGINT)-Market value of equity deflated by sales $(\mathrm{MVE} / \mathrm{s})$ relationship estimating equation (4) and sequentially allowing for zero, single, double, and triple thresholds. Our test statistics F1, F 2 and F3, critical values, and bootstrap $p$-values are all reported in table 
TABLE 21 Estimated coefficients of MVE/s

\begin{tabular}{lrrrr}
\hline Coeff. & Value & Std. error & White & $t$-stat. \\
\hline$\Phi_{1}$ & -58.098 & 56.150 & 44.265 & -1.313 \\
$\Phi_{2}$ & -1493.025 & 388.485 & 10.491 & -1.809 \\
$\Phi_{3}$ & 1165.510 & 449.053 & 351.348 & 3.317 \\
$\Phi_{4}$ & 136.104 & 164.413 & 82.185 & 1.656 \\
\hline
\end{tabular}

19. The null hypothesis ( $\mathrm{Ho}$ ) is rejected at 0.01 in the single threshold F1, double threshold F2, and triple threshold F3, with bootstrap p-values of $0.01,0.00$, and 0.00 respectively. We thus conclude that a three threshold is contained in the relationship.

Table 20 shows the estimations, which are $0.00068,0.00093$ and o.oo110, and these are small in ENGINT-MVE/s distribution. The estimations represents the following firm clusters: 'low energy usage firms', 'medium energy usage firms,' 'high energy usage firms' and 'very high energy usage firms.'

Table 21 reports the regression slope coefficients, standard errors, the standard errors and $t$-stat and for four regimes. And our estimated model from the findings is expressed as:

$$
\begin{aligned}
& \text { if } q_{i t-1} \leq 0.00068, \\
& \text { if } 0.00068<q_{i t-1} \leq 0.00093, \\
& \text { if } 0.00093<q_{i t-1} \leq 0.00110, \\
& \text { if } q_{i t-1}>0.00110 .
\end{aligned}
$$

In the first regime (low energy usage firms) where ENGINT ratio is less than 0.00068 , the estimated coefficient $\Phi_{1}$ is -58.098 , indicating that $\mathrm{MVE} / \mathrm{s}$ decreases by -58.098 with $1 \%$ increase in ENGINT ratio. In the second regime (medium energy usage firms) where ENGINT ratio is between 0.00068 and 0.00093 the estimated coefficient $\Phi_{2}$ is -1493.025 . This indicates that MVE/s decreases by -1493.025 with $1 \%$ increase in ENGINT ratio. In the third regime (high energy usage firms) where ENGIN T ratio is between 0.00093 and 0.00110, the coefficient $\Phi_{3}$ is 1165.510 . This however shows that MVE/s increases by 1165.510 with $1 \%$ increase in ENGINT ratio. In the last regime (very high energy usage firms) where ENGINT exceeds 0.00110 the estimated coefficients $\Phi_{4}$ is 136.104 . This again shows that MVE/s increases by 136.104 with $1 \%$ increase in ENGINT ratio. The results suggest that the relationship between ENGINT and MVE/s varies in accordance with different changes in ENGINT, with ENGINT showing a linear relationship (inverse U-shape). 
TABLE 22 EMSINT Threshold Effect on MVE/s

\begin{tabular}{ll}
\hline F 1 & 261.0626 \\
$P$-value & 0.01 \\
Critical values & $48.13166,111.6253,204.607$ \\
\hline F 2 & 210.1656 \\
$P$-value & 0.00 \\
Critical values & $31.67894,40.76298,58.78185$ \\
\hline F3 & 1534.627 \\
$P$-value & 0.00 \\
Critical values & $117.333,185.4831,533.403$ \\
\hline
\end{tabular}

NOTES CVS at $10 \%, 5 \%$ and $1 \%$.

TABLE 23 EMSINT-MVE/s Threshold Estimate

\begin{tabular}{ll}
\hline Estimate & $95 \%$ Confidence Interval \\
\hline 0.0005 & {$[0.0005,0.0005]$} \\
0.0006 & {$[0.0006,0.0006]$} \\
0.0005 & {$[0.0005,0.0005]$} \\
\hline
\end{tabular}

The study finally determined the number of thresholds in the carbon output intensity (EMSINT)-market value of equity deflated by sales ( $\mathrm{MVE} / \mathrm{s})$ relationship by estimating equation (4) sequentially and allowing for zero, single, double, and triple threshold. Our test statistics, F1, F 2 and $\mathrm{F} 3$, critical values, and $p$-values are all reported in table 22 . The null hypothesis (Ho) is rejected at 0.01 in each of the three cases, i.e. single threshold F1, double threshold F2, and triple threshold F3, with $p$-values of $0.01,0.00$ and 0.00 , in each of the regression relationship. We therefore conclude that the relationship contains a three threshold.

Table 23 contains the estimates, which are $0.00053,0.00055$, and 0.00061 ; these values are small in the EMSINT-MVE/s distribution. Our classes of firms as exhibited by point estimates are 'low emitting firms,' 'medium emitting firms,' 'high emitting firms' and 'very high emitting firms.' Table 24 reports the regression slope coefficients, standard errors, the standard errors and $t$-stat and for four regimes. In addition, we expressed the estimated model from the findings as:

$$
\begin{aligned}
& \text { if } q_{i t-1} \leq 0.00053, \\
& \text { if } 0.00053<q_{i t-1} \leq 0.00055, \\
& \text { if } 0.00055<q_{i t-1} \leq 0.00061,
\end{aligned}
$$


TABLE 24 Estimated Coefficients of MVE/s

\begin{tabular}{lrrrr}
\hline Coeff. & Value & Std. error & White & $t$-stat. \\
\hline$\Phi_{1}$ & -126.2427 & 51.6465 & 48.4104 & -2.6078 \\
$\Phi_{2}$ & 476.1397 & 343.8062 & 198.8222 & 2.3948 \\
$\Phi_{3}$ & -3515.8567 & 177.9356 & 84.9313 & -41.3965 \\
$\Phi_{4}$ & -121.7860 & 196.2598 & 84.9824 & -1.4331 \\
\hline
\end{tabular}

if $q_{i t-1}>0.00061$.

In the first regime (low emitting firms) where EMSINT ratio is less than 0.00053 , the estimated coefficient $\Phi_{1}$ is -126.2427 , indicating that $\mathrm{MVE} / \mathrm{s}$ decreases by -126.2427 with $1 \%$ increase in EMSINT ratio. In the second regime (medium emitting firms) where EMSINT ratio is between 0.00053 and 0.00055 , the estimated coefficient $\Phi_{2}$ is 476.1397 . The result indicates that $\mathrm{MVE} / \mathrm{s}$ increases by 476.1397 with $1 \%$ increase in EMSINT ratio. In the third regime (high emitting firms) where EMSINT ratio is between 0.00055 and 0.00061 , the coefficient $\Phi_{3}$ is -3515.8567 . This indicates that $\mathrm{MVE} / \mathrm{s}$ decreases by -3515.8567 with $1 \%$ increase in EMSINT ratio. In the last regime (very emitting firms) where EMsINT ratio exceeds o.00o61, the estimated coefficients $\Phi_{4}$ is -121.7860 . This also shows that $\mathrm{MVE} / \mathrm{s}$ decreases by -121.7860 with $1 \%$ increase in EMSINT ratio.

\section{Discussions and Conclusion}

Our results showed a decline in the financial performance, measured by return on asset and return on sale by -0.08868 and -3.0147 respectively as energy usage intensity ratio exceed 0.00093 . On the contrary, when energy usage intensity ratio is in the range of 0.00017-0.00093, these firms are able to maximise return on asset and return on sale. With return on asset showing an increase of 0.29772 , and return on sale of 0.2413 . Market value of equity deflated sale ( $\mathrm{MVE} / \mathrm{s})$ on the other hand increases when energy usage intensity ratio exceeds 0.00093 , and a higher increase when energy usage intensity ratio is in the range of $0.00093-0.00110$. Equity returns also at its highest when energy usage intensity ratio exceeds -6.555347 . The results again showed that return on asset exhibited the highest performance when the emissions intensity ratio is above 0.00053 , showing an increasing of 0.51799. Return on sale also showed an increase of 1.0841738 when emissions intensity ratio is between the range of 0.00044-0.00061. Similarly, Market value of equity deflated sale showed an improvement at the point when the emissions intensity ratio is 
in the range of $0.00053^{-0.00055}$. A decline in equity returns is minimised when emissions intensity ratio is between -10.0995 and -8.052812 .

The study has demonstrated the importance of threshold analysis in determining financial implications of carbon emissions reduction. Which it's believed could contribute to internal corporate carbon policy through the application of threshold analysis to help determine the level of carbon reduction that might be economically feasible and/or worthwhile to maintain a permissible level of carbon at a tolerable economic level for a firm's economic capacity. The threshold assessment should be able to direct management as to what level they should swing into action regarding carbon abatement management.

The assessment could also inform policy on carbon reduction investment commitments, and signal management as to where to stop or continue with carbon improvement activities and investments, to help enhance internal policy on carbon reduction in a more sustainable competitive manner. Given the controversies surrounding the carbon emissions reduction effect on corporate financial performance much work remains to be done to help understand the dynamics and fundamentals of the carbon emissions reduction effect on firms' general financial performance.

Conventional managerial performance evaluation is normally based on financial and other non-financial measures which excludes environmental variables such as greenhouse gas and fossil energy consumption. But results from this study makes it evident that managerial performance evaluation needs transformation to include environmental ratios such as, emissions intensity, energy usage intensity to the traditionally adopted internal managerial performance measures against divisional investment and/or earnings.

As climate change policies trigger unprecedented emergence in internal corporate carbon policies, and companies are increasingly developing ambitious carbon reduction agendas in all activities. Yet, one of the setbacks amongst others is how to determine which of the corporate activities that have significant influence on corporate carbon levels (Kjaer et al. 2015). The findings support the stakeholder and institutional theories as the results indicated the extent to which firms manage fossilenergy resources to create balance between environmental responsibility and financial gains to preserve their legitimacy. The results further seemed to indicate why companies institute integrated and multifaceted programmes and activities in the attempt to enhancing corporate interaction with the natural environment. 


\section{References}

Arellano, M., and S. Bond. 1991. 'Some Tests of Specification for Panel Data: Monte Carlo Evidence and an Application to Employment Equations.' The Review of Economic Studies 58 (2): 277-97.

Barley, R. 2009. 'Drax in Power Struggle with s\& P, Heard on the Street.' The Wall Street Journal, 25 June.

Chien, C., and C. Peng. 2011. 'Does Going Green Pay off in the Long Run?' Journal of Business Research 65 (11): 1636-42.

Chudick, A., K. M. Mohaddes, H. M. Pesaran, and M. Raissi. 2015. Is There a Debt-Threshold Effect on Output Growth? Working Paper 5434, CEsifo, Munich.

Clarkson, P. M., M. B. Overell, and L. Chapple. 2011. 'Environmental Reporting and its Relation to Corporate Environmental Performance.' Abacus 47 (1): 27-6o.

Dang, V. A., M. Kim, and Y. Shin. 2012. 'Asymmetric Capital Structure Adjustments:' New Evidence from Dynamic Panel Threshold Models. Journal of Empirical Finance 19 (4): 465-82.

Ebaid, I. E. S. 2009. 'Impact of Capital Structure on Firm Performance:' Empirical Evidence from Egypt. Journal of Risk Finance 10 (5): 477-87.

Friedman, M. 1970. 'The Social Responsibility of Business is to Increase its Profits.' New York Times, 13 Septtember.

Fujii, H., K. Nishitani, S. Kaneko, and S. Komatsu. 2012. 'Are Firms' Voluntary Environmental Management Activities Beneficial for the Environment and Business? An Empirical Study Focusing on Japanese Manufacturing Firms.' Journal of Environmental Management 105:121-30.

Gallego-Alvarez, I., L. Segura, and J. Martínez-Ferrero. 2014. 'Carbon Emission Reduction: The Impact on the Financial and Operational Performance of International Companies.' Journal of Cleaner Production 103:149-59.

Gonzalez-Benito, J., and O. Gonzalez-Benito. 2005. 'Environmental Proactivity and Business Performance:' An Empirical Analysis. Omega 33 (1): 1-15.

Guthrie, J., and L. Parker.1989. 'Corporate Social Reporting: A Rebuttal of Legitimacy.' Accounting and Business Research 19 (76): 343-52.

Hansen, B. E. 1999. 'Threshold Effects in Non-Dynamic Panels:' Estimation, Testing, and Inference. Journal of Econometrics 93 (2): 345-68.

Horvathova, E. 2014. 'Does Environmental Performance Affect Financial Performance: A Meta-Analysis?' Ecological Economics 70 (1): 52-9.

Kjaer, L. L., N. K. Høst-Madsen, J. H. Schmidt, and T. C. McAloone. 2015. 'Application of Environmental Input-Output Analysis for Corporate and Product Environmental Footprints: Learnings from Three Cases.' Sustainability 7 (9): 11438-61. 
Klingenberg, B., R. Timberlake, T. G. Geurts, R. J. Brown. 2013. 'The Relationship of Operational Innovation and Financial Performance: A Critical Perspective.' International Journal of Production Economics 142 (2): 317-23.

Ki-Hoon, L., M. Byung, and Y. Keun-Hyo. 2015. 'The Impacts of Carbon $\left(\mathrm{CO}_{2}\right)$ Emissions and Environmental Research and Development (R\&D) Investment on Firm Performance.' International Journal of Production Economics 167:1-11.

Lioui, A., and Z. Sharma. 2012. 'Environmental Corporate Social Responsibility and Financial Performance: Disentangling Direct and Indirect Effects.' Ecological Economics 78:100-11.

Makni, R., C. Francoeur, and F. Bellavance. 2009. 'Causality between Corporate Social Performance and Financial Performance: Evidence from Canadian Firms.' Journal of Business Ethics 89 (3): 409-22.

Margaritis, D., and M. Psillaki. 2010. 'Capital Structure, Equity Ownership and Firm Performance.' Journal of Banking \& Finance 34 (3): 621-32.

Miller, M. H., and F. Modigliani. 1958. 'The Cost of Capital, Corporate Finance and the Theory of Investment.' American Economic Review 48:261-97.

- 1963. 'Corporate Income Taxes and the Cost of Capital: A Correction.' American Economic Review 53 (3): 433-43.

Muhammad, N., F. Scimgeour, K. Reddy, and S. Adidin. 2015. 'The Relationship between Environmental Performance and Financial Performance in Periods of Growth and Contraction: Evidence from Australian Publicly Listed Companies.' Journal of Cleaner Production 102: 324-32.

Nakao, Y., A. Amano, K. Matsumura, K. Genba, and M. Nakano. 2007. 'Relationship between Environmental Performance and Financial Performance: An Empirical Analysis of Japanese Corporations.' Business Strategy and the Environment 16 (2): 106-18.

Nickell, S., 1981. 'Biases in Dynamic Models with Fixed Effects.' Econometrica: Journal of the Econometric Society 49:1417-26.

Nishitani, K., S. Kaneko, H. Fujii, and S. Komatsu. 2011. 'Effects of the Reduction of Pollution Emissions on the Economic Performance of Firms: An Empirical Analysis Focusing on Demand and Productivity' Journal of Cleaner Production 19 (17): 1956-64.

Orlitzky, M. 2001. 'Does Firm Size Confound the Relationship between Corporate Social Performance and Firm Financial Performance?' Journal of Business Ethics 33 (2): 167-8o.

Przychodzen, J., and W. Przychodzen. 2014. 'Relationships between EcoInnovation and Financial Performance.' Journal of Cleaner Production 90:253-63. 
Qi, G. Y., S. X. Zeng, J. J. Shin, X. H. Meng, H. Lin, and Q. X. Yang. 2014. 'Revisiting the Relationship between Environmental and Financial Performance in Chinese Industry.' Journal of Environmental Management $145(1): 349-56$.

Salama, A. 2005. 'A Note on the Impact of Environmental Performance on Financial Performance'. Structural Change and Economic Dynamics 16 (3): 413-21.

Sambasivan, M., S. M. Bah., and H. Jo-Ann. 2012. 'Making the Case for Operating Green: Impact of Environmental Proactivity on Multiple Performance Outcomes of Malaysian Firms.' Journal of Cleaner Production 42:69-82.

Sen, P., M. Roy., and P. Pal. 2015. 'Exploring Role of Environmental Proactivity in Financial Performance of Manufacturing Enterprises: A Structural Modelling Approach.' Journal of Cleaner Production 108:583-94.

Seo, M. H., and Y. Shin. 2014. 'Dynamic Panels with Threshold Effect and Endogeneity.' Working Paper Series Em/2014/577, London School of Economics, London.

Telle, K. 2006. 'It Pays to be Green: A Premature Conclusion'? Environmental \& Resource Economics 35 (3): 195-220.

Wahba, H. 2008. 'Exploring the Moderating Effect of Financial Performance on the Relationship between Corporate Environmental Responsibility and Institutional Investors: Some Egyptian Evidence.' Corporate Social Responsibility and Environmental Management 15 (6): 361-71.

Wagner, M., N. Van-Phu, T. Azomahou, and W. Wehrmeyer. 2002. 'The Relationship between the Environmental and Economic Performance of Firms: An Empirical Analysis of the European Paper Industry.' Corporate Social Responsibility and Environmental Management 9 (3): 13346.

Wingard, H. C., and Q. Vorster. 2001. 'Financial Performance of Environmentally Responsible South African Listed Companies.' Meditari Accountancy Research 9 (1): 313-32.

This paper is published under the terms of the Attribution-

NonCommercial-NoDerivatives 4.o International (CC B Y-NC-ND 4.O)

License (http://creativecommons.org/licenses/by-nc-nd/4.o/). 



\title{
Navigating New Marketing Technologies, Channels and Metrics
}

\author{
Petra Leonora Cvitanović \\ Microsoft Hrvatska d.o.o., Croatia \\ petraleonora@gmail.com
}

The goal of this paper is to analyse the advantages of today's marketing technologies, marketing channels and marketing metrics and to identify the difficulties which companies face in navigating them. Modern technologies in all industries are drastically changing human lifestyle, interactions and expectations from the brands. Companies are directing more of their marketing investment into online, mobile, as well as combined online and retail channels, while traditional marketing channels become less effective. New retail and mobile technologies offer many possibilities for interaction with consumers and planning of an effective marketing strategy. A variety of marketing analytics tools helps the companies to measure digital marketing performance. The conclusion of the paper is that new marketing technologies, channels and metrics dictate new standards for managing of company's marketing in the 21st century market. Research methodology includes study of literature, scientific articles and online sources related to digital marketing, technology and consumer behaviour.

Key Words: marketing technologies, multi-channel marketing, marketing analytics, marketing metrics, the future of marketing

JEL Classification: M30, M31

https://doi.org/10.26493/1854-6935.16.379-40o

\section{Introduction}

Today's technology is developing so rapidly that its continuous improvements are getting increasingly difficult to keep the pace with. It is changing the society and vice versa - the society is affecting the development of the technology and directing where it wants the technology to go, to match the needs of average consumers and improve their every-day life. Yet, some companies still fail to understand the significance which the technology has on the lives of the consumers and how important it is to design a memorable consumer experience and relevant personalized content which will attract them. The increased use of technology by consumers has led to market and product differentiation (Ampountolas 2018, 
14) and there is a widespread assumption that recent advances in Internet technologies have transformed the previous pattern of human communication (Bannor, Asare, and Bawole 2017, 343) which has consequently led to a drastic change in personal interactions, relationship and lifestyle in general. With Internet as the first point of contact between companies and consumers, and mobile channel accounting for $57 \%$ of Internet traffic (Leuman 2018), companies today are affecting consumers' beliefs about the brand or the product by providing them interesting online/mobile consumer experience.

For the past 15 years digital transformation has been taking place in all aspects of businesses across all industries. Digitalization is one of the most significant on-going transformations of contemporary society and encompasses many elements of business (Hagberg, Sundstrom, and EgelsZandén 2016, 694). Companies which have invested in modern technologies and which update them regularly, have set a new level of doing business as a standard for other players in their industry. Understanding and using new marketing technologies helps companies improve consumer experience in all marketing channels and at every point of contact with the brand. Companies which utilize them can achieve competitive advantage and plan a more effective marketing strategy. New online IT solutions and applications allow the tracking of marketing activities in online environment through marketing dashboards by providing easy and transparent measurement of their effectiveness.

The purpose of this paper is to analyse new marketing technologies, marketing channels and marketing metrics, to outline their positive effects on today's companies business and to identify some of the difficulties which companies face in navigating them. Research was conducted in the period from July 2018 to January 2019 through methods of collecting and studying of open access literature and scientific articles found in $\mathrm{Li}$ brary Catalogue of Zagreb University Faculty of Economics and Business, Emerald Insight database and Hrčak Portal of Scientific and Professional Journals. For this purpose the following areas were researched: marketing strategy, marketing channels, online advertising, mobile marketing, marketing metrics, marketing effectiveness, marketing performance, marketing measurement, multi-channel marketing, omni-channel marketing, retail marketing, digital displays, marketing technologies, mobile channel, and similar. However, not many sources provide overview of new marketing channels which have developed owing to modern technology possibilities and new metrics of marketing activities conducted through 
those channels. Additionally, practical suggestions and implications on how to use new technologies to improve specific dimensions and metrics of marketing activities can seldom be found in books and other professional papers. Therefore, the author had to include in the research also Internet sources such as recently published online articles and YouTube videos which cover these narrowed research areas. The majority of found sources deal with the influence of modern-day technology on consumer behaviour patterns, which have radically changed in the past fifteen years which has affected traditional marketing in all aspects and the way of doing business in general. Therefore, as a source of information for some cases mentioned in the paper was author's knowledge gained at Marketing Management postgraduate study at Zagreb University Faculty of Economics and Business. Also, author's own experience from working at positions of Marketing Investment Officer in Samsung Electronics and Marketing Analytics Manager in Microsoft, present a foundation for expressing some personal viewpoints and for making general conclusions.

Even though online has been the first point of contact with the brands for the consumers around the world, mobile communication channel is gradually taking over. Mobile is becoming the leading channel because unlike other channels, through it the companies are able to reach the consumers directly and communicate with them in real time, providing them benefits such as unique brand experience and opportunity for interaction with the brand whenever and wherever they want. Apart from interaction with the brand they are interested in, consumers look for unique brand experience so companies which know how to provide a memorable consumer experience via any marketing channel, don't face as many obstacles in gaining high positions in consumers' perception. Companies are challenged to provide compelling consumer experience across offline and online touch points (Hilken et al. 2018, 510). With so many brands in the marketplace fighting for consumers' attention, it is essential that brands ensure solid recognition in consumers' minds. To do that, they need to be different and better in all aspects of business, especially their approach to consumers. The objective of the paper is to attract attention of managers to competitive advantage possibilities which can be achieved by combining new technologies with marketing channels and greater possibilities than ever before for measuring marketing performance and return on investment.

The contribution of this paper in relation to previous published papers which have been written on similar subjects can be recognized in the form 
of its progressive character where the authors is pushing of the 'pre-set boundaries' by analysing marketing-related terms and subtopics which had not previously been addressed often by too many other authors. In this paper the readers will be able to engage in progressive thinking about the future of marketing, combined with the vast possibilities which new technologies bring to humanity, opening a whole new world with modern marketing channels and consumer targeting possibilities.

This paper is structured in seven sections. After the Introduction, in the second section main concepts and terminology used in the paper are defined. Separate sections cover three main research areas of this paper, discussing marketing technologies, marketing channels and marketing metrics. The end of this paper contains sections concerning practical implications and conclusions.

\section{Main Concepts and Terminology Definition}

The term 'digital marketing' refers to promotion of products or brands via electronic media, digital marketing channels and methods (s as Software 2014). The term 'marketing technology' is used to describe a blend of two separate disciplines - marketing and technology - and defines all the technology which companies use to perform marketing activities in the second decade of 21st century. Since it would not be possible to conduct modern marketing activities without the use of technology, today these two concepts are bound together within the term 'marketing technology', often also referred to as 'MarTech. Except for online and mobile marketing technologies, there are many other types of digital technologies which have to do with retail marketing possibilities or outdoor advertising and consumer interaction via displays. The term 'marketing channels' encompasses all the routes, channels or platforms which companies use to reach the consumers. Marketing channels are a set of people, activities and intermediary organizations that play a role in the process of transferring the ownership of goods/products from point of production to the point of consumption. They are interdependent on each other and interact with each other (Bhasin 2018). The term 'omni-channel' is used to describe a form of retailing that allows customers not only to shop across channels but also to interact with the brand anywhere and at any time, providing them with a unique, complete and seamless shopping experience that breaks down the barriers between virtual and physical stores (Mosquera et al. 2018, 64). Omni-channel marketing allows the customer to experience a 'holistic' shopping experience, one in which a customer's buying 
journey is smooth and seamless, irrespective of the channels used (Payne, Peltier, and Barger 2017, 189). The term 'multi-channel' means using two or more synchronized marketing channels (Payne, Peltier, and Barger $2017,186)$ to deliver company's marketing message to the consumers and by doing so, to support the distribution of company's goods or services. As a result of technological advance, a new multi-device consumer has emerged, who uses several channels simultaneously (Mosquera et al. 2017, 65). The term 'marketing metrics' refers to numerous measures of marketing efficiency, effectiveness and success of performance of undertaken marketing activities of a company. The speed and immediacy of digital combined with advanced analytics make it possible to measure, monitor, and test digital campaign performance, to learn what works and what doesn't work, which helps companies achieve higher ROI and improve customer experience (s As Software 2014).

\section{Marketing Technologies}

It is a fact that an average consumer uses five different technological devices in a day, including: one or two smartphones, desktop computer/laptop at work, personal laptop, tablet and even Smart TV screen (Digital Marketing Institute 2016). The idea is not about seizing this opportunity and simply targeting prospects directly through all devices and all channels available (companies doing so are often perceived as intrusive or annoying, and are therefore ignored by consumers). The goal is to attract consumers' attention and interest and find a way to keep them for a longer period of time. This can be done either by engaging the consumers in a dynamic brand relationship characterized by interesting interaction and benefits, or by requesting from them to help build the brand with their recommendations and opinions, which will increase their loyalty and sense of pride because of their contribution to the world. The most important thing in marketing management is to remember that brands exist because of consumers and for the consumers so listening to them and empathizing with them is essential. It all comes down to the human note in doing business and the technology today is what can help leverage a brand-consumer relationship to the next level and make the companies thrive.

Research shows that in 2012, 65\% of consumers had a digital experience affect a change in their opinion about the brand (Conversation, LLC 2012). In 2014, 30\% of consumers were communicating with brands through their social media profiles (Digital Marketing Institute 2016) In 
$2016,77 \%$ of world population owned at least one mobile device and most of the users habitually check their mobile device 150 times a day in average (Digital Marketing Institute 2016). In 2017, 74\% of shoppers made a purchase based on a mobile device search and at the same time $79 \%$ of top advertisers didn't have a mobile optimized site (Prismaxel 2017). According to Internet World Stats, in June 2017, a 51\% of world population - more than 3.8 billion people - were actively using Internet (KostićStanković and Vukmirović 2018, 158). In 2018, social media has become a hugely important part of company's marketing communications so retailers which decided to invest in social media strategies perform better than the competition (Vend 2018). With advanced technology allowing mass usage of smart communication devices, a change in traditional consumer purchasing behaviour is affecting the society in a drastic way. Today, in 2019, over 6 billion people use mobile phones daily and mobile devices are changing purchasing patterns and buyer behaviour which used to exist over the last century.

Marketing capability requires the use of digital technology as digital technology determines the organizational capability to research customers, competitors and the broader market environment (Foroudi et al. 2017, 232). Depending on the industry, the aspect of new technologies in marketing will have a stronger or weaker role in creating a company's competitive advantage and better competitive position in the market. Digital technology adopted by the organization enhances the ability to respond positively to customer needs and, at the same time, improves customer-side operations. The most important contribution of digital technology is that it focuses on the consumers and businesses and helps drive sales and increase efficiencies by reducing costs (Foroudi et al. 2017, 239). Technological developments offer opportunities to SMES to achieve growth and innovation, which can be delivered through greater resources, and help sMEs to attract and retain more customers (Foroudi et al. 2017, 242).

Technologies in marketing can be sorted into two groups: must-have technologies are those technologies which companies have to implement in order to maintain their existence on the market, most of the competitors have them and most of the consumers expect to find them. Optional technologies are technologies which can support everyday business and boost financial results, but are mostly used by large companies which can afford them. Standard marketing technologies include various technological solutions developed for marketing purposes, which most of today's 
companies use, including: desktop website, live chat, e-Commerce platforms/web shop, social media marketing, search engine optimization, Pay-Per-Click advertising, Google display advertising, mobile website and web shop, mobile device applications, QR (quick response) codes, social media marketing for mobile devices, in-store $\mathrm{Wi}$-Fi, video walls and in-store displays. Advanced marketing technologies imply the technologies which still many companies have not implemented, but which market leaders are already using, such as: mobile optimized websites and m-Commerce (mobile shopping) sites, 'Click \& Collect' service, interactive digital video displays, beacon technology, security cameras with heat maps, sensors linked via Wi-Fi to consumers' mobile devices, Near-Field Communication (NFC) and Bluetooth Low Energy (B LE) linked to app on consumers' smartphones, CRM database on Cloud linked to consumers' smartphones for in-store ad targeting and linked to consumers' emails for invoice sending, outdoor interactive displays/signages, as well as mWallet pos payment solutions and applications, and e-Wallet payment solutions.

\section{Marketing Channels}

Marketing Managers in companies of all sizes are increasingly directing company's communication towards digital channels, meaning mobile and online. At the same time mainstream media (television, radio, newspapers and magazines) are slowly being put in second place because they are gradually losing their effectiveness (Bannor, Asare, and Bawole 2017, 343) and because new channels are relatively cost-effective compared to traditional ones and within reach of every business (s As Software 2014). Traditional media are often too expensive and too complicated for an average (small or medium-sized) company. Digital marketing leveraging social media channels provides SMES with a new innovative way to interact with customers, providing an alternative, cost-effective and attractive proposition (Foroudi et al. 2017, 236), a so-called 'online value proposition. However, even more evident reason why companies move away from traditional marketing channels is because of the evident decrease in their effectiveness while new mobile marketing methods are getting more and more effective. New media is dominantly used to target younger population and traditional mass communication media will have more effect with older population (Bannor, Asare, and Bawole 2017, 352). Advertisers rely less on traditional media and more on Internet advertising, product placements, using of social media, buzz marketing, etc. (Kostić-Stanković 
and Vukmirović 2018, 159). It is understood that companies don't focus all of their marketing activities in one channel and that the same marketing message tends to be systematically driven through different channels.

Successful marketing strategy will prioritize channels most used for communication, direct contact and interaction with consumers and consumer marketing will be directed through channels which are most convenient for the consumers and not the ones which are most convenient for the company generating the message. Today, the consumers decide by themselves which channels they wish to use and Marketing Managers need to align their cross-channel communication programs with brand messaging strategies that are consistent across consumer touch-points (Payne, Peltier, and Barger 2017, 186).

Online media today is used to distribute all sorts of valuable information to citizens, and not just marketing/sales messages. For an example, it allows for health institutions to reach a wider audience and deliver health information and health-related issues to patients (Bannor, Asare, and Bawole 2017, 342). Online as a must-have channel is a medium through which various campaigns can be conducted which don't necessarily have to do with marketing and/or sales campaigns but can address large groups of population, educate them, motivate them to a certain action and distribute valuable information which are relevant for various aspects of their lives. However, even though online channel is the first point of contact, consumers prefer to use the mobile channel because smartphones and/or tablets are always within arm's reach even when consumers are 'on the go.' Consumers use smartphones to gather information anytime, anywhere, from multiple sources, and execute transactions instantaneously, they are personal and handy (Mahapatra 2017, 930). That is why mobile is becoming the number one marketing channel which is slowly but surely replacing other traditional channels. Mobile shopping is a natural extension of e-Commerce and has more advantages when compared to e-Commerce, with accessibility, instant connectivity and access to real-time information being some of them (Phong, Khoi, and Le 2018, 188). Since online and mobile marketing channel have a lot in common, a lot can be achieved by combining these two channels. Considering that desktop and mobile versions have been optimized and adjusted to be used on various electronic devices, most of the service elements are the same: website, web shop, social media networks, display ads, live chat, videos, blogging platforms, email services, etc. The differential advantage of mo- 
bile channel are mobile applications which in combination with new technologies have no limits.

In digital environment, marketing mix consists of five elements - besides product, price, place and promotion, the fifth element refers to people. People are an immensely important factor which drives digital marketing strategy, which is why it is essential for companies to take into account everything related to their consumers, the existing one or the potential ones. Today it is possible to gather and store personal consumer data in large databases, and the data collected allows the companies to shape their marketing strategies and tactics better than before. Such data includes consumers' personal data, purchasing patterns, details of purchasing transactions, favourite sales channels, purchasing history, list of complaints, and other demographic, economic, psychographic and behaviouristic characteristics of consumer segments. Smart management of this data will allow the companies to predict future purchases of each consumer segment and plan production, orders, procurement, sales volume, forecast revenues and profit. Marketing Managers need to know how to use the huge potential of big data and information technologies in order to collect data which is important for the company (da Gama 2012, 219) including data on consumers' attitudes and perceptions of the brand, perceived quality of service, appropriateness of prices, distribution channels, brand position compared to competition, brand awareness, etc. For an example, companies can design the optimal communication strategy based on consumer data extracted from their databases, afterwards choose the most appropriate channel and then personalize the marketing message to a particular consumer segment.

After conducting a market segmentation and a detailed analysis of consumer segments, a company will find out which segments recognize and use technology more and which technologies in marketing they value the most. Mobile channel is becoming the leading channel because it allows companies to get through to consumers directly, providing them benefits such as unique brand experience and greater real-time interaction, which will subsequently result in greater brand recognition and higher brand loyalty on consumer side. Even though there are some companies which are not able to successfully integrate digital online and offline consumer experiences (Hilken et al. 2018, 510), most of today's large companies implement a multi-channel marketing strategy in order to deliver a more persuasive message to consumers. Today's consumers are ready to embrace the next level newsletters as main direct marketing tool, and 
would like direct mailing to be high-tech, more useful than it is and not so generic. Direct mailing is still considered the best tool for reaching the consumers directly, especially Generation $X$ consumers (born approximately 1965-1979) who prefer email communication in general. However, it has a slightly different effect on older and younger generations of consumers. For an example, Generation Y consumers, so called 'The Millennials' (born approximately 1980-1994), prefer to be reached by text messages rather than by emails, so email newsletters will not have the same impact on them. Another modern marketing channel is outdoor advertising on interactive digital displays and signages in all sizes. Since Generation $Z$ consumers (born approximately 1995-2015) prefer communication using photos, videos and other visual media, it is understandable why interactive digital displays appeal to them the most and why we can expect to see them dominating the streets and shopping centres in the future.

The efficiency of new technologies in retail marketing can be proved in real time. New technologies offer a range of possibilities for interacting with consumers at every moment while they are inside of a 'brick \& mortar' store. Technologies such as indoor positioning systems based on BLE beacon devices and NFC offer a wide range of opportunities for reaching consumers via brand's mobile application in consumers' smartphones. Digital technologies allow the consumers to connect to Internet through their mobile devices inside of the physical store, which has been changing the way they shop, the way they gather information about the products, and their entire in-store shopping behaviour (Hagberg, Sundstrom, and Egels-Zandén 2016, 697). It is a fact that $70 \%$ of consumers use smartphones while in the store and $79 \%$ of consumers use smartphones to help them with shopping (Prismaxel 2017). Tech-savvy consumers bring their smartphones to every shopping as a shopping companion (StarMobileSolutions 2013).

If a retailer wants to provide a more enjoyable and easier shopping experience to consumers, more attention will have to be paid to consumers' needs and suggestions on what should be improved in the stores. Some consumers probably want to spend more time in-store but are lacking fun and motivational elements so they leave the store disappointed. Consumers are ready for next level technologies so retail stores which use newest and more interesting technologies are perceived as more attractive. Consumers show an increasing desire to have a more engaging experience while shopping because they have high level of expectations to- 
wards technology-based innovations able to support them while entertaining them at the same time (Papagiannidis et al. 2017, 166). Also, in order for the retailers to be able to upgrade consumers' satisfaction and boost own sales results, they will have to make an effort to find out why they use mobile devices when they are physically inside their store and what technology they would like to have at disposal at that moment. Except for the goal of reaching the consumers and offering them a certain product or a service to buy, the retailer might prefer to invest efforts in providing them information and by doing so, assist them to make a purchasing decision. Perhaps some consumers would like the product tags (on clothes or shoes) to have QR codes which would help them. For an example, after scanning the tags with their mobile app, the app would inform them if the product is available in other sizes, what quantity of the same product is available in warehouse, or if the product can be bought at a lower price in another shop of the same brand. This will make the consumers happy because it will help them find the information they are looking for quickly and without having to ask the sales personnel for assistance, or without having to wait in line, which will save them time. Other group of consumers will appreciate interaction via their mobile device - for an example, receiving a greeting message when they enter the store or user specific ads sent to their messaging app as they stroll down the store aisle. If retailers combine Cloud service, Internet of Things (Іот) technology, mobile applications, positioning systems and smart home technologies, systems and services (under the assumption that consumers are using them), retailers' marketing messages will be consistent and seamlessly delivered to consumers.

In retail, in-store Wi-Fi and digital video displays have become a general standard and are the basics of what all consumers expect to see when they enter the store. Stores which don't have Wi-Fi are not able to interact with consumers via their mobile devices and because of that the total buyer experience is perceived as less in quality in the eyes of consumers. Still, this doesn't mean that the retailers are not investing in advanced technologies for their stores because some technologies go unnoticed by consumers, but are highly valued by retail managers because of their usefulness for the business. Retail store technology, for instance, beacon technology allows real-time monitoring of products on the shelves, which helps the retailer to find out which products are most popular among the consumers, and to place new orders on time to keep up with the demand and avoid possible unexpected stock-out. Some retailers are al- 
ready connecting consumers' mobile devices to CRM database via NFC and BLE. The system can be set up in a way that the database 'communicates' directly to with the consumer, and that no one else has access to their personal data. In CRM database customers' purchasing history can be found, customers' preferences, regular shopping items (or shopping list), filled out satisfaction questionnaires, complaints list, contact information as well as their purchasing patterns. Having at disposal databases, marketing decision support systems, applications and software can result with long-term positive effects to marketing function and business because they allow synthesis and analysis of marketing data and gathered consumer data (Prismaxel 2017), as well as creation of comprehensive reports on market trends. Without databases, operating and coordinating marketing activities would be much more difficult for the company.

Next, there are technologies such as sensors which monitor and analyse consumer buying behaviour and patterns of their movement while they are in store. General visitor data is collected without the consumers knowing about it, such as their age group, sex, average duration of one visit to the store, isles (product categories) which certain consumer segment prefers, their way of moving around the shop, where they spend most time, how much store do they cover during one visit, how long do they wait in line, when the consumer again visited the shop and the time between two visits, etc. The idea is to collect the data on consumer behaviour and to adapt future marketing activities and shelf merchandising activities accordingly (Rieland 2013). Retailers have been collecting such data for the past five years, inspired by similar data on consumer behaviour which is continuously being collected in the online channel. Other technologies used for the same purpose include security cameras which create heat maps and in this way identify the best in-store locations to place products and/or product display stands, and which to avoid since they appear to be 'blind spots' for the consumers (Rieland 2013). Except for devices which allow customers to perform automatic checkout, there are also technologies that make it easier for customers to locate specific products quickly in the store (Mosquera 2017, 66).

Consumers like the combination of online/mobile channel and retail channel because of the convenience it provides them. Many retailers have adopted delivery innovations such as buy-online-pickup-in-store (Lim, Jin, and Srai 2018, 308), fashionably referred to as 'Click \& Collect' service. This e-Commerce/m-Commerce \& retail trend has been readily welcomed by millions of consumers around the world because consumers 
TABLE 1 New Marketing Technologies per Channel(s)

\begin{tabular}{ll}
\hline $\begin{array}{l}\text { Marketing } \\
\text { channel(s) }\end{array}$ & New technologies in marketing \\
\hline Mobile & $\begin{array}{l}\text { m-Commerce, Mobile applications, mobile optimized websites and } \\
\text { web shop sites }\end{array}$ \\
\hline e-Retail & e-Commerce platform (web shop), e-Wallet payment solution \\
\hline Online/Retail & 'Click \& Collect' service \\
\hline Retail & $\begin{array}{l}\text { Interactive digital video displays, beacon technology, security cam- } \\
\text { eras with heat maps, CRM database on Cloud linked to consumers' } \\
\text { smartphones for in-store ad targeting }\end{array}$ \\
\hline Retail/Mobile & $\begin{array}{l}\text { NFC and B be linked to app on consumers' smartphones, sensors } \\
\text { linked via Wi-Fi to consumers' mobile devices, m-Wallet Pos pay- } \\
\text { ment solutions }\end{array}$ \\
\hline Direct & $\begin{array}{l}\text { CRM database on Cloud linked to consumers' emails for invoice } \\
\text { sending }\end{array}$ \\
\hline Outdoor & OOH interactive displays/signages \\
\hline
\end{tabular}

like to search for information about the products online when they have time and order them from home, and then pick them up later at the retail store's point of collection. After finding the best offer for the product which can be bought in a particular store in their city, consumers will also check product reviews, and the research shows that $88 \%$ of them will take action within the same day, be it calling or visiting the store (StarMobileSolutions 2013). When it comes to mobile payments applications, consumers value more the usefulness which this payment solution offers, while at the same time, it doesn't have to be easy to use, and they will still use it because of its practicality (Aslam, Ham, and Arif 2017, 171). Digital retailing, also called Internet retailing, has become a multi-billion pound industry which continues to experience double-digit growth rates, and is characterized by intense competition and consumers demanding highquality service (Hooley et al. 2017, 352). There are many digital retailers such that engage only in online trading and are therefore referred to as $e$ tailers. Today's e-tailers place a strong emphasis on delivering a superior e-service to online consumers which includes the new payment solution such as digital wallet or $e$-Wallet. Also, one of the main concerns is how to communicate effectively by conveying a lot of information (such as product specifications) in a concise and relevant way and in a consumerfriendly format (p. 353).

In order to be able to implement specific new marketing technologies 
in chosen marketing channel(s), a company has to have at disposal certain level of technological prerequisites. Table 1 shows a brief overview of new technologies in marketing which are used in new marketing channels and which present the new way of doing business. Even though these technologies may still be perceived as futuristic by many business owners or company managers, in several years from now some of these technologies will be considered outdated and will be replaced by even newer technologies, which are not yet on the horizon. Another option is that these technologies will become the basis which will only get more and more upgraded in the upcoming years. In any case, companies which are resisting to implement these new technologies, are only hurting their business in the long run by doing so.

\section{Marketing Metrics}

When consumers use digital channels, they leave behind a huge trail of data (s A s Software 2014). For an example, social networking sites collect large streams of detailed user data, and to be able to understand it, they deploy data mining and data analytics tools. These technologies allow for various behavioural patterns to be discovered and users to be served with tailored, localized content which is more relevant to them (Jones 2017, 915). When consumers visit certain website or search for certain terms by using certain search words, their online activity is recorded, stored and analysed. The term 'analytics' often involves finding patterns and correlations in the data which have to do with consumers, their responses or purchases, in order to produce a deeper understanding of the consumers (Stone et al. 2017, 218). Besides the latter, companies today have at disposal a variety of marketing analytics tools for they use for tracking of daily, weekly, monthly, quarterly and yearly online and mobile marketing performance at chosen markets. A company which integrates marketing analytics tools and techniques in its strategy, has the advantage of better forecasting its cash flow dynamics and making necessary adjustments of marketing efforts in a timely manner. If company's cash flow is at a critical point, sales needs to be boosted in a rather short period of time in order to attain financial liquidity. In such situation, marketing team will have to choose the best tactics and direct them towards the right target group and adjust certain elements of marketing mix. If the company has readily available actual data about the market, previously gathered and systemized, it will know which tactics to use, which sales/distribution channels to use, which prices to set and how to reach the consumers in the best possible way. 
Often, investment in marketing is perceived as risky investment due to insecure return on investment from marketing activities. Because of that, it is not possible to determine what effect on sales increase marketing activities actually have. In spite of that, modern Marketing Managers manage marketing metrics and marketing investment better than the previous generation. At the beginning of each calendar year many of them make reservations of budget for measuring of marketing and determining the effectiveness of marketing activities because by doing so, they ensure credibility of marketing business function (Marshall 2007). Development of marketing strategy which will motivate consumers to buy a certain product, decisions on optimal combination of communication channels, and profitability calculations should be based on figures. In order to ensure profitability for the company, customer portfolio has to be analysed in detail and decisions on marketing investment should be made in a strategic manner (Beasty 2007). It is recommended that once in a while companies do a critical review of achieved marketing goals and marketing profitability and to examine market approach strategies. This is done by marketing effectiveness review, regular marketing activities control and analysis, and by auditing of the marketing plan. For Marketing Managers and company management, the areas of marketing profitability and marketing effectiveness are the main marketing areas of interest (Ferrell and Hartline 2008). A company can learn about the effectiveness of a marketing strategy by analysing marketing costs and by comparing sales results with related marketing costs and profit margins. By doing this, Marketing Managers will be able to allocate available financial funds for future marketing activities in a more adequate way.

There are many standard metrics which can be used to measure the effectiveness of offline marketing activities. The most important marketing metrics which today's companies use are: relative market share, return on (marketing) investment, relative price, product availability, ad reach or campaign reach, total revenue per month, market share, total number of consumers, relative perceived quality, relative price, customer retention rate due to brand loyalty, customer satisfaction, customers' complaints (Farris et al. 2014; Belch and Belch 2015), brand awareness, product availability (Hooley et al. 2017), profitability and sales growth (Faridyahyaie, Faryabi, and Noubar 2012). With the rise of digital technology and digital marketing, a variety of new marketing metrics have also appeared, including: traffic on website, number of unique visitors, number of visits, average time on site, webpage eye tracking, average revenue per lead, total 
TABLE 2 Some of standard marketing metrics vs. some of new marketing metrics

\begin{tabular}{ll}
\hline Standard marketing metrics & New marketing metrics \\
\hline Relative market share & Traffic on website \\
Return on (marketing) investment & Number of unique visitors \\
Relative price & Number of visits \\
Product availability & Average time on site \\
Ad reach or campaign reach & Webpage eye tracking \\
Total revenue per month & Average revenue per lead \\
Brand awareness & Total revenue per month \\
Total number of customers & Number of impressions \\
Customer retention rate & Advertising exposure time \\
Customer satisfaction & Click-rate \\
Customer complaints & Cost per conversion \\
\hline
\end{tabular}

NOtes Adapted from Farris $(2014,13-20)$ and Belch and Belch $(2015,521)$.

revenue per month, number of impressions, advertising exposure time, click-rate, conversion rate, cost per conversion, etc.

Marketing Managers must have a clear understanding of the potential of information technologies and the best ways to use them, in order to gather the relevant data which is important for company's marketing (da Gama 2012, 219). Collected information about consumers and from the consumers, should be analysed and synthetized into 'easy to use' reports which will guide the management in decision-making process. The principles of big data allow the companies today to integrate all the collected data and use sophisticated analytics to generate consumer insight (Stone and Woodcock 2014, 8-9). The term 'big data' refers to the ability to collect, store and use massive volumes of data, some of which arises from increased use of mobile technology and social media (Stone et al. 2017, 223). Thanking to the widespread and continuous utilization of Internet as the main platform for all digital marketing channels, marketing dashboard has been developed. This tool enables the analysis of online activities marketing metrics and a superb overview of them all gathered in one place. Standard marketing metrics include a number of total website visitors, the ratio of number of visitors who clicked on an ad and the number of visitors who saw the ad, the ratio of visitors who made a conversion/purchase transaction online in a certain period and the total number of visitors in that period, and other analytics which can be 
used to measure effectiveness and strength of implemented marketing tactics. Another advantage of online marketing is the fact that it allows even small companies which don't have many employees, large shops nor modern IT equipment, to conduct marketing activities in certain digital channels for small amount of investment and successfully measure return on investment for these activities.

Beside the mentioned activities, Internet allows the companies the insight into competitive digital marketing activities and comparison of marketing metrics through a variety of available marketing reporting tools which analyse the content on websites of interest. Many companies would find it difficult to imagine implementing their digital marketing strategies without online marketing dashboards which they use on a daily basis to monitor activities that take place online. Marketing trends and data analytics platforms such as Google Analytics, Jumpshot, SimilarWeb, SEM Rush or Klipfolio are excellent for tracking of digital marketing performance through statistical data and trends overview, key performance indicators, share, ratios, and various mathematical calculations, according to company's needs and preferences. Additionally, these tools allow Marketing Managers understanding of marketing performance in a visually attractive and simple way by presenting the data in many different (pre-set) graphic options. Owing to them, Marketing Managers have a clear knowledge of company's position when compared to the competition, which serves them as a basis for making decisions on appropriate marketing tactics and channels in the shortest period of time. All the data which refers to online marketing are automatically found, collected and analysed by the software in a matter of seconds. However, for offline channels there isn't a tool or a dashboard which would allow such easy collection of data in a single place, and marketing metrics for offline activities often require Marketing Managers to have extensive knowledge to be able to interpret them correctly and accurately. Often such data cannot be gathered quickly, easily and at low expense of company's resources so the companies usually outsource the measurement of offline marketing activities performance to specialized agencies or companies for measurement and data analytics such as The Nielsen Company. It is a fact that traditional marketing is getting less effective by the minute.

\section{Practical Implications}

For the past few years all companies have been undergoing a digital revolution, a process of transforming their businesses because the outside 
market factors request it. Marketing dashboards provide a convenient way of tracking marketing investment, monitoring market share, measuring scores in comparison to industry average results, and receiving a numerical feedback about implemented marketing tactics in the form of the return on investment. However, if companies want to understand what makes the strategies of their competitors so successful, they need to pay more attention to the psychology behind consumer behaviour. In the future, it will not be enough for marketing to ensure only evident impact on business, but its progress will be mostly noticeable in customer retention. Successful brands of the future will make it their priority to continuously keep up with ever changing consumer wants and expectations, find out consumers' actual and latent needs, and make an effort to investigate the underlying beliefs which drive their actions and decisions. Currently there is a need to raise the awareness of companies to the human aspect of marketing communication and brand interaction since people are an integrated part of digital marketing strategy of the present and the future. In the upcoming years the entire concept of running a business just to achieve profit will have to be changed because the consumers are what keeps any business going so they should be approached with more respect and not be treated just as statistical figures on a marketing dashboard. Needless to say, if the consumers feel valued by the brand, they will return and bring with them other, new consumers. It all comes down to the human note in doing business and the technology today is what can help leverage a brand-consumer relationship to the next level and make the companies thrive. In the future, integrated multi-channel marketing communications will include a seamless flow of company's communications through various inter-connected channels. In a decade from now, revolutionary marketing innovations combined with technologies that are yet to be developed, will have a significant effect on society's behaviour and consumers lifestyle. We can expect future technological trends to make buyer behaviour incomparable to what it is today, especially considering the yet unknown consumer behaviour patterns which the new generation of consumers will develop, together with their future expectations from the brands as well as their marketing mix.

\section{Conclusion}

In this paper new marketing technologies and new marketing channels in modern-day business are analysed, together with the possibilities of measuring marketing performance in digital environment. New channels, 
such as online and mobile, allow the companies increased transparency of their business and online marketing activities. A successful business model at 21st century marketplace includes recognizing the value of new technologies in marketing and implementing them together with progressive, modern marketing know-how, which will allow companies to achieve better business results.

Not many books and scientific articles had been written on similar subject. However, it is noted that this topic is becoming an interesting research area to other scholars around the world. Previous research shows that in the previous 15-20 years' timeframe, Marketing Managers and retailers have observed how modern digital technologies influence the behaviour of consumers, their perception of the brand, their purchase intention and their overall shopping experience. When compared with the research of other authors who mostly focused on a specific subtopic of digital technologies or marketing channels, this paper offers a bird's view of new marketing technologies in regards to new marketing channels, by mentioning all the relevant terms and by outlining the obvious convergence of digital marketing discipline with technology, IT, and ICT. Since managing of digital marketing of today's companies means among other the collection and interpretation of big data, the topic of marketing metrics had to be explained. This paper offers easy comparison of traditional marketing metrics with the new ones which refer to digital marketing activities (online and mobile ones).

Considering that technology is continuously moving forward, companies which invest their financial resources in up-to-date technological solutions, are bound to stay ahead of their competitors who are not as quick to adapt. Eventually, they will also have to embrace new technologies if they want to remain in business. With the technology advancing so fact, companies don't have a choice but to digitize and adapt, and the sooner they do it, the better. In order to successfully reach the consumers, all companies have to update their outdated technologies and adjust their integrated marketing communication in all the channels, including the new ones. While the choice of communication channels will affect to which extent will the company stand out from competitors, implementation of these new technologies will surely contribute to better marketing performance and better business results. Companies which own sophisticated technologies are setting a new standard of doing business and are acting as benchmarks for other companies in their markets and industries.

Paper limitations include a lack of books and scientific articles on the 
subject of new technologies in marketing, new sales/marketing /distribution channels and new marketing metrics. Further research should be made on comparison of consumers' virtual shopping experience with physical shopping experience. In order to further examine the implementation of new marketing technologies, new channels and new metrics and their business impact, a suggestion is to conduct on-field research on a sample of companies from different industries. Business success of these companies should be monitored through a longer period of time and then compared to those of the companies which resist the digital transformation and prefer to use traditional marketing channels and metrics instead.

\section{References}

Ampountolas, A. 2018. 'Peer-to-Peer Marketplaces: A Study on Consumer Purchase Behaviour.' Journal of Hospitality and Tourism Insights. https://doi.org/10.1108/JHTI-05-2018-0028

Aslam, W., M. Ham, and I. Arif. 2017. 'Consumer Behavioral Intentions towards Mobile Payment Services: An Empirical Analysis in Pakistan.' Market-Tržište 29 (2): 161-76.

Bannor, R., A. K. Asare, and J. N. Bawole. 2017. 'Effectiveness of Social Media for Communicating Health Messages in Ghana.' Health Education 117 (4): 342-71.

Beasty, C. 2007. 'Predicting Profitability: CrM CrM.' Customer Relationship Management 11 (11): 18-23.

Belch, G. E., and M. A. Belch. 2015. Advertising and Promotion: An Integrated Marketing Communications Perspective. 1oth ed. New York: McGraw-Hill.

Bhasin, H. 2018. 'Marketing Channels.' https://www.marketing91.com/ marketing-channels

Conversation, LLC. 2012. 'Marketing 2020: The Future of Advertising.' https://www.youtube.com/watch?v=rw-tlt3AnIo

da Gama, A. P. 2012. 'Marketing Audits: The Forgotten Side of Management?' Journal of Targeting, Measurement and Analysis for Marketing $20(3-4): 212-22$.

Digital Marketing Institute. 2016. 'Rob Farrell Talks Digital Marketing Trends 2017.' https://www.youtube.com/watch? $v=A t f s 5 s U y e s 4$

Faridyahyaie, R., M. Faryabi, and H. B. K. Noubar. 2012. 'Identifying Marketing Effectiveness Metrics (Case Study: East Azerbaijan’s Industrial Units).' Poslovna izvrsnost 6 (2): 47-57.

Farris, P. W., N. T. Bendle, P. E. Pfeifer, and D. J. Reibstein. 2014. Marketing metrics: The Definitive Guide to Measuring Marketing Performance. 2nd ed. Upper Saddle River, NJ: Pearson Education. 
Ferrell, O. C., and M. D. Hartline. 2008. Marketing Strategy. 4th ed. Mason, oH: Thomson/South-Western.

Foroudi, P., S. Gupta, A. Nazarian, and M. Duda 2017. 'Digital Technology and Marketing Management Capability: Achieving Growth in smes.' Qualitative Market Research: An International Journal 20 (2): 230-46.

Hagberg, J., M. Sundstrom, and N. Egels-Zandén. 2016. 'The Digitalization of Retailing: An Exploratory Framework.' International Journal of Retail \& Distribution Management 44 (7): 694-712.

Hilken, T., J. Heller, M. Chylinski, D. I. Keeling, D. Mahr, and K. de Ruyter. 2018. 'Making Omnichannel an Augmented Reality: The Current and Future State of the Art.' Journal of Research in Interactive Marketing 12 (4): 509-23.

Hooley, G., N. Piercy, B. Nicoulaud, and J. Rudd. 2017. Marketing Strategy \& Competitive Positioning. Harlow: Pearson Education.

Jones, S. 2017. 'Doing Social Network Ethics: A Critical, Interdisciplinary Approach.' Information Technology \& People 30 (4): 910-26.

Kostić-Stanković, M., and V. Vukmirović. 2018. 'Tendencies in Contemporary Marketing Communication Caused by Technological Preferences of Generation Y.' Hum 13 (19): 157-82.

Leuman, Anne. 2018. '4 Significant Marketing Channels You Should Adopt in 2018.' https://www.toprankblog.com/2017/11/emerging-marketing -channels

Lim, S. F., X. Jin, and J. S. Srai. 2018. 'Consumer-Driven E-Commerce: A Literature Review, Design Framework, and Research Agenda on LastMile Logistics Models.' International Journal of Physical Distribution \& Logistics Management 48 (3): 308-32.

Mahapatra, S. 2017. 'Mobile Shopping Among Young Consumers: An Empirical Study in an Emerging Market.' International Journal of Retail \& Distribution Management 45 (9): 930-49.

Marshall, J. 2007. 'Are Finance and Marketing Getting Closer?' Financial Executive, Business Premium Collection 23 (2): 46-8.

Mosquera, A., C. Olarte-Pascual, E. Juaneda Ayensa, and Y. Sierra Murillo. 2018. 'The Role of Technology in an Omnichannel Physical Store: Assessing the Moderating Effect of Gender' Spanish Journal of Marketing 22 (1): 63-82.

Papagiannidis, S., E. Pantano, E. W. K. See-To, C. Dennis, M. Bourlakis. 2017. 'To Immerse or Not? Experimenting with two virtual retail environments.' Information Technology \& People 30 (1): 163-88.

Payne, E. M., J. W. Peltier, and V. A. Barger. 2017. Omni-Channel Marketing, Integrated Marketing Communications and Consumer Engagement: A Research Agenda. Journal of Research in Interactive Marketing 11 (2): 185-97. 
Phong, N. D., N. H. Khoi, and A. N.-H. Le. 2018. 'Factors Affecting Mobile Shopping: A Vietnamese Perspective.' Journal of Asian Business and Economic Studies 25 (2): 186-205.

Prismaxel. 2017. 'Mobile Marketing/Digital Marketing Trends 2018.' https:// www.youtube.com/watch? $v=F X_{9}$ Gsblingk

Rieland, R. 2013. 'How Are Stores Tracking the Way That We Shop?' https:// www.smithsonianmag.com/innovation/how-are-stores-tracking-theway-that-we-shop-180948271

SAs Software. 2014. 'What is Digital Marketing and Why It Matters - The s As Point of View.' https://www.youtube.com/watch?v= _PWqIMQux-g

StarMobileSolution. 2013. 'The Mobile Movement is Changing Consumer Behaviour.' https://www.youtube.com/watch?v=p2Pe8Bl5b14.

Stone, M. D., and N. D. Woodcock. 2014. 'Interactive, Direct and Digital Marketing: A Future That Depends on Better Use of Business Intelligence.' Journal of Research in Interactive Marketing 8 (1): 4-17.

Stone, M., E. Aravopoulou, G. Gerardi, E. Todeva, L. Weinzierl, P. Laughlin, and R. Stott. 2017. 'How Platforms Are Transforming Customer Information Management.' The Bottom Line 30 (3): 216-35.

Vend. 2018. 'A Round up of Our Top 12 Forecasts for 2018 and beyond.' https://www.vendhq.com/2018-retail-trends-predictions 


\title{
Future Job Profile at Smart Factories
}

\author{
Andrej Jerman \\ Ljubljanski potniški promet, Slovenia \\ andrejjerman1@gmail.com \\ Tine Bertoncel \\ University of Primorska, Slovenia \\ tine.bertoncel@gmail.com \\ Ivan Erenda \\ TPV d.o.o., Slovenia \\ i.erenda@tpv.si \\ Anita Trnavčević \\ University of Primorska, Slovenia \\ anita.trnavcevic@fm-kp.si
}

In this paper, we focus on future job profiles at smart factories. We conducted a case study from the Slovene automotive industry, because this industry is one of the first to adopt the guidelines of Industry 4.0 and has already started transforming into a smart factory. The method of interviewing a focus group was chosen as the method of data collection. An interview with focus group experts was done with the aim of getting data on job profiles and competencies in the future. Our sample included six participants, managers from automotive company TPV in Slovenia, who are the most knowledgeable informants, due to their expertise on the topic of the study. The key theoretical contributions are to be found in the list of future job profiles, which is under-researched, especially in the field of smart manufacturing. Therefore, the identification of those is an important theoretical contribution of this study.

Key Words: Industry 4.0, smart factory, job profiles

JEL Classification: M11, M12

https://doi.org/10.26493/1854-6935.16.401-412

\section{Introduction}

The research is focused on understanding and exploring the concept of smart factories in the automotive industry in terms of addressing changes to job profiles and the emergence of new job profiles. After the review of domestic and foreign literature, this area was perceived as a rather unexplored and worthwhile in-depth scientific treatment. There is a small 
amount of research on this topic abroad, which mainly includes literature reviews on the subject of Industry 4.0 and not empirical research.

\section{Research Question: How Is the Transformation from a Classical to a Digital Business Model Changing Job Profiles at Automotive Smart Factories?}

The goal of the paper is to present to managers and researchers the strategic framework for establishing jobs at automotive smart factories. To understand the transition from classic manufacturing to smart manufacturing, we need to understand the particularities of the fourth industrial revolution. For this reason, the authors begin the paper with the definition of Industry 4.0 and then continue with human resource trends in Industry 4.o, followed by challenges, according to job profiles, that factories will face during the transition and post transition phase.

\section{Industry 4.0 and Smart Factories}

In 2011, at the Hannover fair, the German government named their new economic program Industry 4.o. Industry 4.o, i.e. the fourth industrial revolution, is based on concepts and technologies that include CyberPhysical Systems (C P s), Internet of Things (IOT) and Internet of Services - (IOS) (Möller 2016; Roblek, Meško, and Krapež 2016). Such new concepts force companies to transform their traditional business models into digital business models, which present a huge challenge for these companies.

Industry 4.0 in general is seen as the application of cyber physical systems within industrial production systems, which can be seen as an equivalent to what has been introduced as 'industrial internet' by General Electric in North America (Posada et al. 2015). Industry 4.0 has become a major influence on manufacturing, particularly in its focus on creating a smart environment. The common name for this smart kind of manufacturing is the term 'smart factory', while other terms are also common in other countries, for example, in Italia the term is Fabricca Intelligente, in Belgium it is Flanders Make, in the Us A it is called the Smart Manufacturing Leadership Coalition, in China it is Made in China and in India it is Made in India (Mabkhot et al. 2018).

A smart factory is the main feature of Industry 4.0, and is characterized 'by self-organized multi-agent systems assisted with big databased feedback and coordination' (Russell and Norvig 2009). The concept of a smart factory describes the vision of future manufacturing (Wang, Wan, and 
Zhang 2016), a future form of industrial networks (Radziwon et al. 2014). Following digital and virtual factories (Ivanov et al. 2016), smart factories represents the next step in the evolution of factories (Lucke, Constantinescu, and Westkämper 2008). Lucke, Constantinescu, and Westkämper (2008) defined a smart factory as a factory that 'context-aware assists people and machines in execution of their tasks.' The smart factory can also be defined as a cyber-physical system, where flexible and agile production is implemented. It integrates physical objects, conveyers, and products with information systems. In smart factories, intelligent machines, systems and products are interlinked, which will consequently make future production system structures increasingly decentralized (Yoon, Shin, and Suh 2012).

The Internet of things enables a continuous interaction and exchange of information in the smart factory (Ghobakhloo and Azar 2018; Yao et al. 2017). While the term artificial intelligence is used to describe a machine that imitates human cognitive functions, such as learning and problem solving, within the context of machines communications, artificial intelligence (also machine intelligence) is understand as the intelligence displayed by machines, in contrast to the natural intelligence displayed by humans and animals (Flynn, Dance, and Schaefer 2017). Because of machine intelligence, smart machines, conveyers and products communicate and negotiate which each other to reconfigure themselves for flexible production of multiple types of products. The industrial network collects massive amounts of data from smart objects and transfers them to the cloud. This enables system wide feedback and coordination based on big data analytics to optimize system performance and to achieve high efficiency (Yao et al. 2017).

A smart factory can develop products virtually; in current times, companies are able to run virtual experiments on a digital prototype. Within the modular structured smart factories, cyber-physical systems monitor physical processes, create virtual copies of the physical world and make decentralized decisions. Via the Internet of Things, cyber-physical systems communicate and cooperate with each other and with humans in real-time both internally and across organizational services offered and used by participants of the value chain (Flynn, Dance, and Schaefer, 2017). As such, digital manufacturing and design are influencing careers, practices, and processes in companies (Crnjac, Veža, and Banduka 2017).

Production organizations have not yet reached the level of development required to become a completely smart factory, although many re- 
searchers and practitioners are extensively researching and working on the topic of Industry 4.o. Current production systems cover some of the concepts of Industry 4.0, mainly in the field of interoperability (Gruber 2013). In order to make production organizations successful in moving to a smart factory, an important part is a well-designed strategy, which incorporates future job profiles.

\section{Future Job Profiles at Smart Factory}

Production paradigms are and have always been shaped by different factors, i.e. sociological, economic and technological (Chu et al., 2016). Sinsel et al. (2017) and Magone (2016) found that the main perspective in Industry 4.0 is a technological perspective. A few studies on the economic valuation of smart factories exist, such as cost-effectiveness analysis (Sinsel et al. 2017) and studies on the productivity of smart factories (Madsen and Mikkelsen 2018; Munyai, Mbonyane, and Mbohwa 2017). The aim of smart factories is not only to create an economic effect, such as reducing costs and increasing productivity, but also to consider human and the sociological aspect of the new paradigm brought by the fourth industrial revolution (Kang et al. 2016). The development and increasing implementation of smart technologies in organizational environments brings about social and economic change, as well as the emergence of new social and ethical problems. Smart technologies namely: (i) have security vulnerabilities in sensitive privacy areas, in regards to people and organizations (business secrets), which can allow hackers to obtain sensitive personal information in real time; (ii) can create a loss of jobs; (iii) can cause employee's to be replaced for different tasks (Meško, Roblek, and Bach 2017).

\section{Methodology}

A qualitative research approach was used, which enables in-depth studies of real-world settings and captures contextual richness and thick descriptions (Yin 2011). Within the qualitative approach, a case study was used in order to explore and gain understanding of an in-depth, multifaceted, complex issue that arises in real life. The case study is used in many disciplines and largely it is used in the field of social sciences (Crowe et al. 2011). The case study is defined as a robust research method, which is used especially in cases where a comprehensive and in-depth study is required. It allows the researcher to carefully examine the data in a particular context. In most cases, a certain geographical area is included in the 
case study or a very limited number of units (individuals) are selected as the subject of study (Zainal 2017). The case study research was carried out in the Slovene automotive manufacturing organization, named TPV. $\mathrm{TPV}$ is a development supplier in the automotive industry with exemplary corporate practice concerning implementations of new technologies. Their programs are grouped in three business divisions: Vehicles, Trailers, and the core business division - AvtoIn. Currently, they have five production sites in Slovenia and one in Serbia and employ over 1,200 people. In the automotive industry, innovation and continuous development are at the forefront and represent the key to the long-term success of the industry. The automotive industry has always been in the field of the fastest transformations and the fastest technological development. Not surprisingly, the first industrial robot was created in General Motors in 1961 (Stamp 2013). Bilas, Franc, and Arbanas (2013) state that, according to oIC A (Organization of International Construction Industries), the automotive industry is the sixth largest industry in the world. It is one of the largest employers around the world and as such is directly or indirectly responsible for every ninth job in developed countries (Bilas, Franc, and Arbanas 2013). The automotive industry is one of the most competitive, advanced and complex industrial sectors (Weyer et al. 2016). No other industry invests more into smart factories than automobile manufacturers (Bongardt 2018). The automotive industry has a strong influence on the economy of a country, it is an industry with a strong tradition, strong technological and economic impact. Innovation and continuous development are at the forefront of the automotive industry and represent the key to the long-term success of the industry. The market for the automotive industry is global - global change and change in the local markets require the maintenance of a dynamic balance (Erenda et al. 2018).

The method of focus group interviews was chosen for data collection, because it generates a wider range of views and ideas than could be captured through individual interviews (Krueger and Casey 2015). An interview with a focus group consisting of experts was done with the aim of getting data from on job profiles and competencies. The focus group is a group of experts selected by researchers in order to discuss and comment on the chosen topic. Due to the synergistic effect, focus groups are more productive than individual interviews (Powell and Single 1996). The aim of the focus group interview is to identify key topics and research issues that are important for the transition from classical to smart factories. Our sample included six participants, managers from the automotive com- 
pany TPV in Slovenia, who are the most knowledgeable informants, due to their expertise on the topic of the study. Focus groups range in size from six to twelve participants in order to stimulate discussion (Guest, Namey, and McKenna 2017). Discussion revolved around one question: What, in your opinion, are the expected job profiles in the future (by 2030), of operative level employees at smart factories in the automotive industry? Focus group interview lasted about 90 minutes. Initially, participants were informed about the purpose and given an option of informed consent.

We structured our analysis with the content analysis method. The content analysis method enables gaining new knowledge based on primary data. In addition, elements of grounded theory were used. The inductive approach requires the theory to be developed after the data is collected, so the expected cause and effect relations among the variables in the model are not known prior to the data analysis (Saunders, Lewis, and Thornhill 2009).

\section{Results and Discussion}

Our research question was How is the transformation from a classical to a digital business model changing job profiles at automotive smart factories? In an inductive study of an automotive company, we conducted a coding procedure, searching for concepts and categories. To increase credibility - reliability, we use three coders to code interviews. Our analysis revealed new jobs profiles presented in table 1.

The professions that will be created in the future at smart factories in the automotive industry are related to the field of design, informatics and computer science, maintenance, robotics and mechatronics. Embedded mechatronics will become prevalent in future automotive manufactoring. A mechatronic engineers will need to become interdisciplinary experts with understand of the various components and instruments involved in manufacturing, such as robots, mechanical systems, actuators, sensors, controllers, computer systems and embedded systems, while at the same time will be required to understand programming languages necessary to run these components and instruments (Meek, Field, and Devasia 2003; Ollero et al. 2006). Mechatronics engineers will also be expected to know how to design user-friendly environments and systems and be able to develop software and hardware modules (Ollero et al. 2006; Kozák et al. 2018).

Robot assisted production, where robots can be trained, through inter- 
TABLE 1 Future Jobs at Automotive Smart Factories

\begin{tabular}{|c|c|}
\hline Future jobs & Sample quotations \\
\hline \multirow[t]{2}{*}{ Mechatronics } & P1: 'There will be a huge demand for mechatronics.' \\
\hline & P5: 'There will be professions such as mechatronics ...' \\
\hline Robotics & P6: 'Mostly, focus will be on the professions of robotics ...' \\
\hline $\begin{array}{l}\text { Smart system } \\
\text { designer }\end{array}$ & P2: 'In my opinion, there will be smart system designer in demand.' \\
\hline IOT designer & P1: 'Designing for example sw services requires гот designing...' \\
\hline $\begin{array}{l}\text { Supervisor of } \\
\text { high-tech } \\
\text { smart systems }\end{array}$ & $\begin{array}{l}\text { P3: 'A comprehensive digitization of the company (data in the cloud, } \\
\text { real-time data/information analysis, visualization ...) requires more } \\
\text { and more control. Therefore, the professions related to the control of } \\
\text { high-tech systems will be required.' }\end{array}$ \\
\hline $\begin{array}{l}\text { Maintenance } \\
\text { of high-tech } \\
\text { smart systems }\end{array}$ & $\begin{array}{l}\text { P4: 'So called smart technology and systems need to be maintained, } \\
\text { and, in my opinion, future job will be related to maintenance of high- } \\
\text { tech smart systems.' }\end{array}$ \\
\hline \multirow{2}{*}{$\begin{array}{l}\text { ICT system } \\
\text { maintenance }\end{array}$} & P4: 'Important job will be maintaining ІС т systems.' \\
\hline & $\begin{array}{l}\text { P5: 'In the future, new professions will be related to IC T mainte- } \\
\text { nance...' }\end{array}$ \\
\hline \multirow{2}{*}{$\begin{array}{l}\text { Data analyst } \\
\text { (big data ...) }\end{array}$} & P5: 'We will get experts for big data processing ...' \\
\hline & $\begin{array}{l}\text { P2: 'Work will be done remotely, data will be collected and managed } \\
\text { in the cloud, which requires suitable analysis and therefore a properly } \\
\text { trained data analyst.' }\end{array}$ \\
\hline Programmer & $\begin{array}{l}\text { P3: 'The programmers will have extraordinary power. Programming } \\
\text { on the computer, game theory, the need for these professions will be } \\
\text { almost infinite.' } \\
\text { P4: 'The future jobs are related to computer science.' }\end{array}$ \\
\hline $\begin{array}{l}\text { A process } \\
\text { analyst }\end{array}$ & P6: 'New ones (jobs) will be linked to process analysis.' \\
\hline
\end{tabular}

action with the environment through sensors, will replace manual labour in production operations, however it will create a new job called the robot coordinator. Robot coordinators will also be involved, to varying degrees, in maintenance and supervisory tasks and machine operators will often have the potential to be retrained for such tasks (Lorenz et al. 2015).

The interviewees also mentioned that a smart system and гот designer will increasingly be sought after in smart factories, in order to create smart systems and гот technology architectures, such as the $5 \mathrm{C}$ architecture (connection, conversion, cyber, cognition, and configuration) (Lee, Bagheri, and Kao 2015; Ollero et al. 2006). 
Smart systems, after they are designed and constructed, will in turn also need someone to supervise them, and as such supervisors of hightech smart systems will also be in demand, where production systems and their environment will be supervised with the help of various connected objects (Wang, Törngren, and Onori 2015).

Smart factories make use of several kinds of programming languages, both visual and textual, object-oriented and non-object oriented. Programming of automation systems based on programmable logic controllers (PLC) mainly use the International Electrotechnical Comission (IEC) standard, however current programming with IEC is mostly nonobject oriented, however efforts have been made to extend the functionality of current IEC languages to meet the requirements of object oriented programming, as this would make the programming language more suitable for large distributed systems (Basile, Chiacchio, and Gerbasio 2012).

Data analysts, especially big data analyst, i.e. analysts of large databases, will play an important future job profile at smart factories. The concept of big data and big data analysis encompasses not only the capacity, but also the technology, tools and skills that enable the capture, manipulation and interpretation of databases with enormous amounts of data (Waterman and Bruening 2014), for example data mining, which is a powerful technique apply to the data for generalisation, characterization, association, classification, clustering, pattern matching on a fundamental level, high level, multiple-levels, etc. (Jain et al. 2016).

Finally, according to the interviewees, a process analyst will be sought after, to find out how current processes in smart factories can be improved or maintained, for example, with the help of optimization or automation of processes.

\section{Conclusion}

Increased productivity achieved with smart technologies can help to provide jobs and increase consumer demand with additional income (compensatory effect), but the use of new production technologies and processes can also destroy jobs (redundancy effects). There is concern that Industry 4.0 will lead to long-term technological unemployment (Hungerland et al. 2015).

In this paper, we focus on an important topic, which is future job profiles at smart factories. We have chosen a case study from the Slovene automotive industry due to the reason that this industry is one of the first ones to adopt the guidelines of Industry 4.0 and has already started 
transforming some of its companies into a smart factory of Industry 4.o.

Our findings possess important implications for conceptualizing job profiles in Industry 4.0 and practical implications for managers concerned with human resource management activities. The key theoretical contributions are to be found in the list of future job profiles that are under-researched, especially in the field of smart manufacturing. Therefore, the identification of those is an important theoretical contribution of this study.

While we believe our study has an important contribution, it has some limitations. The main limitation derives from the chosen methodology, qualitative research approach. The case study research method does not allow statistical generalization to the population. Case studies enable 'generalizations to theoretical propositions and not to populations or universes' (Yin 2003). Other common limitations of qualitative research are the lack of trustworthiness and credibility. To overcome this limitation, various procedures have been used and the research is presented as transparently as possible.

\section{References}

Basile, F., P. Chiacchio, and D. Gerbasio. 2012. 'On the Implementation of Industrial Automation Systems Based on PLC.' IEEE Transactions on Automation Science and Engineering 10 (4): 990-1003.

Bilas, V., S. Franc, in B. Arbanas. 2013. 'The Impact of Current Economic Crisis on the Automotive Industry.' Ekonomska misao i praksa 22 (1): 299-320.

Bongardt, D. 2018. 'Automotive Industry Leads the Way with Smart Factories.' http://www.hannovermesse.de/en/news/automotive-industry -leads-the-way-with-smart-factories-84996.xhtml

Chu, W. S., M. S. Kim, K. H. Jang, C. N. Chu, and S. H. Ahn. 2016. 'From Design for Manufacturing (DFM) to Manufacturing to Design (MFD) via Hybrid Manufacturing and Smart Factory. International Journal of Precision Engineering and Manufacturing 3(2): 209-22.

Crnjac, M., I. Veža, and N. Banduka. 2017. 'From Concept to the Introduction of Industry 4.o.' International Journal of Engineering and Management 8(1): 21-30.

Crowe, S., K. Cresswell, A. Robertson, G. Huby, A. Avery, and A. Sheikh. 2011. 'The Case Study Approach.' вMC Medical Research Methodology 11 (1): 100.

Erenda, I., A. Metelko, V. Roblek, and M. Meško. 2018. 'The Leadership Competencies and Intuitive Decision-Making of Top and Middle Level Managers in The Automotive Industry'. In Governing Business Systems, 
edited by G. Dominici, M. Del Giudice, and R. Lombardi, 119-40. Cham: Springer.

Flynn, J., S. Dance and D. Schaefer. 2017. 'Industry 4.0 and its Potential Impact on Employment Demographics in the U K.' Advances in Transdisciplinary Engineering 6:239-44.

Ghobakhloo, M., and A. Azar. 2018. 'Business Excellence via Advanced Manufacturing Technology and Lean-Agile Manufacturing.' Journal of Manufacturing Technology Management 29 (1): 2-24.

Gruber, F. E. 2013. 'Industry 4.0: A Best Practice Project of the Automotive Industry' In Digital Product and Process Development Systems, edited by G. L. Kovács, and D. Kochan, 36-40. Berlin: Springer.

Guest, G., E. Namey, and K. McKenna. 2017. 'How Many Focus Groups Are Enough? Building an Evidence Base for Nonprobability Sample Sizes.' Field Methods 29 (1): 3-22.

Hungerland F., J. Quitzau, C. Zuber, L. Ehrlich, C. Growitsch, M. C. Rische and H. J. Haß. 2015. The Digital Economy, Strategy 2030: Wealth and Life in the Next Generation. Hamburg: Berenberg.

Ivanov, D., A. Dolgui., B. Sokolov, F. Werner, and M. Ivanova. 2016. 'A Dynamic Model and an Algorithm for Short-Term Supply Chain Scheduling in the Smart Factory Industry 4.o.' International Journal of Production Research 54 (2): 386-402.

Jain, A., G. Hautier, S. P. Ong, and K. Persson. 2016. 'New Opportunities for Materials Informatics: Resources and Data Mining Techniques for Uncovering Hidden Relationships.' Journal of Materials Research 31 (8): 977-94.

Kang, H. S., J. Y. Lee. S. Choi. B. H. Kim, and S. D. Noh. 2016. 'Smart Manufacturing: Past Research, Present Findings, and Future Directions.' International Journal of Precision Engineering and Manufacturing 3 (1): 111-28.

Kozák, Š., E. Ružický, J. Štefanovič, and F. Schindler. 2018. 'Research and Education for Industry 4.0: Present Development.' Paper presented at Cybernetics and Informatics 2018, Lazy pod Makytou, 31 January-3 February.

Krueger, R. A., and M. A. Casey. 2015. 'Participants in a Focus Group.' In Focus Groups: A Practical Guide for Applied Research, edited by R. A. Krueger and M. A. Casey, 280-89. Los Angeles: Sage.

Lee, J., B. Bagheri, and H. A. Kao. 2015. 'A Cyber-Physical Systems Arhitecture for Industry 4.0-Based Manufacturing Systems.' Manufacturing Letters 3:18-23.

Lorenz, M., M. Rüßmann, R. Strack, K. L. Lueth, and M. Bolle. 2015. Man and Machine in Industry 4.o. Boston, MA: The Boston Consulting Group. 
Lucke, D., C. Constantinescu, and E. Westkämper. 2008. 'Smart Factory: A Step towards the Next Generation of Manufacturing.' In Manufacturing Systems and Technologies for the New Frontier, edited by M. Mitsuishi, K. Ueda, and F. Kimura, 115-18. London: Springer.

Madsen, E. S., and L. L. Mikkelsen. 2018. 'The Need of Knowledge Modification in Technology Change: A Framework to Consider Changes in Domain Complexity, Knowledge and Productivity.' Production, Planning and Control 29 (2): 91-105.

Mabkhot, M. M., A. M. Al-Ahmari, B. Salah, and H. Alkhalefah. 2018. 'Requirements of the Smart Factory System: A Survey and Perspective.' Machines 6 (2): 1-22.

Magone, A. 2016. 'Technology and the Human Factor in the Digital Factory.' Industria 37 (3): 407-26.

Meek, S., S. Field, and S. Devasia. 2003. 'Mechatronics Education in the Department of Mechanical Engineering at the University of Utah.' Mechatronics 13:1-11.

Meško, M., V. Roblek, and M. Pejić Bach. 2017. Social Responsibility and Ethical Issues about Smart Technology Usage. In Program and Abstracts 2017: From Science to Systemic Solutions; Systems Thinking for Everyone, 55. Vienna: Tu Wien.

Möller, D. P. F. 2016. Guide to Computing Fundamentals in Cyber-Physical Systems. Heidelberg: Springer.

Munyai, T. T., B. L. Mbonyane, in C. Mbohwa. 2017. Productivity Improvement in Manufacturing SMEs: Application of Work Study. Abingdon: Taylor and Francis.

Ollero, A., S. Boverie, R. Goodall, J Sasiadek, H. Erbe, and D. Zuehlke. 2006. 'Mechatronics, Robotics and Components for Automation and Control IfAC Milestone Report.' Annual Reviews in Control 30 (1): 4154.

Posada, J., C. Toro, I. Barandiaran, D. Oyarzun, D. Stricker, R. De Amicis, ... and I. Vallarino. 2015. 'Visual Computing as a Key Enabling Technology for Industry 4.0 and Industrial Internet.' IEEE Computer Graphics and Applications 35 (2): 26-40.

Powell, R. A., and H. M. Single. 1996. 'Focus Groups.' International Journal for Quality in Health Care 8 (5): 499-504.

Radziwon, A., A. Bilberg, M. Bogers, and E. S. Madsen. 2014. 'The Smart Factory: Exploring Adaptive and Flexible Manufacturing Solutions.' Procedia Engineering 69:1184-9o.

Roblek, V., M. Meško, and A. Krapež. 2016. 'A Complex View of Industry 4.o.' Sage Open 6 (2): 1-12.

Russell, S. J., and P. Norvig. 2009. Artificial Intelligence: A Modern Approach. 3 rd ed. Upper Saddle River, NJ: Prentice Hall. 
Saunders, M., P. Lewis, and A. Thornhill. 2009. Research Methods for Business Students. 5th ed. Harlow: Prentice Hall/Financial Times.

Sinsel, A., C. Bangert, J. Stoldt, and T. Buttner. 2017. 'Economic Evaluation of the Smart Factory: An Approach to the Assessment of Digitalization in Production.' $z W F$ Zeitschrift für wirtschaftlichen Fabrikbetrieb 112 (9): 602-6.

Stamp, J. 2013. 'A Brief History of Robot Birds.' https://www .smithsonianmag.com/arts-culture/a-brief-history-of-robot-birds $-77235415 /$ ?no-ist

Yao, X. J. Zhou, J. Zhang, and C. R. Boër. 2017. 'From Intelligent Manufacturing to Smart Manufacturing for Industry 4.o Driven by Next Generation Artificial Intelligence and Further On.' In 5th International Conference on Enterprise Systems, 311-8. Piscataway, NJ: IEEE.

Yin, R. K. 2003. Case Study Research: Design and Methods. Thousand Oaks, CA: SAGE.

- 2011. Qualitative Research from Start to Finish. New York: The Guliford Press.

Yoon, J. S., S. J. Shin, and S. H. Suh. 2012. 'A Conceptual Framework for the Ubiquitous Factory.' International Journal of Production Research 50 (8): 2174-89.

Wang, S., J. Wan, D. Li, and C. Zhang. 2016. 'Implementing Smart Factory of Industry 4.0: An Outlook.' International Journal of Distributed Sensor Networks 12 (1). http://dx.doi.org/10.1155/2016/3159805

Wang, L., M. Törngren, and M. Onori. 2015. 'Current Status and Advancement of Cyber-Physical Systems in Manufacturing.' Journal of Manufacturing Systems 37:517-27.

Waterman, K., and Bruening, P. J. 2014. 'Big Data Analytics: Risks and Responsibilities.' International Data Privacy Law 4 (2): 89-95.

Weyer, S., T. Meyer, M. Ohmer, D. Gorecky, and D. Zühlke. 2016. 'Future Modeling and Simulation of cPs-Based Factories: An Example from the Automotive Industry.' IFAC-PapersOnLine 49 (31): 97-102.

Zainal, Z. 2017. 'Case Study as a Research Method.' Journal Kemanusiaan 5 (1): $1-6$.

This paper is published under the terms of the Attribution-

NonCommercial-NoDerivatives 4.o International (CC B Y-NC-ND 4.0)

License (http://creativecommons.org/licenses/by-nc-nd/4.o/). 


\title{
Abstracts in Slovene
}

\author{
Zunanje izvajanje na področju informacijskih tehnologij \\ in poslovnih procesov na Poljskem: motivacija \\ in okoljski dejavniki \\ Wojciech Piotrowicz in Damian Kedziora
}

Namen prispevka je povzeti literaturo s področja informacijske tehnologije in zunanjega izvajanja poslovnih procesov na Poljskem ter prispevati k razumevanju motivacije in okoljskih dejavnikov, ki spodbujajo selitev storitev v srednjo in vzhodno Evropo. Raziskovalna študija temelji na akademski literaturi in na dveh podatkovnih virih: vladnih in gospodarskih poročilih, ter na raziskavi manjšega obsega. Ugotovitve potrjujejo, da je glavni dejavnik zmanjšanje stroškov, sledi mu pripravljenost za izboljšanje procesov in uspešnosti poslovanja. Bistvena prednost Poljske so človeški viri - razpoložljiva visoko usposobljena in dobro izobražena delovna sila v povezavi z relativno nizkimi stroški. Čeprav so plače pogosto višje kot v Aziji, je kompenzacija mogoča zaradi števila diplomantov in znanja tujih jezikov. Pomembno vlogo ima tudi članstvo v Evropski uniji in politična stabilnost. Ta raziskovalna študija je - poleg pregleda selitvenih trendov - omogočila uvid v poglede ponudnikov storitev in njihovo primerjavo $\mathrm{z}$ gospodarskimi in vladnimi poročili.

Ključne besede: informacijska tehnologija, zunanje izvajanje, delokalizacija, poslovni procesi, tranzicijsko gospodarstvo, Poljska, Srednja in Vzhodna Evropa

Klasifikacija JEL: M15

Managing Global Transitions 16 (4): 307-333

Ekonometrična analiza vpliva gospodarske globalizacije, energetske intenzivnosti, urbanizacije, industrializacije in rasti emisij $\mathrm{CO}_{2} \mathbf{v}$ Bangladešu

\section{Mowshumi Sharmin in Mohammad Tareque}

Prispevek proučuje učinke gospodarske globalizacije, energetske intenzivnosti, urbanizacije, industrializacije in rasti emisij $\mathrm{CO}_{2}$ na prebivalca v Bangladešu z uporabo tehnike Johansenove kointegracije, modelov vektorske korekcije napak in Grangerjevih testov vzročnosti. Za analizo vplivov inovacij na vse spremenljivke $\mathrm{v}$ povezavi $\mathrm{z}$ emisijami $\mathrm{CO}_{2}$ študija za večjo zanesljivost uporablja tudi razgradnjo variance. Rezultat 
dolgotrajnega in vzročnega testa je predpostavka, da rast spodbuja porabo energije in posledično veča emisije $\mathrm{CO}_{2}$. Rezultat razgradnje variance predvideva, da energijska intenzivnost, urbanizacija, industrializacija in rast dolgoročno prispevajo več kot $60 \%$ emisij $\mathrm{CO}_{2} \mathrm{v}$ Bangladešu. Po drugi strani pa je učinek gospodarske globalizacije na dolgi rok močnejši, vendar pri pojasnjevanju nihanj emisij $\mathrm{CO}_{2}$ prispeva le $9 \%$. Da bi se izognili škodljivim učinkom rasti, so potrebne politike varčevanja $z$ energijo.

Ključne besede: Johansenova kointegracija, globalizacija, emisije $\mathrm{CO}_{2}$, urbanizacija, industrializacija

Klasifikacija JEL: O44, Q20, Q43

Managing Global Transitions 16 (4): 335-354

\section{Analiza razlik v razmerjih med okoljsko odgovornostjo in finančno uspešnostjo \\ Thomas Adomah Worae, Collins C. Ngwakwe in Cosmas C. Ambe}

Prispevek proučuje vpliv praga okoljske odgovornosti na finančno uspešnost podjetij JSE SRI za obdobje 2008-2014. Z uporabo dinamičnih napovedi pragov na zagonski plošči potrjuje obstoj trojnega praga v vseh regresijskih razmerjih. Poleg tega študija vzpostavlja nelinearno (obrnjena U-oblika) povezavo med okoljsko pobudo, merjeno s pomočjo intenzivnosti porabe energije in donosnosti prodaje, ter linearno (inverzno) obliko povezave med intenzivnostjo vsebnosti ogljika in tržno vrednostjo kapitala, padajočega zaradi prodaje. Ugotovili smo tudi, da se donosnost prodaje zmanjša za -0,08868, če je okoljska odgovornost, merjena $\mathrm{z}$ razmerjem intenzivnosti porabe energije, večja od o,00093. Rezultati pa so pokazali, da povečanje razmerja intenzivnosti porabe energije v vsakem trenutku poveča donosnost kapitala.

Ključne besede: intenzivnost emisij, intenzivnost porabe energije, finančna uspešnost, razkorak, Južna Afrika

Klasifikacija JEL: Q5, Q56

Managing Global Transitions 16 (4): 355-377

\section{Uporaba novih tržnih tehnologij, kanalov in metrik Petra Leonora Cvitanović}

Namen prispevka je analizirati prednosti današnjih tržnih tehnologij, tržnih kanalov in tržnih metrik ter opredeliti težave, $s$ katerimi se posledično soočajo podjetja. Sodobne tehnologije v vseh panogah drastično 
spreminjajo življenjski slog, vzajemno sodelovanje in pričakovanja, povezana z blagovnimi znamkami. Podjetja usmerjajo več svojih tržnih naložb v spletne, mobilne in kombinirane spletne in maloprodajne kanale, tradicionalni tržni kanali pa postajajo manj učinkoviti. Nove maloprodajne in mobilne tehnologije ponujajo veliko možnosti za vzajemno sodelovanje s potrošniki in načrtovanje učinkovitih tržnih strategij. Različna orodja za tržno analitiko pomagajo podjetjem meriti uspešnost digitalnega trženja. Zaključek raziskave kaže, da nove tržne tehnologije, kanali in metrike narekujejo nove standarde za upravljanje trženja podjetij na trgu 21. stoletja. Raziskovalna metodologija vključuje študij literature, znanstvenih člankov in spletnih virov, povezanih z digitalnim trženjem, tehnologijo in vedenjem potrošnikov.

Ključne besede: tržne tehnologije, večkanalno trženje, tržna analitika, tržna metrika, prihodnost trženja

Klasifikacija JEL: M30, M31

Managing Global Transitions 16 (4): 379-400

\section{Profil delovnega mesta prihodnosti v pametnih tovarnah}

Andrej Jerman, Tine Bertoncel, Ivan Erenda in Anita Trnavčević

$\mathrm{V}$ tem prispevku se osredotočamo na profile delovnih mest $\mathrm{v}$ prihodnosti, v pametnih tovarnah. Izvedli smo študijo primera iz slovenske avtomobilske industrije, saj je ta industrija ena izmed prvih, ki je sprejela smernice Industrije 4.0 in se je že začela preoblikovati v pametno tovarno. Metoda anketiranja ciljne skupine je bila izbrana kot metoda zbiranja podatkov. Izvedli smo razgovore s strokovnjaki iz ciljnih skupin, $\mathrm{z}$ namenom pridobivanja podatkov o profilih delovnih mest in sposobnostih $\mathrm{v}$ prihodnosti. V našem vzorcu je sodelovalo šest udeležencev, vodij avtomobilske družbe TPV v Sloveniji, ki so zaradi svojega strokovnega znanja s področja, ki ga študija obravnava, zagotovo najbolj usposobljeni za podajanje informacij. Ključen teoretični prispevek je pravzaprav seznam prihodnjih profilov delovnih mest, ki so trenutno še premalo raziskani, zlasti na področju pametne proizvodnje. Zato je identifikacija le-teh pomemben teoretični prispevek te študije.

Ključne besede: Industrija 4.0, pametna tovarna, profili delovnih mest Klasifikacija JEL: M11, M12

Managing Global Transitions 16 (4): 401-412 